University of Louisville

ThinkIR: The University of Louisville's Institutional Repository

\title{
The relationship between dispositional mindfulness and eating : an analysis of self-reported and in vivo eating behaviors in undergraduate females.
}

\author{
Megan E. Jablonski \\ University of Louisville
}

Follow this and additional works at: https://ir.library.louisville.edu/etd

\begin{abstract}
Recommended Citation
Jablonski, Megan E., "The relationship between dispositional mindfulness and eating : an analysis of selfreported and in vivo eating behaviors in undergraduate females." (2013). Electronic Theses and Dissertations. Paper 666.

https://doi.org/10.18297/etd/666

This Doctoral Dissertation is brought to you for free and open access by ThinkIR: The University of Louisville's Institutional Repository. It has been accepted for inclusion in Electronic Theses and Dissertations by an authorized administrator of ThinkIR: The University of Louisville's Institutional Repository. This title appears here courtesy of the author, who has retained all other copyrights. For more information, please contact thinkir@louisville.edu.
\end{abstract}


THE RELATIONSHIP BETWEEN DISPOSITIONAL MINDFULNESS AND

EATING: AN ANALYSIS OF SELF-REPORTED AND IN VIVO

EATING BEHAVIORS IN UNDERGRADUATE FEMALES

\author{
By \\ Megan E. Jablonski \\ B.A., University of North Carolina at Chapel Hill, 2007 \\ M.A., University of Louisville, 2010

\begin{abstract}
A Dissertation
Submitted to the Faculty of the

College of Arts and Sciences of the University of Louisville

In Partial Fulfillment of the Requirements

for the Degree of
\end{abstract}

Doctor of Philosophy

Department of Psychological and Brain Sciences

University of Louisville

Louisville, Kentucky

August, 2013 
Copyright 2013 by Megan Elizabeth Jablonski

All rights reserved 

THE RELATIONSHIP BETWEEN DISPOSITIONAL MINDFULNESS AND

EATING: AN ANALYSIS OF SELF-REPORTED AND IN VIVO EATING

BEHAVIORS IN UNDERGRADUATE FEMALES

By

Megan Elizabeth Jablonski

B.A., University of North Carolina at Chapel Hill, 2007

M.A., University of Louisville, 2010

A Dissertation Approved on

July 22, 2013

by the following Dissertation Committee:

Paul Salmon, Ph.D., Dissertation Chair

Benjamin Mast, Ph.D.

Karen Newton, R.D., M.P.H.

Sandra Sephton, Ph.D.

Barbara Stetson, Ph.D. 


\section{DEDICATION}

This dissertation is dedicated in loving memory of my grandparents,

Ralph and Mildred Winstead, who taught me to love others and enjoy life to the fullest. 


\section{ACKNOWLEDGMENTS}

First, I wish to thank my research mentor and friend, Dr. Paul Salmon, who has provided invaluable assistance with this dissertation project. I am also very grateful to the other members of my committee for their support and guidance. This dissertation would not have been possible without the tireless efforts of three outstanding research assistants: Crystal Adams, Jennifer Baker, and Shannon Shaughnessy. I would also like to thank those with whom I worked during my clinical internship at Mountain Home VAMC, who supported and encouraged me as I completed my writing.

I wish to acknowledge my husband, Bradley Palmer, who has been the epitome of patience and support. I couldn't have done it without you, Brad. I must also acknowledge Baxter, my dog and personal mindfulness guru, for his companionship and gentle reminders to take a break every now and then. I'd like to thank my parents, Mary Winstead and John Jablonski, for always believing in me. Finally, I wish to thank my friends Nekeisha Briggs, Meagan Daup, Kara Spencer, Lauren Wall, and Robert Wells, for keeping me sane these past six years. I am tremendously grateful to have had such wonderful family members, friends, and teachers throughout my life, who have each contributed in their own way to helping me reaching this goal - many thanks to them all. 


\title{
ABSTRACT \\ THE RELATIONSHIP BETWEEN DISPOSITIONAL MINDFULNESS AND EATING: AN ANALYSIS OF SELF-REPORTED AND IN VIVO EATING BEHAVIORS IN UNDERGRADUATE FEMALES
}

\author{
Megan E. Jablonski
}

July 22, 2013

This dissertation theorized that higher levels of dispositional mindfulness (DM), the innate tendency to be aware and accepting of the present moment, is associated with fewer maladaptive eating behaviors, particularly in response to stress and negative emotions. Previous research has established that DM is predictive of decreased stress perception and more skillful emotion regulation. However, few studies have explored how this quality might relate to eating behaviors, which can be influenced by psychological stress and negative affect.

A sample of non-clinical female undergraduates $(N=158)$ completed self-report questionnaires assessing DM, perceived stress, emotional regulation skills, and problematic eating patterns. Participants were also randomized to complete either solvable anagrams (low stress condition) or unsolvable anagrams (high stress condition). Four snack foods, varying in fat content (high/low) and flavor (sweet/salty), were offered for participants to consume during the stress induction, in order to examine food selection and intake. Participants also provided estimates of the amount of each food consumed, to 
determine whether DM was associated with greater accuracy regarding the amount of food eaten.

Bivariate correlations supported the association between DM and more adaptive stress management and emotion regulation. In addition, there were significant negative correlations between DM and several maladaptive eating behaviors, including: emotional eating, external eating, and uncontrolled eating. DM was significantly positively correlated with a measure of mindful eating. Participants were classified into three groups (low, average, and high DM). ANOVA analyses revealed that individuals with higher DM scores reported significantly less stress and negative affect in response to the stress manipulation. However, DM did not influence the amount or type of food consumed or the accuracy of estimated intake.

This study reaffirms the strong relationship between mindfulness and reduced reactivity to stress. Although hypotheses regarding in vivo eating behaviors were not supported, self-report data suggests an inverse relationship between DM and several negative eating tendencies. Limitations of this study included use of an undergraduate sample and the somewhat high level of suspicion reported regarding the presence of food during the experiment. This study supports the possible utility of using mindfulnessenhancing interventions to cultivate more healthy eating patterns. 
TABLE OF CONTENTS

PAGE

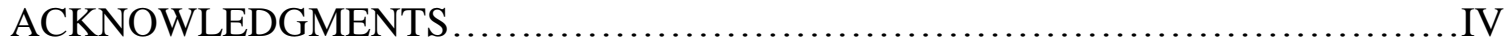

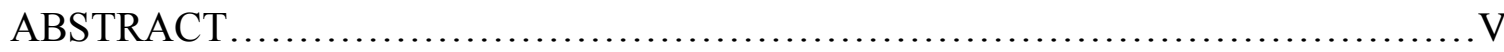

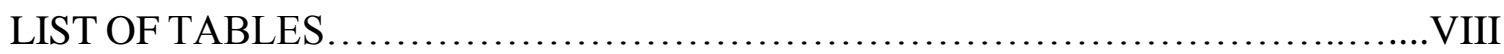

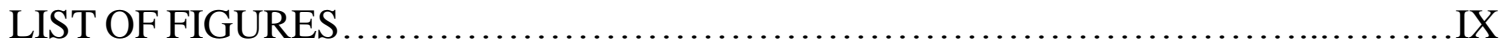

CHAPTER

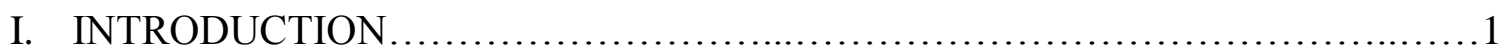

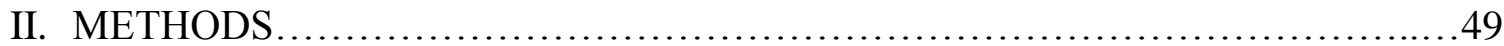

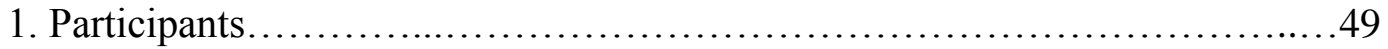

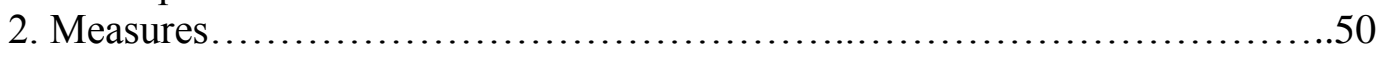

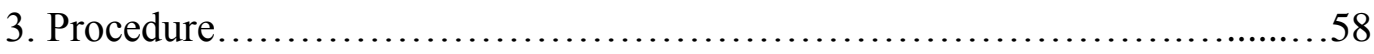

4. Data Preparation and Analysis...........................................64

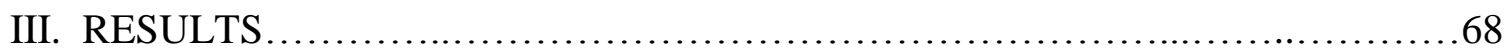

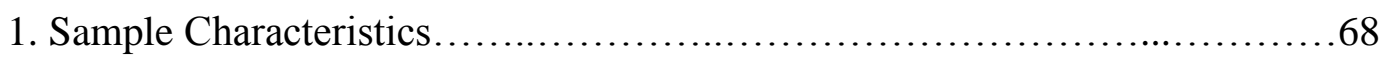

2. Preliminary Analyses...................................................... 77

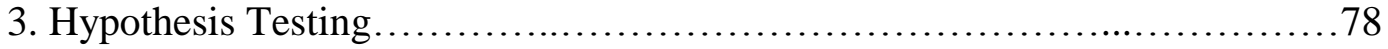

4. Additional Analyses..................................................... 83

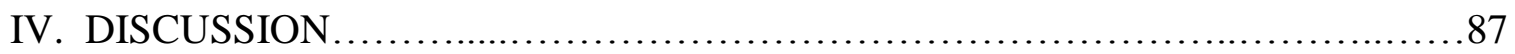

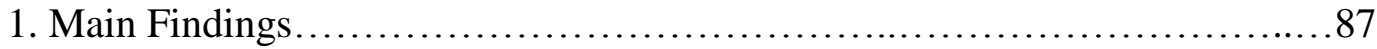

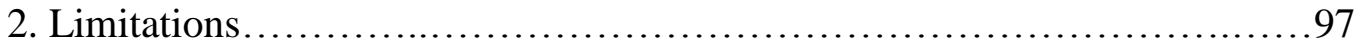

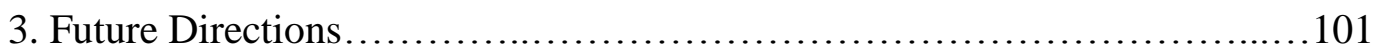

4. Summary and Conclusions............................................. 102

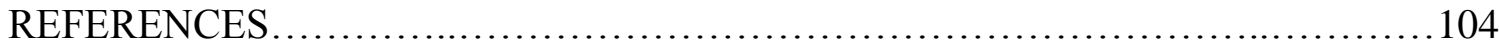

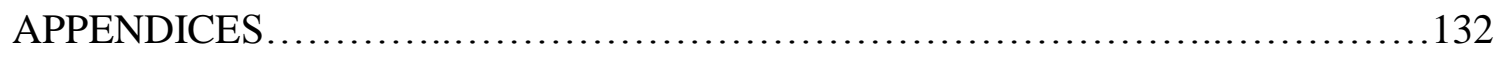

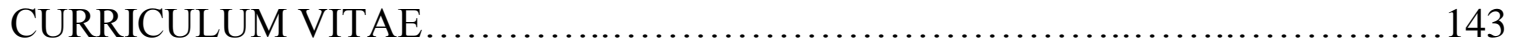




\section{LIST OF TABLES}

TABLE

PAGE

Table 1. Demographic Characteristics of the Sample.............................68

Table 2. Five Facet Mindfulness Questionnaire (FFMQ) Subscale Scores................70

Table 3. Difficulties with Emotional Regulation Scale (DERS) Subscale Scores.........71

Table 4. Mindful Eating Questionnaire (MEQ) Subscale Scores.......................72

Table 5. Average Food Intake.................................................. 75

Table 6. Bivariate Correlations between FFMQ Scores and Psychological Variables....79

Table 7. Bivariate Correlations between FFMQ Scores and Measures of Eating..........80 Behavior 


\section{LIST OF FIGURES}

$\begin{array}{lll}\text { FIGURE PAGE } & \text { PAR }\end{array}$

Figure 1. Weight distribution of sample .....................................69

Figure 2. Distribution of total grams of food consumed............................ 75

Figure 3. Distribution of total number of calories consumed.......................76

Figure 4. Main effects of DM and stress condition on stress rating.................. 81

Figure 5. Main effect of DM on negative affect................................ 81 


\section{INTRODUCTION}

\section{1.) Overweight/Obesity: A Public Health Crisis}

\section{1.) Prevalence and Contributing Factors}

The overweight/obesity $(\mathrm{OW} / \mathrm{OB})$ epidemic is the fastest growing public health problem ever encountered, occurring across all socioeconomic groups, with prevalence rates particularly high among those with lower income and education levels (Zhang \& Wang, 2004). Based on recent Behavioral Risk Factor Surveillance System (BRFSS) data, $63.5 \%$ of Americans report a Body Mass Index (BMI) classified as either overweight or obese (Centers for Disease Control and Prevention [CDC], 2011). One recent report estimates that, at the current rate of increase, by 2018 over 103 million American adults will be obese, with several states having obesity rates exceeding 50\% (Thorpe, 2009).

The negative health consequences of obesity are well-established, including: heart disease, hypertension, hyperglycemia, ischemic stroke, infertility, hypercholesterolemia, respiratory disorders, Type 2 diabetes mellitus, and others (Manson, Skerrett, \& Willett, 2001; Must et al., 1999; National Institutes of Health [NIH], 1998). Further, OW/OB has been shown to negatively affect psychological health and quality of life (Pan, Cole, \& Geliebter, 2011). The increased incidence of weight-related illnesses also has significant economic repercussions, with estimates projecting that in less than ten years the United States will be spending over $\$ 343$ billion on healthcare costs due to obesity alone (Thorpe, 2009). 
A number of variables are thought to contribute to the development of OW/OB, including a complex array of genetic, developmental, medical, socioeconomic, cultural, cognitive, and perceptual factors (Blass, 2008). Additionally, rapid changes in technology, such as the decreased need for manual labor in the home and workplace and the increased reliance on automobiles for transportation, may also be partially responsible for the dramatic increase of OW/OB within recent years (Blass, 2008; Finkelstein, Ruhm, \& Kosa, 2005). In combination with the abundance of low-cost energy-dense foods and significant increases in standard portion sizes, industrialized societies have developed into 'obesogenic' (Lee et al., 2007) or 'food toxic' (Brownell \& Horgen, 2004) environments. Each of these factors increases the likelihood of consuming more calories than are expended, leading to the storage of excess calories as fat and increasing the risk of OW/OB (Caballero, 2007). Furthermore, research suggests that emotional factors, such as psychosocial stress and difficulties with emotional regulation, can negatively affect eating behaviors in a variety of ways, leading to an increased risk of weight gain and the associated health risks of OW/OB (O’Connor \& Connor, 2011).

\section{2.) Effectiveness of Current Weight Management Interventions}

In response to the magnitude of this issue, there has been increased focus on developing more effective weight management interventions. Randomized-controlled trials indicate that popular fad diets do not result in significant and maintainable weight loss (Douketis, Macie, Thabane, \& Williamson, 2005). By contrast, three types of interventions have received the most empirical support: bariatric surgery, weight-loss medication, and lifestyle intervention (Douketis et al., 2005). Although bariatric surgery has been shown to elicit the greatest reduction in weight, invasive medical procedures 
carry serious risks and potential side effects (Moldovan \& David, 2011). In addition, surgery is only recommended for those with either Class III obesity (BMI > 40) or Class II obesity (BMI > 35) and co-morbid health conditions (NIH, 1998). This precludes individuals who are not extremely obese from accessing this form of treatment. Similarly, weight-loss medications can also produce a number of adverse side effects (Glandt \& Raz, 2011) and fail to fully address the complex factors underlying the development of OW/OB (Bond, Phelan, Leahey, Hill, \& Wing, 2009). As a result, psychosocial interventions, which provide education about lifestyle modification, represent a safer method of long-term weight management.

Typically, a standard behavioral weight-loss intervention includes multidisciplinary instruction focused on reducing caloric intake and increasing physical activity, combined with specific behavioral modification skills such as self-monitoring, goal-setting, problem-solving and relapse prevention (Gokee-LaRose et al., 2009). Programs typically include 10-20 patients, who participate in sessions lasting 60-90 minutes for 20-24 weeks, with additional follow-up sessions focused on maintenance strategies (Pinto, Gokee-LaRose, \& Wing, 2007). The duration of weight loss interventions has gradually lengthened over time, increasing from an average of eight weeks in 1974 to 31 weeks in more recent trials (Pinto et al., 2007). Although interventions have become much more successful at eliciting short-term weight loss (Jeffery et al., 2000), long-term follow up studies report that over half return to their original weight within five years (Anderson, Konz, Frederich, \& Wood, 2001; Wadden \& Butryn, 2003), with over one-third gaining more weight than was initially lost (Mann et al., 2007). These findings may be related to evidence that weight loss among obese 
individuals can lead to metabolic changes that increase resistance to additional fat loss and can trigger weight regain (Tremblay \& Chaput, 2012).

As a result of these disappointing outcomes, the usefulness of psychosocial weight management interventions has been questioned, with some suggesting that they are a "waste of time" that should "be abandoned" (Kern, Friedman, Reichmann, Costanzo, \& Musante; 2002, p. 114). In contrast, others have urged for continued research to discern more effective ways of preventing and treating OW/OB (Jeffery et al., 2000). It has also been suggested that interventions should not solely be evaluated based on the number of pounds lost, suggesting that changes in specific eating behaviors are also an important indicator of treatment success, along with a variety of other behavioral, medical, and psychological factors (Foster \& Kendall, 1994). However, there is considerable debate regarding which eating behaviors are most important in the development and maintenance of OW/OB (Moldovan \& David, 2011).

Numerous studies have documented that negative emotions can trigger unhealthy eating behaviors among certain individuals, who have been labeled "emotional eaters" (van Strien, Frijters, Bergers, \& Defares,1986). One prospective study that followed over 1,500 Dutch adults for a period of two years found that high levels of emotional eating was predictive of weight gain, more so than any other dietary or lifestyle factor (Koenders \& van Strien, 2011). Psychological stress has been identified as one trigger of unhealthy eating behaviors among emotional eaters (Greeno \& Wing, 1994), likely due to feelings of distress and negative affect that are often elicited during times of heightened stress. 
The following section provides an overview of the physical and psychological sequellae of stress. In addition, findings pertaining specifically to the relationship between stress and eating behaviors will be reviewed, including a detailed discussion of variables that have been proposed to influence stress-induced eating.

\section{2.) Stress-Induced Eating}

\section{1) Stress \& Physical/Psychological Health}

Stress has been defined by Lazarus and Folkman as "the relationship between the person and the environment that is appraised by the person as taxing or exceeding his or her resources and endangering his or her well-being,” (1984, p. 21). This definition clearly emphasizes the importance of the subjective cognitive evaluation of a potential stressor, which can differ based on a number of individual factors (e.g., coping skills and social support; Sun, Buys, Stewart, \& Shum, 2011). The concept of stress has received an increasing amount of attention in recent years, with some labeling our current time period as the "Age of Stress" (Wallis, Thompson, \& Garvin, 1983, as cited in Hobfoll, 2004). Indeed, a national survey found that Americans report high levels of psychological stress regarding a number of issues, including: financial problems, employment concerns, interpersonal relationships, and physical health (Mental Health America [MHA], 2006). Since that time, many have been affected by a global economic recession, which researchers worry may contribute to a rise in stress-related illnesses, particularly in the context of budget cuts to healthcare programs (Hughes \& Dennison, 2009).

Stress has been identified as a contributing factor in a number of psychological difficulties, such as depression (Hammen, 2005) and insomnia (Dikeos \& Soldatos, 
2005), as well as physical illnesses, including heart disease (Esler, Schwarz, \& Alvarenga, 2008) and chronic pain (Hwang et al., 2008). It has been shown that unremitting stress can directly affect health through a variety of physiological pathways, including dysregulation of autonomic, biological, and neuroendocrine functions (Sapolsky, 2004). Glucocorticoids and catecholamines are the hormones primarily responsible for the body's stress response, which is essential for short-term adaptation; however, under conditions of chronic stress, release of these hormones can cause significant damage, which has been termed "allostatic load" (McEwen, 2000). Allostatic load has been operationalized and measured using a composite of ten indices of physical functioning (e.g. blood pressure and cholesterol levels) and has been shown to be predictive of physical health status (McEwen, 2000). Stress-related dysregulation decreases the responsiveness of the immune system (Pedersen, Zachariae, \& Bovbjerg, 2009) and slows wound healing (Walburn, Vedhara, Hankins, Rixon, \& Weinmen, 2009). In addition to the direct effects of physiological dysregulation, stress can elicit changes in key health behaviors, thus affecting health through indirect pathways as well (O'Connor \& Conner, 2011). Given the important role of eating behaviors in obtaining vital nutrients and maintaining a healthy weight, changes in eating patterns that occur in response to stress can have a significant impact on health. Therefore, targeting stressinduced eating may be a particularly fruitful avenue for researchers seeking to improve current weight management interventions. The following sections will provide an overview of: 1) conceptual models of stress-induced eating;2) specific ways that stress has been shown to negatively influence eating patterns; and 3) variables which have been proposed to influence the relationship between stress and eating. 


\section{2.) Models of Stress-Induced Eating}

A great deal of research has investigated the relationship between stress and eating behaviors, exploring this subject both in animals and humans. In Greeno and Wing's seminal review of stress-induced eating (1994), they describe two distinct paradigms of research in this area: the general effects model and the individual differences model. The general effects model is based on the premise that food intake increases when an organism is exposed to stressful conditions. The basic theory underlying the general effects model is that stress results in physiological changes which are thereby responsible for increases in food consumption. This theoretical paradigm has been used almost exclusively in non-human species. Typically, animals are exposed to acute stressors, such as tail-pinching or electrical shock, or, more rarely, chronic stressors, such as stressful living environments. Food preference and intake are subsequently examined among the animals randomized to stressful versus control conditions. Based on early studies, there was preliminary evidence supporting the general effects model in animals; however, due to variability in the type and severity of laboratory stressors; inconsistencies in reported findings; and the relatively small number of studies available for review, Greeno and Wing suggested that these results should be considered cautiously (1994).

Subsequent findings have largely demonstrated that animals generally reduce food intake when they are exposed to stress, contrary to the general effects model. However, it is notable that food intake increases when highly palatable (i.e., sweet/high fat) food is available for consumption (Dallman et al., 2003). In fact, one study reports evidence of binge-eating behavior among rats under these conditions (Hagan, Chandler, 
Wauford, Rybak, \& Oswald, 2003). In contrast, food intake after exposure to an acute stressor remains unchanged when less palatable foods are available (Dallman et al., 2003). These finding may help explain the contradictory results among the animal studies cited by Greeno and Wing (1994). It is also notable that greater intake of highly palatable foods has been shown to decrease corticotropin-releasing factor (CRF) in the hypothalamus of rats, leading to a reduction in their stress response (Dallman et al., 2003). This finding may have significant implications for evidence suggesting that humans under stress also tend to prefer less healthy "comfort foods," as will be discussed in greater detail in Sections 2.3 and 2.4.

In contrast to the general effects model, the individual differences model proposes that individual factors, such as developmental history, psychological variables, and biological factors, play a substantial role in stress-induced eating (Greeno \& Wing, 1994). This model has been utilized primarily in studies exploring the eating behaviors of humans, and it focuses mainly on the psychological and environmental factors involved in stress-induced eating, rather than physiological mechanisms. It is posited that individual differences result in either high or low vulnerability to stress-induced eating. Exposure to stress is hypothesized to elicit physical and/or psychological changes, which are thought to lead to eating or overeating among those with a high degree of vulnerability, while inhibiting eating among those with low vulnerability. It should be noted that this model is very general, with little specificity regarding the possible "individual differences" or "physical and/or psychological changes" that are theorized to combine to result in stress-induced eating, nor does it appears that this model has been empirically tested. Rather, it seems that the individual differences model is more 
theoretical in nature, depicting a way of conceptualizing the wide variety of factors that influence the stress-eating relationship.

The basic theory underlying the individual differences model has been supported, as indicated by the identification of several variables that are predictive of stress-induced eating (Greeno \& Wing, 1994). As might be expected, classification as an emotional eater is one variable that has been linked with a greater tendency to engage in stressinduced eating (Macht, 2008). Though related, stress-induced eating and emotional eating are not synonymous, and have been studied separately in eating literature. Another factor shown to be influential in the relationship between stress and eating is classification as a "restrained eater" (Greeno \& Wing, 1994). Individuals high in dietary restraint report chronic efforts to restrict consumption of unhealthy foods, often for the purpose of weight loss (Herman \& Mack, 1975). Psychological stress has been shown to disrupt these dietary rules and can have a disinhibiting effect on food consumption (O’Connor \& Conner, 2011). The following section provides a more detailed discussion regarding the general effects of stress on eating behaviors, followed by a discussion of these risk-factors.

\section{3.) Effects of Psychological Stress on Eating Behaviors}

Early research on stress and eating focused primarily on whether stress elicited an increase, decrease, or no change in food intake (O’Connor \& Conner, 2011). Since that time, research has shifted to more nuanced questions, examining "how stress affects eating, in whom, and in what situations" (Greeno \& Wing, 1994, p. 444). Given that heightened stress has been shown to evoke gastric changes, which typically inhibit eating (Blair, Wing, \& Wald, 1991), reduced food intake is considered the normative response 
to stress. However, although physiological hunger and satiety cues are clearly important in eating behavior, stress has been shown to increase food cravings and food intake among some individuals, even in the absence of hunger (Lemmens, Rutters, Born, \& Westerterp-Plantenga, 2011). As noted above, this phenomenon may be partially due to the reduction in the physiological stress response that has been linked with the intake of comfort foods (Dallman et al., 2003). Thus, the consumption of these less healthy foods may represent an effective means of reducing the physiological manifestations of stress in the short term. From a physiological perspective, it has been proposed that obesity might even be considered a "normal consequence to a changed environment," given the “modern, computer-dependent, sleep-deprived, physically inactive...[and] chronically stressed" environments characteristic of industrialized societies (Chaput, Doucet, \& Tremblay, 2012). However, in absence of developing more adaptive coping strategies, the long-term effects of these eating patterns can be highly detrimental to health and wellbeing.

A number of survey studies have examined self-reported changes in eating in response to stress, typically studying convenience samples of female undergraduates. Most studies have revealed that some individuals tend to overeat due to stress, whereas others report that they lose their appetite. Some studies report that the proportion of individuals who overeat due to stress is approximately equivalent to those who reduce their food intake (Oliver \& Wardle, 1999; Wallis \& Hetherington, 2009). However, others have reported a much higher percentage of stress-induced overeaters. For example, Zellner and colleagues (2006) report that $71 \%$ of a sample of female undergraduates endorse overeating when stressed. It is possible that the large percentage 
of individuals who report overeating due to stress may be linked with the easy availability of highly palatable foods. It is notable that, of those who endorsed stress-induced overeating, $75 \%$ were classified as restrained eaters, meaning that they report a tendency to restrict intake of unhealthy foods, often in order to manage or lose weight; in contrast, only $35 \%$ of those who report no change in food intake due to stress were classified as restrained eaters (Zellner, 2006). This result is consistent with prior research demonstrating the moderating effect of dietary restraint on stress-induced eating, which is discussed in more detail below. The frequency of snacking has also been examined as a possible result of stress-induced eating, with one diary-based study reporting a positive linear relationship between the number of daily hassles and snacks (Conner, Fitter, \& Fletcher, 1999). Other studies have explored the influence of stress on the type of food consumed. Multiple self-report studies have shown that women report eating high calorie and high fat snack foods more frequently during periods of stress, while healthier options, such as fruits, vegetables, and "meal-type foods," are eaten less than usual (Weinstein, Shidle, \& Rolls, 1997; Oliver \& Wardle, 1999).

Although these self-report and diary-based studies can be informative regarding how individuals perceive that their eating behaviors are influenced by stress, research tends to demonstrate that awareness of the factors that impact food consumption is surprisingly poor (Wansink, 2006). In a fascinating series of experiments, Brian Wansink, a professor in consumer behavior and marketing, establishes that eating behaviors are unknowingly influenced by a number of environmental factors, such as plate size and food presentation (Wansink, 2006). These results are highly consistent, yet during these experiments, most participants adamantly deny that these factors may have 
played a role in their food consumption. Thus, reliance upon self-report data alone is insufficient to fully understand stress-induced eating. Fortunately, these findings are supplemented by studies exploring in-vivo eating behaviors following laboratory stressors.

Laboratory stress induction studies have examined how stress influences the amount and type of foods consumed. Zellner and colleagues (2006) conducted a study examining the effects of a laboratory stressor on food selection among female undergraduates, randomizing participants to a high versus low stress task (unsolvable and solvable anagrams). In this study, participants in the stressed group ate more of the unhealthy sweet food (M\&M's) while consuming less of the healthy sweet food (grapes), as compared with participants in the low stress group. However, dietary restraint was not measured, making it impossible to determine the possible effects of this variable. Interestingly, a highly similar study conducted among male undergraduates revealed the opposite pattern; males in the unstressed group ate less than those in the stress group (Zellner, Saito, \& Gonzalez, 2007).

The increased consumption of highly palatable foods during times of heightened stress is one of the more robust findings within the stress-induced eating literature, with important implications for OW/OB and chronic diseases linked to diet (O'Connor \& Conner, 2011). One particular area of concern is that this change in eating behavior is likely to increase visceral fat, given that increased cortisol has been linked with this more dangerous fat distribution (Adam \& Epel, 2007). Individuals with greater amounts of visceral, or abdominal, fat have been shown to experience more severe negative health outcomes than those with peripheral fat distributions (Jones et al., 2012). 
Indeed, new research clearly demonstrates that the hypothalamic-pituitary-adrenal (HPA) axis, which governs the body's physical response to stress, is integral to understanding stress-induced eating. Although less is known about the possible interrelationships between food intake and chronic stress in humans, a recent study found a connection between blunted cortisol responsiveness and greater intake of comfort foods in a sample of chronically stressed women exposed to an acute laboratory stressor (Trier Social Stress Test; Tryon, DeCant, \& Laugero, 2013). In contrast, another study found that individuals high in cortisol reactivity consumed larger amounts of food - particularly sweet, high fat options - during the same experimental stress induction (Epel, Lapidus, McEwen, \& Brownell, 2001). Taken together, these findings might suggest that, initially, high cortisol reactivity is predictive of greater consumption of comfort foods. It is possible that over time the chronic exposure to stress hormones may cause physiological dysregulation and result in the blunted cortisol response observed Tryon et al.'s chronically stressed sample (2013). Further complicating this issue is evidence that lowcalorie diets can lead to greater release of cortisol (Tomiyama et al., 2010).

Another vein of physiological research pertinent to the stress-eating connection involves the role of ghrelin, a hunger stimulating hormone. One recently published model proposes that stress increases ghrelin levels, which activates the hedonic signaling pathway and results in greater consumption of comfort foods, leading to increased dopamine signaling which thereby reduces stress and negative affect (Schellekens, Finger, Dinan, \& Cryan, 2012). Unfortunately, over time, this process leads to a desensitization of dopamine reward signaling, similar to that observed in substance abuse literature, and ultimately increases the likelihood of developing greater anxiety, 
depression, and obesity (Schellekens et al., 2012). The influence of these physiological processes is a key component in fully understanding how stress and eating are related.

In summary, based upon the findings from self-report studies, laboratory stress manipulations, and physiological research, it is evident that stress exerts an influence on eating behavior among some individuals. However, there is considerable variance in how individuals respond to stress. It has been proposed that stress-induced eating may vary depending upon the severity of the stressor, with mild stress eliciting greater food intake and severe stress having the opposite effect (Oliver, Wardle, \& Gibson, 2000; Macht, 2008). However, given that laboratory stress inductions are relatively mild and brief in comparison to more significant stressful events which occur naturally, such as being diagnosed with a serious illness or the financial strain of unemployment, this hypothesis is difficult to test experimentally. Alternately, Oliver and colleagues (2000) reiterate that individual difference variables may be responsible for differential responses to stress. Several variables which have been proposed to affect stress-induced eating will be discussed in the following sections. The most widely researched variables include: 1) emotional eating; 2) dietary restraint; 3) gender; and 4) weight. A discussion of how these variables are believed to influence the relationship between stress and eating is provided below.

\section{4.) Variables Proposed to Influence Stress-Induced Eating}

\subsection{1.) Emotional Eating}

An early and influential explanation of the relationship between eating and emotion was Kaplan and Kaplan's psychosomatic theory of obesity (1957), which asserted that weight problems are the result of overeating, rather than metabolic 
dysfunction - a novel suggestion at the time (Stroebe, Papies, \& Aarts, 2008). This theory conceptualized overeating as a learned behavior resulting from classical conditioning. They propose that eating reduces feelings of fear and anxiety; as a result, individuals can become conditioned to eat during negative emotional states, even in the absence of hunger or appetite. It is notable that this theory did not suggest a mechanism through which eating might reduce fear and anxiety, nor why this phenomenon would only occur among those who are OW/OB (Stroebe et al., 2008). Similarly, it did not explain why some individuals might become conditioned to external factors while others do not. Although several elements of this theory have received inconsistent support, the psychosomatic theory of obesity was profoundly important in establishing a possible link between emotional states and eating - a connection that subsequently has received strong empirical support in studies focusing on women.

The majority of emotional eating research has focused on the impact of negative emotional states. However, a naturalistic study using experience-sampling methodology among a small sample of healthy males and females suggests that eating may occur in response to positive emotions approximately as frequently as negative emotions (Macht, Haupt, \& Salewsky, 2004). However, in a study comparing the effects of induced mood states (joy versus sadness) among emotional eaters, participants ate significantly more food following the sad mood induction (van Strien et al., 2013). Thus, it was concluded that eating in response to positive and negative feelings represent two distinct constructs (van Strien et al., 2013). Given the obvious connection between stress and negative emotional states, this discussion will focus solely on the effects of negative affect on eating behaviors. 
One study utilizing ecological momentary assessment (EMA) methodology found that negative affect is associated with a greater desire to eat and a heightened experience of hunger. In contrast, positive affect, feelings of relaxation, or the absence of emotion were not associated with the desire to eat. (Macht \& Simons, 2000). In addition to increasing the desire to eat, emotional eating has also been shown to influence food preferences. Similar to stress-induced eating, emotional eating also tends to elicit greater intake of high-fat, sweet foods among females (Macht, 2008). However, although intake of comfort foods has been shown to reduce negative affect temporarily, this behavior frequently causes feelings of guilt afterward (Dube, LuBel, \& Lu, 2005). Thus, individuals relying upon comfort eating for emotional regulation might enter a 'spiral' in which their efforts to cope begin to trigger the negative emotions they are seeking to avoid.

A number of theories have proposed possible mechanisms for the influence of emotional state on eating. Most notable is the 'escape' theory of eating proposed by Heatherton and Baumeister (1991). This theory asserts that overeating results from a "motivated attempt to escape from self-awareness" in response to negative affect (Heatherton \& Baumeister, 1991, p. 88). In order to reduce these feelings, some individuals are theorized to engage in overeating in order to narrow their attention to the immediate environment and reduce their level of self-awareness. This is consistent with self-report data from emotional eaters, who identify "distraction" as a primary goal of emotional eating (Polivy \& Herman, 1999). The premise that some eating behaviors particularly binge eating - involve an element of avoidance/dissociation continues to be prevalent in contemporary models of eating pathology, and is incorporated in an 
overview of Binge-Eating Disorder in the recently published DSM-V (American Psychiatric Association [APA], 2013).

Macht (2008) proposes a model which seeks to synthesize the psychological, biological, and physiological theories of emotional eating. First, the model proposes that emotions aroused in response to food stimuli (e.g., the smell of a tempting food) influence food selection. This premise is based upon findings that highly palatable foods elicit a positive emotional response and that food-related stimuli can trigger powerful cravings. Another component of this model concerns the influence of intense emotional states. During these situations, food intake tends to be suppressed. This is consistent with the behavior of individuals experiencing severe sadness, who typically demonstrate behavioral deactivation and withdrawal from the environment. Third, the model proposes that both negative and positive emotions can impair cognitive control over eating and lead to increased food intake, thus incorporating the extensive body of literature on the disinhibiting effects of dietary restraint, which will be discussed below. Fourth, the model notes that negative affect may elicit eating in order to regulate emotion among those with poor coping abilities. This theory shows a great deal of promise because it provides a unified conceptualization of multiple factors thought to influence eating behaviors. Interestingly, it does not directly address the influence of stress, but notes that responses to various types of stressors can be instructive in better understanding the differences between emotional eating and restrained eating. The following section provides an overview of dietary restraint, including a review of how it is distinct from emotional eating and how it pertains to stress-induced eating. 


\subsection{2.) Dietary Restraint}

Dietary restraint - the tendency to restrict food intake for the purpose of weight control - was first proposed as a possible trigger of overeating by Herman and Mack (1975), with further development by Herman and Polivy (1980). Restraint theory suggests that individuals who are OW/OB frequently attempt to restrict their food intake through self-control and cognitive rules designed to manage weight. These individuals, often termed, "restrained eaters," attempt to exert control over eating through rigid pattern of thoughts and behaviors related to food. For example, restrained eaters are more likely to attempt to consciously count calories, avoid eating any fattening foods, or only eat at certain times of the day, regardless of hunger cues. However, numerous studies have demonstrated that restrained eaters, as defined by high scores on the Restraint Scale (Herman \& Mack, 1975) are vulnerable to intermittent periods of overeating, known as “disinhibited eating” (Herman \& Polivy, 1980). This vulnerability is thought to arise during situations in which the control exerted by restrained eaters is challenged in some way.

Several factors have been shown to lead to disinhibited eating among restrained eaters. One of the earliest findings involved the differential responses of restrained and unrestrained eaters to a "pre-load" of food (Herman \& Polivy, 1980). A pre-load typically consists of a high-calorie or high-fat snack consumed by participants prior to a subsequent eating task, such as a taste test or meal. Restrained eaters given a pre-load of food have been shown to eat more than restrained eaters who do not consume a pre-load (Herman \& Polivy, 1980), regardless of the caloric content of the pre-load food (Mills \& Palandra, 2008). In contrast, unrestrained eaters do not demonstrate this increased 
response to the pre-load, instead reducing their food intake to compensate for the food consumed previously. It has been proposed that consumption of the pre-load among restrained eaters constitutes a violation of their dietary "rules," increasing the likelihood of a subsequent lapse. Thus, subsequent overeating has been conceptualized as an example of the abstinence violation effect (AVE; Stice, Fisher, \& Lowe, 2004), a concept that originated within substance abuse literature, involving a period of uncontrolled substance use resulting from a minor lapse in sobriety. Applied to eating behaviors, the AVE occurs when individuals attempting to manage their weight adopt restrictive dietary rules about the types and amounts of food consumed, but ultimately lapse to less healthy eating patterns, even after a minor dietary violation.

Several other factors have been shown to interfere with the self-control of restrained eaters. As noted previously, psychological stress is one of the variables shown to elicit disinhibited eating among restrained eaters (O’Connor \& Conner, 2011). Results of one stress induction study utilizing the Stroop test among a sample of undergraduate females demonstrated a disinhibiting effect of cognitive load, even in the absence of negative affect (Lattimore \& Maxwell, 2004). These findings suggest that coping adaptively requires the use of cognitive resources; the increased strain on these limited cognitive resources may reduce adherence to dietary goals. (Lattimore \& Maxwell, 2004).

One significant limitation of these findings stems from the fact that virtually all of these studies were conducted among samples of undergraduate females, highly limiting the understanding of how dietary restraint might affect eating patterns among other groups. Secondly, is notable that the majority of the findings linking dietary restraint and 
overeating are based upon restraint status as measured by Herman and Polivy's Restraint Scale. Interestingly, studies using later measures of dietary restraint, such as the restraint subscales of the Dutch Eating Behavior Questionnaire (DEBQ; van Strien et al., 1986) and the Three Factor Eating Questionnaire (TFEQ; Stunkard \& Messick, 1985), have been less consistent in reproducing these results. More recent research indicates that the Restraint Scale does not correlate strongly with measurements of actual food intake (Stice et al., 2004). Thus, Stice and colleagues (2004) suggest that the Restraint Scale is more accurately understood as a measure of unsuccessful dieting, rather than true dietary restraint. It has been proposed that there is a distinction between rigid restraint, marked by an "all or nothing" approach to dieting, versus flexible restraint, a more moderate approach to weight loss (Westenhoefer, Stunkard, \& Pudel, 1999). Flexible restraint has been shown to be associated with lower BMI and more successful weight loss (Westenhoefer et al., 2013). In addition, individuals high in flexible restraint are less likely to demonstrate disinhibition in response to laboratory tasks (Westenhoefer, Broeckmann, Munch, \& Pudel, 1994). However, most existing measures do not attempt to differentiate between these different types of dietary restraint.

As with emotional eaters, restrained eaters also exhibit disinhibition in response to negative affect (Stroebe et al., 2008). It is unclear to what degree these two eating patterns might overlap. However, there is some evidence that these represent distinct constructs, with positron emission tomography scans demonstrating differential dopamine activation between individuals scoring high on measures of these eating tendencies (Volkow et al, 2003). In summary, there are a number of factors which can lead to disinhibition among restrained eaters. Cognitive load and negative affect have 
direct implications for this discussion of stress-induced eating, as they are both commonly experienced during heightened stress. The following section will discuss gender differences which have been observed among in the areas of stress-induced eating, emotional eating, and dietary restraint.

\subsection{3.) Gender}

A number of studies have revealed the presence of gender differences in typical food intake patterns as well as stress-induced eating (Kiefer, Rathmanner, \& Kunze, 2005). As noted above, a smaller percentage of men tend to report restrained or emotional eating, likely due to a combination of psychological and socio-cultural factors (Greeno \& Wing, 1994). In laboratory stress and negative affect inductions studies, male samples often do not exhibit the same increase in eating observed in female samples, with some studies demonstrated opposite patterns. Although one self-report study found that similar proportions of males and females endorse in response to stress, dietary restraint was not related to stress-induced eating among men (Weinstein et al., 1997). Even among the minority of studies suggesting that males and females report similar levels of emotional eating, there appear to be distinctive qualities that vary by gender. For example, among adolescents, although emotional eating is endorsed at comparable levels, among girls it appears to be significantly associated with specific emotional states, such as perceived stress, worry, and tension/anxiety; in contrast, among boys, emotional eating is associated with diffuse, or non-specific, emotional states (Nguyen-Rodriguez, Unger, \& Spruijt-Metz, 2009). Similar gender differences in emotional eating have also been reported in adults, with male emotional eaters endorsing greater alexythymia than female 
emotional eaters (Larsen, van Strien, Eisinga, \& Engels, 2006; Kenardy, Butler, Carter, \& Moor, 2003).

Overall, gender differences appear to be reflective of the differences in the prevalence of the two individual difference variables discussed above - emotional eating and restrained eating. As a result of the gender differences which have consistently been demonstrated in these variables, many studies of eating behaviors have chosen to recruit only female participants.

Another individual difference factor which has been proposed to effect stressinduced eating is weight classification (normal weight, overweight, or obese). The research examining differences between these groups is summarized below.

\subsection{4.) Weight}

Some of the first studies to examine differences in stress-induced eating based upon weight emerged from early efforts at explaining the occurrence of OW/OB. As noted above, the psychosomatic theory of obesity (Kaplan \& Kaplan, 1957) proposed that obese individuals eat in response to negative affect, because they cannot distinguish the physical arousal associated with these emotions from feelings of hunger. Similarly, the 'externality' theory of obesity (Schachter, Goldman, \& Gordon, 1968) posited that obese individuals are minimally aware of their internal hunger and satiety cues, instead tending to eat in response to external stimuli, such as time of day or palatability of food. While both theories were supported in initial studies (Goldman, Jaffa, \& Schachter, 1968), later research was less consistent (Greeno \& Wing, 1994). For example, in regard to externalizing theory, evidence of externally-motivated eating has been found in individuals of widely varying weight, rather than being distinctly characteristic of obese 
persons (Rodin, 1981). Overall, given the important role of dietary restraint in predicting stress-induced eating behavior, it appears that dieting status may account for the significant results obtained in some studies, rather than weight classification.

In summary, stress has been shown to have a negative impact on several health behaviors associated with eating and has been linked to OW/OB in both cross-sectional and longitudinal studies (Torres \& Nowson, 2007; Block, He, Zaslavsky, Ding, \& Ayanian, 2009). Several variables - particularly restrained and emotional eating - are important in understanding this relationship, and it is important for weight management interventions to directly address these factors. Given that many existing psychosocial treatments for OW/OB report disappointing long-term outcomes, innovative techniques are needed to improve and maintain the effectiveness of weight loss interventions. Increasingly, programs designed to alter eating behaviors are beginning to include elements of mindfulness training, which involves cultivating a heightened sense of nonjudgmental awareness present moment experience (Kabat-Zinn, 1990). Such programs are designed to de-automate habitual patterns of responding, while increasing awareness and acceptance and may be uniquely effective in addressing maladaptive eating patterns. Below is an overview of the history of mindfulness and its empirical study within Western psychology and integrative medicine.

\section{3.) Mindfulness}

\section{1.) Historical Overview and Operational Definitions}

During the past three decades, Western culture has experienced a burgeoning interest in mindfulness, a word which can be defined most simply as non-judgmental awareness of the present moment (Kabat-Zinn, 1990). Though it has only recently been 
introduced into mainstream Western society, the concept of mindfulness was first conceived during the sixth century B.C.E. within the context of ancient Buddhist psychology (Siegel, Germer, \& Olendzki, 2009). Mindfulness is commonly accepted as the English translation of the Pali word, "sati," which means awareness, attention, and remembering (Siegel et al., 2009). While different forms of meditation are thought to cultivate awareness, mindfulness - or vipassana - meditation focuses on moment-tomoment awareness, which is thought to create insight into one's habitual internal experiences as well as the continually changing nature of mental states (Siegel et al., 2009). Many of these ideas can be found within the Dhammapada, a collection of 423 verses containing teachings of the Buddha. This work is widely considered to be one of the most influential Buddhist texts in existence. According to the Dhammapada, selfobservation and self-awareness can reduce suffering through greater insight into the (often inaccurate) perceptions created by the mind, ultimately leading to enhanced emotional clarity and peace (Fronsdale, 2006).

Mindfulness was first introduced into Western clinical practice largely through the pioneering efforts of Jon Kabat-Zinn, who initiated the Mindfulness-based Stress Reduction (MBSR) program at the University of Massachusetts Medical Center in 1979. The goal of this program was to determine if a secular form of mindfulness meditation could reduce suffering among patients in a hospital setting, as it had within its original Buddhist context (Carmody, 2009). This 8-week group intervention was originally developed for chronic pain patients referred by their physicians when traditional medical interventions proved unsuccessful, eventually expanding to include patients with a variety of physical and psychological difficulties (Kabat-Zinn, 1982). The components of 
MBSR are well-described elsewhere (Kabat-Zinn, 1990; Santorelli \& Kabat-Zinn, 2004). Briefly, MBSR is comprised of five key elements: 1) "body scan," which involves systematic and progressive focusing on sensations present in the body, without judgment or attempts to change them; 2) sitting meditation; 3) gentle Yoga; 4) informal mindfulness practices, such as mindful walking and eating; and 5) didactic discussions regarding stress. Overall, MBSR seeks to increase non-judgmental present-moment focus through consistent practice, with participants committing to a minimum of 45 minutes of home practice, six days per week, in addition to the weekly group session (Kabat-Zinn, 1990).

Since the program's inception, MBSR has undergone substantive changes in its application. As noted, although traditionally MBSR programs have catered to heterogeneous groups of participants, there has been a trend in recent years toward tailoring the intervention to specific disease populations. This is likely due to the difficulties inherent to conducting research with highly heterogeneous groups, as this introduces additional variance which complicates interpretation of results. Currently, a much higher percentage of MBSR participants are self-referred, rather than receiving a referral from a physician (Salmon, Santorelli, Sephton, \& Kabat-Zinn, 2009). To date, over 19,000 people have participated in MBSR at the University of Massachusetts Stress Reduction Clinic, and there are over 900 registered MBSR teachers worldwide (Center for Mindfulness [CM], 2013).

Following MBSR's surge in popularity, several related interventions incorporating elements of mindfulness training and acceptance-based strategies have emerged, in what has been termed the "Third Wave" of Cognitive-Behavioral Therapy. 
In contrast to traditional cognitive-behavioral therapy, these approaches share a common focus on the development on non-judgmental acceptance of inner experience, rather than viewing one's thoughts or feelings as "maladaptive" and seeking to focus on contradicting evidence (Roemer \& Orsillo, 2009). Some prominent examples within clinical psychology include Mindfulness-Based Cognitive Therapy (MBCT; see Coelho, Canter, \& Ernst, 2007); Acceptance and Commitment Therapy (ACT; see Powers, Vording, \& Emmelkamp, 2009 and Pull, 2009); and Dialectical Behavioral Therapy (DBT; see Feigenbaum, 2007 and Lynch, Trost, Salsman, \& Linehan, 2007).

One manifestation of growing interest in mindfulness and the proliferation of mindfulness-based interventions and research is interest in developing an agreed-upon characterization of just what the term means. Several academically-oriented clinicians have proposed definitions of mindfulness, emphasizing primarily non-judgmental or nonreactive awareness of present-moment experience (Baer, Walsh, \& Lykins, 2009). One notable exception to this is a definition of mindfulness proposed by psychologist Ellen Langer (1989) that emphasizes the capacity to create new categories or ways of viewing experience; being open to new information; and the ability to entertain multiple perspectives. Her focus seems to be primarily on cognitive flexibility, with comparatively little emphasis on formal meditative practice. While in some ways, diversified conceptions of mindfulness can stimulate healthy debate, they can inhibit systematic research. Awareness of this problem led Bishop et al. (2004) to convene a series of conferences attended by scholars to try to achieve some degree of unanimity. The result of their efforts culminated in the creation of this two-part operational definition of mindfulness: 1) “...the self regulation of attention so that it is maintained on 
immediate experience, thereby allowing for increased recognition of mental events in the present moment” and 2) “...adopting a particular orientation toward one's experiences in the present moment, an orientation that is characterized by curiosity, openness, and acceptance" (Bishop et al, 2004, p. 232). This characterization of mindfulness emphasizes deliberate control of attention, directing it predominantly toward present moment experience, with an underlying attitude of acceptance. It appears to capture key elements that can actually be traced by to the Buddhist origins of mindfulness. This definition has been cited frequently in subsequent research, but based on the proliferation of mindfulness measures in recent years, each demonstrating its own unique conceptualization of the construct, it is clear that differences remain. Because dispositional or 'trait' mindfulness is based upon scores on self-report assessment instruments, these differences in conceptualization complicate efforts to explore this area of research. An overview of the development of mindfulness assessment is provided below.

\section{2.) Measurement of Mindfulness}

One criticism of early mindfulness-based intervention research was the absence of validated self-report mindfulness measures (Dimidjian \& Linehan, 2003). Without the ability to quantify mindfulness, understanding and enhancing this state of awareness presented a significant challenge to researchers (Baer, 2007). In response, over 15 selfreport mindfulness measures have been developed to date. The first mindfulness measure was designed solely for use among experienced meditators (Freiburg Mindfulness Questionnaire [FMI]; Buchheld, Grossman, \& Walach, 2001), but subsequent scales have begun to use language that is more inclusive of the general population, allowing for the 
study of innate mindfulness levels among non-meditators. Most recently, there has been a trend toward developing mindfulness measures appropriate for children and adolescents (Brown, West, Loverich, \& Biegel, 2011; Greco, Baer, \& Smith, 2011).

Overall, mindfulness measures show strong psychometric properties, demonstrating internal consistency ranging from acceptable to excellent. They generally have been shown to correlate significantly with other constructs in the predicted directions, demonstrating convergent and divergent validity. Each scale measures a unique formulation of mindfulness, based on the authors' conceptualization of what facets are most representative of this state of awareness. For example, the Kentucky Inventory of Mindfulness Skills (KIMS) measures four mindfulness skills which are taught in DBT, examining each as a separate component of mindfulness; thus, it does not purport to include all key elements of mindfulness (Baer, Smith, \& Allen, 2004). The Mindful Attention Awareness Scale (MAAS) focuses solely on awareness and attention to the present moment, noting that factor analysis revealed no incremental validity when attitudinal factors (i.e., acceptance and non-judgment) were included (Brown \& Ryan, 2003). Conversely, the Philadelphia Mindfulness Scale (PHLMS) includes attention/awareness and acceptance subscales, asserting that attention in the absence of acceptance can be indicative of obsessiveness or rumination (Cardaciotto, Herbert, Forman, Moitra, \& Farrow, 2008).

The Five Facet Mindfulness Questionnaire was created through a factor analysis of the five most commonly used mindfulness questionnaires, and is comprised of the items which had the highest loadings on the five factors emerging from this analysis (FFMQ; Baer et al, 2008). In contrast, factor analysis of other mindfulness measures has 
yielded one factor (MAAS; Brown \& Ryan, 2003 and FMI; Buchheld et al. 2001), two factor, (PHLMS; Cardaciotto et al., 2008) and four factor conceptualizations (KIMS; Baer et al., 2004), making it difficult to definitively determine which factors are most integral to the construct of mindfulness. Indeed, several researchers have noted the difficulty of adequately defining and measuring this construct, given its highly experiential nature (Brown \& Ryan, 2003; Baer et al., 2009). In part, this is due to assertions that mindfulness is essentially non-conceptual in nature, something that can only truly experienced at an experiential level (Grossman \& Van Dam, 2011; Kabat-Zinn, 2003). This viewpoint has contributed to the ongoing ferment in discussions of how to best reconcile the Western empiricist tradition with its emphasis on externally-based measurement practices with Eastern meditative traditions that employ introspective investigative practices that do not necessarily lend themselves well to conceptual analysis of experience.

While increasing breadth of available mindfulness measures is promising in terms of furthering the empirical study of mindfulness, it complicates the comparison of results across studies. The MAAS, which focuses solely on awareness of present moment experience, is the most frequently cited mindfulness measure (Cordon \& Finney, 2008). However, as noted above, it has been criticized for not incorporating core attitudinal factors foundational to most conceptualizations of mindfulness, such as nonjudgment or acceptance (Cardaciotto et al., 2008). Further, a study utilizing item-response theory found that most of its items did not discriminate well between different trait levels of mindfulness, with only five questions showing high discrimination parameters (Van Dam, Earleywine, \& Borders, 2010). Van Dam and colleagues (2010) propose that 
improving the measurement of this complex construct may involve further consideration of its original historical underpinnings, infusing secular conceptualizations of mindfulness with a greater emphasis on its fundamental Buddhist elements. Currently, no single self-report questionnaire is universally accepted as the most representative or "accurate" measure of mindfulness. However, because the FFMQ was created through a factor analysis of a number of different mindfulness questionnaires, this measure may represent the first step toward a more unified measurement tool.

Although there is continued debate regarding the content, structure, and utility of mindfulness measures, continued efforts to develop reliable and valid measures of this construct is a vital objective. The development of measures which are validated for use among non-meditators broadens the field of mindfulness research, allowing for investigation of mindfulness as a quality that exists naturally, in varying levels, among all individuals. In addition, through the refinement of these scales, researchers and clinicians can better ascertain the success of mindfulness-based interventions in teaching mindfulness skills. Specifically, mindfulness measures can reveal how shifts in mindful awareness might relate to other aspects of psychological functioning. Furthermore, mindfulness measures comprised of multiple subscales might shed light upon which specific components are most helpful for particular patient populations, potentially aiding in the development of more powerful interventions.

The following section will review findings from mindfulness-based interventions. In addition to a general overview of MBSR, the research pertaining to mindfulness-based eating interventions will also be discussed. 


\section{3.) Overview of Mindfulness Research}

Numerous studies have examined the effects of mindfulness-based interventions since their emergence within what has been termed 'complementary and alternative medicine.' Mindfulness-based treatments have been used for individuals suffering from a wide range of illnesses, both physical and psychological. One recently published clinical handbook compiles information regarding the application of mindfulness-based interventions for the following conditions: anxiety disorders, attention-deficit hyperactivity-disorder (ADHD), substance abuse, depression, and a variety of physical health concerns (Didonna, 2009). A volume of this nature signifies the existence of a broad research base and supports the validity of mindfulness-based clinical interventions.

Given the voluminous nature of this literature, the following review articles and meta-analyses are discussed in order to provide a general overview of current findings, with studies pertaining to the application of mindfulness to eating behaviors discussed in more detail below. This overview focuses solely on MBSR, because it is primarily comprised of mindfulness-enhancing practices. In contrast, other prominent mindfulness-based interventions (e.g., MBCT, DBT, and ACT) include mindfulness as one element within a broader treatment approach (Roemer \& Orsillo, 2009). Grossman, Niemann, Schmidt, and Walach (2004) conducted a meta-analysis of 20 published and unpublished MBSR studies examining effects on health, but excluded many additional studies due to insufficient information to calculate effect size. The remaining studies consistently demonstrated improvements, with medium effect sizes reported for a wide array of mental and physical health variables $(\mathrm{d}=0.54$ and 0.53 , respectively; Grossman et al., 2004). More recently, Greeson (2009) reviewed a broad range of mindfulness 
studies published between 2003-2008, reporting evidence for salutary effects on the brain, autonomic nervous system, stress hormones, immune system, and health behaviors.

A third review focused on MBSR trials for healthy individuals, identifying ten studies that have been conducted among non-clinical populations (Chiesa \& Serretti, 2009). These studies were conducted almost exclusively among undergraduates, professional students (e.g., medical students), or healthcare providers. Their results suggest that mindfulness exerts a significant nonspecific effect on stress reduction, decreasing rumination and trait anxiety while increasing empathy and self-compassion, supporting the usefulness of mindfulness interventions among non-clinical populations. These findings may result from the increased focus on present-moment experience, rather than the future-oriented focus that often characterizes anxiety. Chiesa and Serretti theorize that a specific effect might also exist; however, in absence of any "dismantling" studies investigating the relative contribution of each element of MBSR, they note that it is difficult to define the "active ingredient" (2009, p. 598). Consistent with other reviews, Chiesa and Serretti (2009) commented that the majority of the studies reviewed were of poor quality, with many handicapped by small sample sizes and the use of nonrandomized study designs, limiting the strength of the conclusions which may be drawn from their results.

As the mindfulness literature has developed, there is greater focus on identifying and empirically evaluating mechanisms which may underlie the positive effects of mindfulness-based interventions. A review by Baer (2003) found that mindfulness has been proposed to work through a variety of mechanisms, including acceptance, relaxation, cognitive change, exposure, and self-management. In this context, exposure 
refers to one's ability to tolerate strong or painful affect without engaging in avoidance behaviors. Shapiro, Carlson, Astin, \& Freedman (2006) theorize that the improvements derived from mindfulness training are due primarily to a gradual alteration in how experiences are perceived, which they term 'reperceiving.' This term refers to the development of greater insight regarding the impermanent nature of thoughts and feelings, thereby cultivating the ability to tolerate, rather than avoid, painful inner experience. Shapiro and colleagues (2006) propose that reperceiving may function as a 'meta-mechanism' of mindfulness that overarches several other direct mechanisms: they suggest four additional sub-mechanisms of action, including: 1) self-management/selfregulation; 2) cognitive, emotional, and behavioral flexibility; 3) values clarification; and 4) exposure. The validity of this model was subsequently tested among a large sample of MBSR participants, compiling outcome data from 17 classes (Carmody, Baer, Lykins, \& Olendzki, 2009). Participants were primarily female (68\%); married (60\%); and employed in white collar/professional occupations. Although mindfulness, reperceiving, and the four additional proposed mechanisms of action all increased significantly and demonstrated correlational relationships with one another, the mediating model proposed by Shapiro and colleagues (2006) was not supported. Although these findings did not support the proposed model, the effort to develop and test formulations of mindfulness is laudable and indicates the growing refinement of research in this area.

Another model of the possible mechanisms of mindfulness proposed by Weinstein, Brown, and Ryan (2009) suggests that mindfulness operates in two ways. First, mindfulness is hypothesized to promote a "less defensive, more willing exposure to challenging and threatening events and experiences, which may reduce negative 
cognitive appraisals of those situations, thus rendering lower levels of perceived stress." Thus, greater mindfulness is predictive of tending to perceive stressors as inherently less stressful. Second, it is suggested that mindfulness enhances the ability to cope adaptively with situations that are perceived as challenging. Indeed, there are many elements of mindfulness which might predict better coping abilities. For example, mindfulness tends to elicit greater non-reactivity, which helps an individual become responsive, rather than reactive, to stress. Indeed, adaptive coping was found to mediate the relationship between mindfulness and well-being, lending support to this theory (Weinstein et al, 2009). However, although promising, this model has not been tested empirically. Another model which has been proposed to clarify mechanisms of mindfulness is based on Lazarus and Folkman's well-known Transactional Model of Stress, Appraisal, and Coping (1984). Their original model proposes that appraisal and coping are mediating processes that influence both immediate effects (e.g., emotional and physiological responses) and long-term effects (e.g., health and well-being). The importance of stress perception and appraisal in health outcomes was subsequently introduced in the context of mindfulness by Kabat-Zinn (1990, p.265) and colleagues, who propose potential psychological and physiological outcomes of mindful, versus mindless, stress response patterns. Salmon and colleagues synthesize Lazarus \& Folkman's Transactional Model with Kabat-Zinn's model of mindful versus mindless stress response patterns (Salmon, Sephton, \& Dreeben, 2010). In addition, they propose additional components which they assert can also affect health and well-being, with each component featuring a "mindful" versus "mindless" outcome. Although this model has 
not been tested empirically, there is evidence from individual studies supporting the hypothesized effects of mindfulness on each component of the model.

In summary, MBSR has been used among a variety of groups, including heterogeneous groups; groups of individuals suffering from specific illnesses or other shared challenges; and groups of healthy people. Several models of mindfulness have been proposed, but there continues to be debate regarding the underlying mechanisms of mindfulness. Even so, mindfulness interventions are increasingly being used to treat specific populations, with interventions designed to address a variety of disorders, both physical and psychological. One promising avenue of research has focused on mindfulness-based eating interventions, which might represent an alternative to traditional psychosocial weight management interventions. The available literature in this area will be reviewed below, in order to provide an understanding of the current state of this newly emerging direction of research.

\section{4.) Mindfulness-Based Eating Interventions: A Review}

With mindfulness-based treatments increasingly being tailored for specific diagnostic groups, several studies have evaluated its usefulness for maladaptive eating patterns and eating disorders. Researchers have recently begun utilizing mindfulnessbased interventions among several diagnostic groups characterized by unhealthy eating patterns, including those with Binge Eating Disorder (BED; Kristeller \& Hallett, 1999; Smith, Shelley, Leahigh, \& Vanleit, 2006), Bulimia Nervosa (BN; Proulx, 2008), and overweight/obesity (OW/OB; Tapper et al., 2009). It should be noted that although there has been some exploration of mindfulness-based treatments for food-limited behaviors (e.g., Heffner, Sperry, Eifert, \& Detweiler, 2002), only studies involving disorders 
characterized by disinhibited eating will be reviewed, given their particular relevance to the topic of stress-induced eating.

A variety of theoretical rationales for applying mindfulness-based interventions have been proposed. There are many reasons why mindfulness may be uniquely able to influence eating behaviors. It has been suggested that mindfulness practice could uniquely benefit those who suffer from BED through increasing awareness of normal hunger and satiety cues and improving self-acceptance (Kristeller \& Hallet, 1999). Similarly, it has been proposed that mindfulness facilitates self-regulation, particularly of emotional states, and may act to reduce emotional eating (Baer, Fischer, \& Huss, 2005a). The cultivation of greater awareness and non-reactivity has been suggested as possible protective factors which might buffer against maladaptive eating behaviors through enhancing behavioral control during times of distress (Lavender, Gratz, \& Tull, 2011). In addition, the focus on heightened awareness might engender the ability to notice hunger/satiety cues, rather than focusing on external indicators (e.g., eating until the bowl is empty).

The first formal mindfulness-based eating intervention was an uncontrolled meditation-based intervention known as Mindfulness-Based Eating Awareness Training (MB-EAT) for obese females diagnosed with BED (Kristeller \& Hallett, 1999). Treatment consisted of a seven session program focusing on three types of mindfulness meditation: general mindfulness meditation, similar to that utilized in traditional MBSR; eating meditations, which applied general meditation techniques to the cognitive and emotional experience surrounding eating; and mini-meditations, which occurred prior to mealtimes and when urges to binge eat occurred. Sessions also included didactic 
discussions regarding several facets of BED, such as awareness of physiological hunger and satiety cues and identifying binge triggers. This exploratory study found evidence for the utility of mindfulness-based interventions, with binges decreasing significantly in frequency and intensity. In addition, sense of mindfulness, awareness of hunger and satiety signals, and perceived control over eating all increased significantly (Kristeller \& Hallett, 1999).

Several other interventions including a mindfulness component have also been studied. Telch, Agras, and Linehan (2000) conducted an uncontrolled trial of a modified DBT program (Wiser \& Telch, 1999) among 11 women diagnosed with BED. The theoretical rationale for the application of DBT was that although negative affect is strongly related to binge eating and its maintenance, prior interventions have not directly addressed this important element. Therefore, given that DBT primarily focuses on emotion regulation and distress-tolerance in combination with mindfulness training, it was hypothesized that it might be particularly effective among this population. By the end of treatment, there was a 95\% reduction in binge episodes. Other studies have supported these results, leading to discussion of potential expansion of DBT for other eating disorders (Wisniewski \& Kelly, 2003).

A total of 27 studies have examined the effects of mindfulness-based interventions on maladaptive eating behaviors (refer to Appendix A for a description of each study's intervention, sample size, population, study design, measures, and results). Due to the relatively small number of studies, any intervention that included reference to a mindfulness component was included in this review. Several articles did not provide detailed information about their intervention, likely meaning that some studies may not 
have emphasized the cultivation of mindfulness as strongly as others. For instance, two studies describe their intervention as "yoga and meditation groups" but did not provide details on the extent or form of the mindfulness practice, instead noting a general focus on increasing bodily awareness. Approximately half of the studies (14) were conducted with specific diagnostic populations, including: Binge Eating Disorder [BED] or "binge eaters" $=6$; bariatric surgery patients $=2$; Prader-Willi Syndrome $=2$; Bulimia Nervosa $[\mathrm{BN}]=1$; morbid obesity $=1$; Borderline Personality Disorder $=1$; and a mixed group of ED patients $=1$. The remaining 13 studies recruited samples of OW/OB adults (7); adults seeking stress-reduction (2); students with elevated scores on measures of disordered eating scores (2); dieters (1); and students with poor body image (1).

These studies vary in terms of the experimental design employed, and include: uncontrolled trials (13); randomized controlled trials (9); case studies (4); and a controlled study (Smith et al., 2008) in which participants self-selected between either mindfulness- or cognitive-based stress reduction programs. There were methodological problems inherent in nearly all of these studies, so the fact that a very high proportion (24/27) reported positive effects should be viewed with healthy skepticism, especially in light of the preponderance of uncontrolled studies. Among the methodological shortcomings were the following. Most studies (23) did not conduct a power analysis. Even among the four studies that did analyze power, only one (Smith et al., 2006) had a sufficient number of participants to detect effects. Further, as is common in eating disorder research, 17 of these studies focused exclusively on female participants. Samples also contained disproportionately large numbers of high-income individuals and European Americans, limiting the generalizability to other demographic groups. Few 
studies (3) included a measure of stress, despite the strong body of research linking stress with maladaptive eating patterns. Interestingly, over half of the studies (15) did not assess mindfulness using a validated measure, making it impossible to determine if improvements were associated with changes in mindfulness.

Most significantly, very few studies (2) assessed stress, mindfulness, and eating patterns. One of these studies (Smith et al., 2008) administered a modified version of traditional MBSR, supplementing the standard format with the inclusion of weekly tenminute exercises focused on the mindful tasting of healthy and unhealthy foods. Participants in this study were primarily college-educated females (80\%) with an average age of 45 years. These individuals were recruited through advertisements for cognitivebehavioral and mindfulness-based stress reduction programs. Individual who participated in these programs paid a fee in order to attend. The cost of MBSR was higher than the cognitive behavioral program, although both groups were given a discount in exchange for their participation. The results of this program were overwhelmingly positive, with the MBSR group showing an increase in mindfulness and reductions in binge eating behavior and stress, with an overall effect size twice as large as that obtained in the cognitive-based stress reduction group. The reported reduction in binge eating is especially significant, given that this study was conducted among a non-clinical sample of individuals from the general population.

These findings suggest that problematic eating patterns, such as binge eating, are likely to exist on a continuum. Thus, even among non-clinical samples, individuals may experience symptoms of disordered eating to a lesser degree, and can benefit from mindfulness training. However, it should be noted that there are several limitations 
inherent to this study. The sample was highly educated and financially able to afford the cost of the stress-reduction program. The difference in the cost of the mindfulness versus cognitive behavioral programs might have had an unintentional influence in outcome, possibility eliciting greater motivation for, and adherence to, the more costly intervention. Additionally, self-selection into MBSR may have also biased the results, with greater improvements in this group possibly resulting from the over-inclusion of individuals who are more open to complementary and alternative medicine, which may not be seen in typical samples. Further, the main focus of Smith et al. (2008), as with the other mindfulness-based interventions, was to examine MBSR's effectiveness on outcome variables, with little analysis of the underlying processes which may have elicited change. In order to develop more effective interventions for OW/OB, it will be critical to learn more about the processes which underlie improvements in eating behaviors.

The second study to examine mindfulness, stress levels, and eating behaviors utilized a novel intervention combining elements of MBSR, MB-EAT, and MBCT among a sample of OW/OB adult females over the course of four months (Daubenmier et al., 2011). This sample $(N=47)$ was found to have higher levels of perceived stress and emotional eating, as compared with normative groups. One particular strength of this study was the inclusion of a physiological measurement of stress (salivary cortisol), in addition to self-reported stress perception. Daubenmier et al. (2011) hypothesized that a mindfulness-based eating intervention might reduce abdominal fat through reducing cortisol secretion through decreasing stress perceptions. However, although there were improvements in mindfulness, anxiety, and external eating compared to control participants, there were no significant differences in weight, cortisol awakening rhythm 
(CAR), or abdominal fat. There was a nonsignificant trend of a lower CAR among obese individuals in the treatment group, which is indicative of a healthier cortisol rhythm. It is also notable that increased mindfulness and decreased chronic stress and CAR were each associated with reductions in abdominal fat. One limitation of this study is the lack of longer-term follow-up. Mindful eating skills, as with other forms of mindfulness practice, are likely to improve with time and additional practice. Likewise, the physiological changes evaluated in this study (cortisol rhythmicity and abdominal fat distribution) may also require time to fully develop. Thus, additional follow-up assessment may provide useful information regarding the long-term outcomes of this type of intervention.

Another noteworthy study is a recently published randomized-controlled trial of MB-EAT (Kristeller, Wolever, \& Sheets, 2013). This multi-site study was the first adequately powered $(N=150)$ study to compare a mindfulness-based intervention with an active control group. Participants were randomized to receive either: 1) MB-EAT; 2) a psycho-educational/cognitive-behavioral eating intervention; or 3) a wait-list control group. In addition, this study recruited a more diverse sample, both in terms of racial/ethnic composition as well as the inclusion of male participants. These results were highly positive, with $95 \%$ of those previously diagnosed with BED in the MB-EAT group no longer meeting criteria for this disorder following the intervention. In comparison, only $76 \%$ of those in the psychoeducational group no longer met criteria for BED. This study represents a significant improvement upon the uncontrolled trials that typified early research in this area, mirroring the gradual improvements that have been noted generally in mindfulness-based intervention research. 
Overall, preliminary reports are encouraging, indicating that mindfulness-based interventions are effective in altering eating patterns among a number of groups (Kristeller, Baer, \& Quillian-Wolever, 2006; Wolever \& Best, 2009). However, methodological weaknesses continue to be problematic. Furthermore, few studies have explored the psychological mechanisms of action and eating-related psychological variables which may underlie how mindfulness elicits these improvements - an issue that is endemic to mindfulness research as a whole (Weinstein et al, 2009). As noted above, there is an extensive amount of literature focused on explaining patterns of eating behaviors. This has yielding information about a number of physiological, perceptual, cognitive, and affective variables that are relevant to this research. With the exception of incorporating measures of disordered eating behaviors as outcome variables, these factors have largely been ignored in mindfulness-based eating intervention studies. Integrating these two rich areas of research would enhance our understanding of the effects of these interventions. Exploring the relationships between DM and eating behaviors might help identify possible mechanisms of action.

\section{5.) Dispositional Mindfulness}

While there is extensive literature focusing on the cultivation of mindfulness through the use of formal interventions, studies are increasingly beginning to explore variations in mindfulness that exist naturally among non-meditators. These innate differences have been termed 'dispositional' or 'trait' mindfulness. This area of research is based upon the premise that all people have the innate capacity for mindfulness to varying degrees (Brown \& Ryan, 2003). There remains a great deal of ambiguity regarding the definition, measurement, and usefulness of this variable. This section will 
provide an overview of DM, focusing on information derived from the following sources: validation studies of the correlational relationships found between mindfulness measures and indicators of physical and emotional health; neurocognitive correlational findings; and findings pertaining specifically to eating behaviors.

DM has been measured using self-report mindfulness measures among individuals without prior formal exposure to mindfulness training. It does not refer to a trait-like characteristic that has been empirically verified. It should be noted that some researchers discourage the study of mindfulness in non-meditators, arguing that mindfulness cannot be fully understood in absence of its experiential context (Rosch, 2007; Grossman \& Van Dam, 2011). However, others assert that this type of research is useful and valid in the context of intervention research. Brown, Ryan, and Creswell (2007) suggest that studies of DM may lead to a better understanding of the active ingredients of mindfulness interventions, increase knowledge of mindfulness in daily life among non-meditators, and explore how mindfulness may develop naturally in other ways.

Correlates of DM have been elicited from validation studies of mindfulness measures. There is a strong body of literature indicating that greater mindfulness is associated with a number of positive indicators of physical and mental health, even in the absence of formal mindfulness training. Several self-report mindfulness questionnaires demonstrate positive correlations with emotional well-being (Baer, Smith, Hopkins, Krietemeyer, \& Toney, 2006; Feldman, Hayes, Kumar, Greeson, \& Laurenceau, 2007; Howell, Digdon, \& Buro, 2010) and emotional intelligence (Brown \& Ryan, 2003; KIMS; Baer et al., 2004), while negatively correlating with thought suppression, 
experiential avoidance, rumination, and other psychological symptoms (Cardaciotto et al., 2008; Buchheld et al., 2001; Baer et al., 2004). Mindfulness has been found to predict high self-esteem and less social anxiety (Rasmussen \& Pidgeon, 2011). One study found that higher levels of mindfulness-based attention correlate with perceptions of better physical and psychological health among young adults (Zvolensky, Solomon, \& McLeish, 2006). Similarly, Roberts and Danoff-Burg (2010) report that undergraduates with higher DM report better sleep quality, greater physical activity, and less binge eating. Mindfulness has also been associated with self-compassion, psychological wellbeing, agreeableness, extraversion, openness to experience, and conscientiousness, while negatively correlating with neuroticism, suggesting that mindful individuals are better able to "recognize, manage, and resolve day-to-day problems" (Hollis-Walker, Colosimo, 2011, p. 225). In a study of stress and coping among college students, DM was associated with more benign appraisals of stress and less frequent use of avoidance coping strategies (Weinstein et al., 2009). Similar findings among adolescents were reported by Marks, Sobanski, and Hine (2010) who report that mindfulness attenuates the relationship between life hassles and psychological symptoms including stress, depression, and anxiety.

In addition to its relationships with other self-report measures, brain imaging techniques have also been used to evaluate the neural underpinnings of this construct. For example, one study of healthy male and female undergraduate students utilized neuroimaging technology to explore the potential mechanism underlying the effectiveness of MBCT for depression (Way, Creswell, Eisenberger, \& Lieberman, 2010). They found that higher self-reported mindfulness (MAAS) was positively 
associated with less resting activity in self-referential processing areas of the brain; in contrast, self-reported depression symptoms were correlated with greater resting activity in these regions. Based on these results, Way and colleagues (2010) suggest that mindfulness is associated with altered neural activity that may be an underlying mechanism for change in mindfulness-based treatments for depression.

A multitude of studies exploring the connection between mindfulness and health behaviors have reported beneficial effects of higher DM (Roberts \& Danoff-Burg, 2010; Ulmer, Stetson, \& Salmon, 2010). However, to date, relatively few have examined the relationships between DM and variables related to eating. All studies thus far have been based on a cross-sectional examination of these variables. Most relevant to the current topic is a study conducted by Lavender, Gratz, and Tull (2011), which examined the relationships between the facets of mindfulness measured by the FFMQ and eating pathology. This study was conducted among a large sample of female undergraduates. The average age of participants was 20.3 years, and the racial/ethnic composition of the sample was consistent with national demographics. Three of the five FFMQ subscales (Nonreactivity, Nonjudgment, and Awareness) were significantly negatively correlated with eating pathology. Results of a hierarchical linear regression indicate that four of the mindfulness subscales (Awareness, Nonjudgment, Nonreactivity, and Describing) were uniquely associated with eating disorder pathology as measured by the Eating Attitudes Test (EAT-26). Contrary to expectations, the Describing subscale was found to be more predictive of greater eating pathology. Lavender et al. (2011) propose that this unexpected finding may have occurred because after controlling for the effects of the other significant subscales, the remaining aspects of Describing that remain may 
represent an expressive quality that is actually less consistent with mindfulness. No relationship was noted between the Observe subscale and eating pathology.

In a similar study, Adams et al. (2012) examine how the FFMQ facets relate to eating pathology among female undergraduate smokers. Participants were largely European-American (83\%) and the average age was 20. Mindfulness subscales (particularly Describing, Nonjudging, and Acting with Awareness) were found to be most predictive of lower rates of eating pathology (bulimic and anorectic symptoms). It is interesting that the Describe subscale was predictive of lower eating pathology among this sample, given that the opposite was reported by Lavender et al. (2011). Interestingly, the Observe subscale significantly predicted higher rates of anorectic symptoms in this sample. This suggests the possibility that some facets of mindfulness may operate different among specific populations (e.g., smokers). Alternately, it is possible that the quality of being observant of one's internal and external experiences might be counterproductive in absence of the attitudinal facets, such as non-judging or nonreactivity, as proposed by Cardaciotto et al. (2008).

Another study examined how self-reported mindfulness (MAAS) and chronic thought suppression might be related to symptoms of bulimia among an undergraduate population (Lavender, Jardin, \& Anderson, 2009). This was one of the few studies of eating behavior that included similar numbers of males and females. Bivariate correlations indicated a significant negative relationship between bulimic symptoms and mindful awareness in both males and females. Further, a hierarchical linear regression indicated that mindfulness and chronic thought suppression contribute unique variance in 
predicting bulimic symptoms among both men and women. This is notable, considering that males and females tend to exhibit distinct eating patterns.

Other studies tended to report similar findings among convenience samples of college undergraduate students. One study conducted among female undergraduates found that DM (MAAS) mediates the relationship between thoughts relating to disordered eating and emotional distress (Masuda \& Wendell, 2010). However, this study did not examine the underlying relationships between mindfulness and disordered eating thoughts. Another cross-sectional study reports that mindfulness (KIMS and FFMQ), was negatively associated with disinhibited eating (Lattimore, Fisher, \& Malinowski, 2011). Finally, a web-based study examined mindfulness and disordered eating among a sample of participants including both male and female undergraduates (Masuda, Price, \& Latzman, 2012). This study found that mindfulness moderated the relationship between disordered eating cognitions and disordered eating behaviors.

In summary, available research indicates that DM exhibits significant relationships with a number of variables indicating health and well-being, including eating tendencies. Overall, though promising, the literature examining the relationships between DM and eating behaviors has significant limitations. Each of these studies was conducted among a convenience sample of college undergraduates and employed a crosssectional design. The majority of these studies focused on the relationship between mindfulness and more severe measures of eating pathology (e.g. vomiting after a meal), rather than the presence of more common maladaptive eating patterns (e.g., emotional eating). In addition, each of these studies was comprised solely of psychometric measures, and did not examine any in vivo eating behaviors. 
Given that mindfulness interventions and DM have both been associated with decreased stress perceptions (Weinstein et al., 2009), exploring the potential relationship between mindfulness and stress-induced eating is an avenue of research that is deserving of attention. Exploring these relationships might serve to improve existing mindfulnessbased eating interventions through elucidating potential mechanisms of action that might underlie the improvements observed in intervention research.

The proposed study seeks to examine the relationships between DM, self-reported eating tendencies, and in-vivo eating behaviors in the context of a randomized stressinduction experiment in a non-clinical sample of female undergraduates. This population was selected because it is most consistent with the majority of previous research in the area of eating behavior. Further, female undergraduates are known to have a higher than average risk of subclinical maladaptive eating behaviors (Renfrew Center Foundation for Eating Disorders, 2003). It hypothesized that DM will be positively associated with greater psychological well-being and healthier eating patterns, while negatively correlating with perceived stress and measures of maladaptive eating behaviors. Individuals with higher DM were also predicted to demonstrate greater awareness of their eating, as evidenced by increased accuracy in recalling how much food was consumed during the stress induction task. Further, individuals with higher DM were predicted to show less reactivity to the stress induction, evidenced by a smaller increase in selfreported stress, negative affect, and food consumption, particularly of high-fat and highsugar comfort foods, which are frequently selected during times of stress. 


\section{METHODS}

\section{1.) Participants}

Participants were primarily recruited through advertisements posted on SONA, the University of Louisville's online psychology experiment scheduling website, from November, 2011 through May, 2013. This website is designed for use by students currently taking a course in the psychology department. A brief description of the study, inclusion and exclusion criteria, and available appointment times were updated regularly on this website. In addition, paper advertisements were posted in various locations on campus and in-person announcements were made during psychology classes in order to increase participation. Participants were compensated with course credit or extra credit, per the preference of their instructor. Students who were not enrolled in a participating psychology course were provided with $\$ 10$ in compensation for their time and effort $(n=$ $13)$.

Inclusion criteria consisted of the following: University of Louisville undergraduate student; gender (female); age (over 18); and the ability to read and understand English sufficiently to complete self-report questionnaires. A total of 158

participants completed this research study, achieving the sample size required in order to obtain adequate power for the statistical analyses which were conducted.

As noted above, the majority of previous research on stress-related eating has focused primarily on women, with many samples comprised solely of female 
participants. The rationale for excluding males from these studies is often based on gender differences in the prevalence of disordered eating patterns (APA, 2013; StriegelMoore et al., 2009) and reported differences in specific eating behaviors, as discussed above. In order to remain consistent with previous studies, and due to demonstrated gender differences in stress-induced eating patterns, participants in this study consisted of female undergraduates only.

\section{2.) Measures}

\section{1) Demographic Information}

Participants completed a brief background questionnaire in order to collect demographic information, including: age, race/ethnicity, marital status, G.P.A., year in college, and current employment status.

\section{2.) Dispositional Mindfulness}

\section{Five-Facet Mindfulness Questionnaire (FFMQ)}

The FFMQ (Baer et al., 2006) is a 39-item measure of mindfulness, developed through a factor analysis of the five most widely used mindfulness measures: the Cognitive and Affective Mindfulness Scale (Feldman et al., 2007); Freiburg Mindfulness Inventory (Buchheld et al., 2001); Kentucky Inventory of Mindfulness Skills (Baer et al., 2004); Mindful Attention and Awareness Scale (Brown \& Ryan, 2003); and the Southampton Mindfulness Questionnaire (Chadwick et al., 2008) . This questionnaire contains five subscales: 1) Observing; 2) Describing; 3) Acting with Awareness; 4) Nonjudging; and 5) Nonreactivity to inner experience. The Observing subscale measures the tendency to notice internal and external experiences and/or stimuli. An example of an item in this subscale is, "I notice how foods and drinks affect my thoughts, bodily 
sensations, and emotions." The Describe subscale refers to the ability to describe and label experiences in words, and includes items such as, "I can easily put my beliefs, opinions, and expectations into words." The Acting with Awareness subscale measures one's ability to be fully aware of current activities or experiences. An example item from this subscale is, "When I do things, my mind wanders off and I'm easily distracted" (reverse-scored). The Nonjudging subscale refers to the ability to view experiences without evaluating them as positive or negative. For instance, one item in this subscale includes, “I tell myself I shouldn't be feeling the way I'm feeling” (reverse-scored). Finally, the Nonreactivity subscale measures the ability to avoid becoming "caught up" in inner experience. One example of an item from the Nonreactivity subscale is, "In difficult situations, I can pause without immediately reacting."

Responses are given on a five point Likert scale, ranging from "never or very rarely true" to "very often or always true." Higher scores indicate greater DM. Originally validated among a college undergraduate population, this measure has been used frequently in mindfulness research. The FFMQ demonstrates good internal consistency (Cronbach alpha coefficients ranging from .75-.91). In addition, it appears to show good construct validity, differing significantly between meditators and nonmeditators and correlating with other psychological variables in the predicted directions.

\section{3). Psychological Stress}

Perceived Stress Scale (PSS)

The 14-item version of the PSS was administered as a global measure of perceived stress (Cohen, Kamarck, \& Mermelstein, 1983; Cohen \& Williamson, 1988). The PSS is based on the principles of Lazarus and Folkman's Transactional Theory of 
Stress, Appraisal, and Coping (1984), seeking to assess how unpredictable, overwhelming, and uncontrollable participants perceive their lives to be. Responses are given on a five-point Likert scale, ranging from 'never' to 'very often.' Scores are summed to create a total perceived stress score, with higher scores indicating greater levels of perceived stress. Factor analysis revealed a two-factor structure, consistent with prior research on the PSS-14 (Hewitt, Flett, \& Mosher, 1992). These factors have been labeled "Perceived Helplessness" and "Perceived Self-Efficacy" (Roberti, Harrington, \& Storch, 2006). Internal consistency, item-total correlations, and interscale correlations between the two identified factors are strong. Similarly, recent administrations of this measure found that internal reliability was acceptable, with Cronbach's alpha coefficient ranging from .78 to .91 (Cohen \& Janicki-Deverts, 2012). This measure has been widely used in prior research and has been shown to be reliable and valid for use among college students (Roberti et al., 2006).

\section{4.) Emotion Regulation Skills}

\section{Difficulties in Emotional Regulation (DERS)}

The DERS (Gratz \& Roemer, 2004) is a 36-item measure assessing problems with emotional regulation. This measure was included given the important relationship between eating behavior and negative affect and problems with emotion regulation. The DERS is comprised of six subscales: 1) nonacceptance of emotional responses; 2) difficulties engaging in goal-directed behavior; 3) impulse control problems; 4) lack of emotional awareness; 5) limited access to emotion regulation strategies; and 6) lack of emotional clarity. Respondents indicate how frequently they typically experience difficulties within each of these areas. This measure utilizes a five point Likert scale with 
responses ranging from "almost never" to "almost always." The DERS was validated on an undergraduate sample and has demonstrated high internal consistency (Cronbach's alpha coefficient $=0.93)$ and good test-retest reliability $(.88$ over a four to eight week timespan). In addition, the DERS demonstrates good construct validity, correlated in the hypothesized directions with other measures of emotional regulation, as well as measures of experiential avoidance and emotional expressivity (Gratz \& Roemer, 2004).

\section{5.) Self-Reported Eating Behaviors}

\section{SCOFF Questionnaire}

The SCOFF Questionnaire (Morgan, Reid, \& Lacey, 1999) is a five-item screening measure designed to detect core symptoms of disordered eating in a concise format appropriate for use in primary care settings. The name of this measure is an acronym that is designed to aide health professionals in remembering its items: $\mathrm{S}=$ Sick/vomiting; $\mathrm{C}=$ Control; $\mathrm{O}=$ One stone (14 pounds); $\mathrm{F}=\mathrm{Fat}$; and $\mathrm{F}=$ Food. More specifically, its items assess: 1) self-induced vomiting ("Do you make yourself vomit because you feel uncomfortably full?"); 2) fear of uncontrolled eating (“Do you worry that you have lost control over how much you eat?"); 3) significant weight loss (“Have you recently lost more than 15 pounds in a 3-month period?"); 4) body image disturbance (“Do you believe that you are fat when others say you are too thin?"); and 5) food domination over life ("Would you say that food dominates your life?"). This measure was developed through focus groups of eating disorder patients and specialists. The items were then administered orally to a separate sample of females referred from eating disorder specialty clinics (Morgan et al., 1999). The initial validation study found that using a cutoff score of two (out of five) affirmative responses provided $100 \%$ sensitivity 
for identifying individuals with diagnosed eating disorders. Specificity for the control participants was $87.5 \%$.

A subsequent study found that responses to the SCOFF Questionnaire are highly consistent when comparing verbal versus written administration formats, with a kappa statistic of 0.811 (Perry et al., 2002). Similar results were obtained in a later study in which participants were administered diagnostic interviews based on the DSM-IV (Luck et al., 2002). The SCOFF Questionnaire successfully identified all individuals meeting criteria for AN, BN, and the majority of those diagnosed with Eating Disorder Not Otherwise Specified (Luck et al., 2002). This measure correlates strongly with the Eating Attitudes Test (EAT-26), which is considered the "gold standard" of eating disorder screening instruments (Noma et al., 2006). Overall, this measure is considered a highly efficient screening instrument (Luck et al., 2002).

\section{Dutch Eating Behavior Questionnaire (DEBQ)}

The DEBQ (van Strien et al., 1986) is a 33-item self-report measure of eating behaviors that is comprised of three subscales: Emotional Eating; External Eating; and Restrained Eating, corresponding to prominent theories of eating behavior. The Emotional Eating subscale contains 13 questions which focus on the effects of emotions on eating patterns. This subscale includes nine items about the effects of specific emotions (e.g., "Do you have a desire to eat when you are irritated?") and four items regarding the effects of undefined or "diffuse" emotional states (e.g., "Do you have a desire to eat when you have nothing to do?"). The External Eating subscale pertains to eating behaviors determined by external factors, rather than internal hunger cues (e.g., "If food smells and looks good, do you eat more than usual?"). Thirdly, the Restrained 
Eating subscale assesses one's tendency to restrict food intake (e.g., "Do you try to eat less at mealtimes than you would like to eat?"). Responses to all items range from one ('never') to five ('very often'). Each subscale has shown good psychometric properties (Wardle, 1987). The DEBQ has been used extensively in prior eating research. Three Factor Eating Questionnaire-R18V2

The Uncontrolled Eating subscale of the 18-item revised Three-Factor Eating Questionnaire (TFEQ-R18V2; Stunkard \& Messick, 1985) was administered to assess the frequency and severity of uncontrolled eating. Uncontrolled eating, also referred to as disinhibited eating, is closely connected to the concept of dietary restraint and has been shown to be predictive of stress-induced eating (Rutters, Nieuwenhuizen, Lemmens, Born, \& Westerterp-Plantenga; 2009). Internal consistency for this 9-item subscale was acceptable (Cronbach's coefficient alpha $=0.89$ ).

\section{Mindful Eating Questionnaire (MEQ)}

The Mindful Eating Questionnaire (MEQ; Framson et al., 2009) measures awareness of the physical sensations and emotions associated with eating. This 28 -item written self-report measure consists of five subscales, which were developed through an examination of both mindfulness and eating-related questionnaires and subsequent factor analysis. The MEQ subscales include: 1) Disinhibition, defined as the inability to stop eating, even when full; 2) Awareness, defined as being observant of the effects of food on the senses; 3) External Cues, defined as eating in response to environmental cues; 4) Emotional Response, defined as eating in response to negative affect; and 5) Distraction, defined as focusing on other activities while eating. Subscales range in length from three to eight items. Responses are provided on a four-point Likert-type scale ranging from 
"Never/Rarely" to "Usually/Always." Higher scores indicate greater mindful eating tendencies.

Strong inverse correlations have been found between each MEQ subscale and BMI. Inverse correlations were also found between mindful eating and dietary restraint. This measure demonstrates good psychometric properties, with adequate consistency between items in each scale. Subscales of the MEQ all demonstrate good internal consistency, with Cronbach's coefficient alphas ranging from 0.64-0.83. Each subscale shows modest to moderate correlations with one another. Unfortunately, the initial validation study was cross-sectional, and no test-retest information is available to determine temporal stability. Also, this measure was validated on seven convenience samples, four of which were selected due to their involvement in physical activities or weight loss (e.g., a mindfulness-based Yoga studio) to assess the relationship between mindful eating and weight. Thus, the validation sample is highly distinct from the general population, with participants being predominantly European American, female, and welleducated. Further, $41 \%$ of the validation sample report practicing Yoga regularly and over 50\% report engaging in regular strenuous physical activity - far higher than the average activity level. Despite its limited generalizability, this measure was included given its clear relevance to the primary focus of this study.

\section{6.) In-Vivo Eating Behaviors}

In addition to self-report measures of eating tendencies, this experiment covertly evaluated each participant's in-vivo eating behaviors during the stress manipulation. Participants were offered a selection of pre-weighed snack foods during the time allotted for the anagram task. The snack foods varied in terms of fat content (high versus low) 
and flavor (sweet versus salty) in order to allow for analysis of the type of foods selected. After the experiment was completed, the remaining amounts of each food were measured and recorded. These measurements were used to calculate the total amount of calories and fat grams consumed by each participant.

At the conclusion of the experiment, participants provided two types of estimates of how much of each food item they had consumed. First, they were given a physical model that contained the exact amounts of the foods they were given. Participants were asked to move pieces of food from this model into four empty bowls, until each bowl represented their estimate of the amount of each food they had consumed. These bowls were later weighed and subtracted from their actual intake, yielding the Visual Accuracy Score. After completing the first estimate, the bowls were removed from view and participants were asked to estimate numerically (i.e., the number of M\&M's) how many of each item they had eaten. Corresponding numbers of each food item were later weighed and this amount was subtracted from their actual intake, in order to calculate the Numerical Accuracy Score.

\section{7.) Positive and Negative Affect}

\section{Positive and Negative Affect Schedules (PANAS)}

This measure is comprised of two ten-item mood scales designed to independently assess positive and negative affect (Watson, Clark, \& Tellegen, 1988). Each item is comprised of a one-word description of a specific mood (e.g., "Irritable" and "Excited"). Participants are asked to rate the degree to which they experience each emotional state during a specified period of time. In this experiment, participants were asked to rate their current affect before and after the stress manipulation, in order to 
detect changes in negative affect that were predicted to occur among those randomized to the high stress group. Response options included: very slightly or not at all; a little; moderately; quite a bit; and very much. The PANAS has been found to be highly reliable with a subsequent validation study reporting Cronbach alpha coefficients of .89 for positive affect and .85 for negative affect, respectively (Crawford \& Henry, 2004). The PANAS is the most widely used dimensional measure of emotion and its orthogonal structure has been confirmed by a recent factor analysis (Tuccitto, Giacobbi, \& Leite, 2010).

\section{Procedure}

Participants were recruited primarily through SONA, the University of Louisville's online psychology experiment scheduling website. The study was described as an experiment exploring how personality variables and chronic stress affect performance on an anagram task. Inclusion criteria consisted of the following: University of Louisville undergraduate student; gender (female); age (over 18); and the ability to read and understand English sufficiently to complete self-report questionnaires. Immediately after registering for this experiment, each participant was sent an automated email thanking her for signing up to participate and reminding her to refrain from eating for three hours prior to the appointment, as noted in the online description of the study.

A small degree of deception was employed in order to provide a rationale for this request: participants were told that they would provide a saliva sample in order to assess their level of chronic stress, and that the results would be adversely affected by recent food/liquid intake, consistent with the study design employed by Royal \& Kurtz (2010). However, this saliva sample was actually not processed or analyzed. The true rationale 
for asking participants to refrain from eating or drinking for three hours prior to the experiment was to attempt to equalize levels of hunger across participants, without drawing direct attention to eating behaviors as a primary focus of the study.

Experiments were conducted individually in the Biobehavioral Research Laboratory and lasted approximately one hour. Data collection was completed by the study coordinator and/or two female research assistants, who were trained by the study coordinator. All experimenters followed a standardized protocol and script (see Appendix B). A document containing information about the study was reviewed and participants were given an opportunity to ask questions prior to signing this form. It should be noted that this form did not fully disclose the true nature of this research experiment, in order to avoid participants consciously altering their self-report responses and eating behaviors. Therefore, as noted above, the study title and consent form characterized the experiment as "a study of the relationship between personality variables, chronic stress, and anagram task performance." This element of deception was approved by the University of Louisville Institutional Review Board. All participants were thoroughly debriefed at the conclusion of the experiment.

After signing the informational document, participants completed the first questionnaire packet, which contained the following measures: demographic information questionnaire; Perceived Stress Scale (PSS; Cohen \& Williamson, 1988)); Difficulties in Emotional Regulation Scale (DERS; Gratz \& Roemer, 2004); Five Facet Mindfulness Questionnaire (FFMQ; Baer et al., 2006); and Positive and Negative Affect Scale (PANAS; Watson et al., 1988). 
After completing the questionnaire packet, the participants provided a saliva sample using a standard salivette collection tube. A piece of cotton was placed in the mouth, allowed to absorb saliva, and subsequently placed back into the plastic tube. Participants were asked if they had eaten during the past three hours and this information was recorded in their data collection materials.

Participants were next randomized to receive one of two unmarked envelopes containing a list of 12 anagrams. Form A (see Appendix C) contained anagrams which were solvable (low stress condition), while Form B (see Appendix D) contained anagrams which were not solvable (high stress condition). These anagram lists were obtained through email communication with Debra Zellner, Ph.D., who has conducted previous studies exploring food selection and eating behaviors, including studies evaluating the influence of stress on eating (Zellner et al., 2006; Zellner et al., 2007). Prior research utilizing these sets of anagrams has found significant between-group differences in self-reported negative affect (Royal \& Kurtz, 2010) and perceived stress (Zellner et al., 2006), indicating that unsolvable anagrams are effective in eliciting a negative emotional response.

Randomization was completed by placing equal numbers of Form A and Form B into unmarked folders. These folders were shuffled together and one folder was selected randomly prior to each experiment session. After being provided with the selected list of anagrams and instructions regarding how to complete the task, the participant was informed that she would have ten minutes to complete the list of anagrams. Timing began from the point at which the instructions had been completed and was measured using a stop-watch. 
The experimenter then stated that she would be leaving the room in order to begin processing the saliva sample and informed the participant that she would return when time had elapsed. Leaving the participant alone reduces the possibility that the experimenter's presence might alter food intake as a result of social influence, which has been well documented in prior studies (Herman \& Polivy, 2005). Before leaving the room, the experimenter invited the participants to eat the selection of snack foods which had been pre-weighted prior to the participant's arrival and placed out of sight of the participant. Snack foods are an important component of eating behavior, and snacking frequency has been positively associated with higher BMI (Berteus Forslund, Torgerson, Sjostrom, \& Lindroos, 2005; Howarth, Huang, Roberts, Lin, \& McCrory, 2007).

Furthermore, stress and daily hassles have been shown to increase self-reported snacking, particularly in regard to high-fat and high-sugar foods (O'Connor, Jones, Conner, McMillan, \& Ferguson, 2008; Oliver \& Wardle, 1999).

The majority of recent stress-induced eating studies have provided participants with a variety of foods of different flavors, typically including a selection of sweet and salty foods (Zellner et al, 2006; Zellner et al., 2007; Habhab, Sheldon, \& Loeb, 2009; Lattimore \& Maxwell, 2004; Royal \& Kurtz, 2010; Rutters et al., 2009). This experiment will utilize the following combinations of sweet/salty, high/ low fat foods: Sweet/High Fat = chocolate candy $($ M\&M's $) ;$ Sweet $/$ Low Fat = graham crackers; Salty/High Fat = potato chips; Salty/Low Fat = pretzels, as employed by Habhab et al. (2009). It has been suggested that the inclusion of stereotypically "healthy foods" (e.g., rice cakes and fruit) may trigger dieting schemas among restrained eaters, thereby altering eating behaviors (Wallis \& Hetherington, 2009); therefore, these foods were deliberately not selected. 
Having foods that varied in terms of flavor and fat content allowed for analysis of potential differences in food selection. The foods selected were consistent with one another in terms of temperature and texture (room temperature and crunchy). Selecting these items also provided logistical benefits, as perishable food products would have expired more quickly and added to the financial costs of the study.

Each participant was offered the selection of snack foods contained within separate paper bowls. The foods were provided in somewhat large amounts, in order to allow most participants to eat as much as they desired and still leave some of the food remaining. This was intended to reduce potential self-presentation concerns regarding the amount of food consumed. In addition, these larger portion sizes are a good simulation of the easy access to large servings of highly palatable foods that likely characterizes their natural environment. Food items were presented in a random order on to the left of where the participant was seated during the anagram task, and were accompanied by a small bottle of water. Participants were told the snack and water were provided because they had been unable to eat for several hours prior to the appointment, consistent with the protocol of Royal and Kurtz (2010). Ten minutes later, the experimenter returned and collected the anagram sheet. The experimenter next orally administered a brief set of interview questions regarding the anagram task. Participants rated the anagrams from 0-10 on a variety of dimensions, including stressfulness. Next, measurements of weight, height, and body composition (WHR and BMI) were obtained.

Afterward, participants completed the second questionnaire packet, containing the second copy of the Positive and Negative Affect Scale (PANAS; Watson et al., 1988); SCOFF questionnaire (Morgan et al., 1999); (Dutch Eating Behavior Questionnaire 
(DEBQ; van Strien et al., 1986), Three-Factor Eating Questionnaire (TFEQ; Stunkard \& Messick, 1985); and the Mindful Eating Questionnaire (MEQ; Framson et al., 2009). It is important to note that the participants were reseated away from the snack foods while completing this set of questionnaires, in order to avoid snacking that was related to mindless eating or any change in eating behaviors that might have occurred in response to the eating-related questions.

After completing the second questionnaire packet, participants were asked to estimate how much of each food she believed she had consumed during the anagram task, providing both a numerical estimate (i.e., the number of each food item consumed) and allowing participants to utilize a model of the foods offered, in order to visually demonstrate a second estimate. These estimates were provided in order to determine if DM might be associated with a more accurate recollection of how much food was eaten.

After all data had been collected, a suspicion probe was conducted and participants were asked whether they had suspicions regarding the food that was offered during the anagram task. If participants endorsed feeling suspicious, they were asked whether they felt that their suspicion had consciously altered their eating behavior. Finally, the experimenter debriefed the participant, using a standardized script. All participants were strongly encouraged not to discuss any information related to the study with other individuals who may participate at a later time. Participants who endorsed two or more items on the SCOFF questionnaire, a disordered eating screening measure, were offered an informational handout regarding eating disorders and local treatment options. At the conclusion of the study, the experimenter documented that the participant had 
completed the study or provided her with financial compensation. All foods were then weighed in order to determine the total grams of each food that were eaten.

All study information was placed into a locked file cabinet housed within the Biobehavioral Research Laboratory for storage. Only laboratory personnel had access to this file cabinet. The list of participant names corresponding to the assigned identification numbers was kept in a separate office, which was accessible only by members of the Biobehavioral Research Laboratory.

\section{4.) Data Preparation and Analysis}

\section{1.) Data Preparation}

All questionnaire data were double-entered into the IBM SPSS Statistics program (Version 21) and checked to verify accuracy of data entry. All distributions were examined for outliers. A randomization check was conducted, to determine whether there were any significant differences among participants assigned to the low versus high stress groups. Independent samples $t$-tests were run to assess the success of randomization. In addition, a manipulation check of the effectiveness of the stressor was conducted by performing paired samples $t$-tests comparing pre-test to post-test differences in positive or negative affect (PANAS) between the low and high stress groups. Independentsamples $t$-tests were also conducted to examine potential differences between participants who endorsed high levels of eating disorder symptomatology ( $\mathrm{SCOFF} \geq 2$ ). Similarly, independent-samples $t$-tests were conducted between participants reported suspicion regarding the study protocol, in order to determine if there were any systematic differences present that might influence the statistical analyses of the primary hypotheses. Further, in order to assess the potential differences between the three experimenters, a 
chi-square test of independence was conducted examining the relationship between experimenter and the presence or absence of suspicion (a dichotomous variable).

For the purposes of the ANOVA statistical analyses, it was necessary to categorize participants based upon their DM scores. Participants were assigned to one of three groups based upon this score: low mindfulness, average mindfulness, and high mindfulness. Participants were classified into groups based upon the percentile of their FFMQ summary score $(0-25 \%=$ low mindfulness $(n=38) ; 25-75 \%=$ average mindfulness $(n=79)$; and 75-100\% = high mindfulness; $(n=41)$.

Below is a description of the study hypotheses and the analyses which were conducted to test each hypothesis. At the outset of the study, a priori power analyses were conducted using the G*Power 3.1 (Faul, Erdfelder, Buchner, \& Lang, 2009) to determine the sample size needed to detect a medium effect size. For Hypothesis A and $\mathrm{B}$, which was tested by conducting two-tailed bivariate correlations, 84 participants were required in order to detect a medium effect size (with $\alpha=0.05$ and power $=0.80$ ). Utilizing these same parameters for the $3 \times 2$ ANOVA analyses used to test Hypotheses CE, this program indicated that a sample size of 158 was necessary to detect a medium effect size.

\section{2.) Statistical Analyses}

4.2.1) Hypothesis A. DM will be negatively correlated with perceived stress and emotion regulation problems.

Bivariate correlations were used to examine the relationships between DM (FFMQ total score) and both perceived stress (PSS total score) and emotion regulation problems 
(DERS total score and subscale scores). Secondary analyses examined the relationship of FFMQ subscales with the PSS and DERS.

4.2.2.) Hypothesis B. DM will be negatively correlated with maladaptive eating patterns and positively correlated with mindful eating.

Bivariate correlations were used to examine the relationships between DM (FFMQ total score) and the subscales of the DEBQ (Restrained Eating, Emotional Eating, and External Eating); one subscale of the TFEQ (Uncontrolled Eating); SCOFF Questionnaire; and the MEQ (Total score, Disinhibition, Awareness, External Cues, Emotional Response, and Distraction). Secondary analyses were conducted analyzing the relationships between the FFMQ subscales and eating patterns.

4.2.3.) Hypothesis C. Individuals with higher mindfulness will report less stress and $\underline{\text { negative feelings in response to the high stress anagram condition. }}$

Two 3x2 ANOVAs (level of mindfulness x stress condition) were conducted on: 1) the rating of stressfulness of the anagram task; and 2) negative affect following the stress induction (PANAS Negative Affect subscale), in order to determine if there was a differential response to the stress induction, based upon DM scores. Individuals with higher mindfulness were predicted to report significantly less stress and negative affect in response to the stress induction.

4.2.4.) Hypothesis D. Individuals with high mindfulness will consume fewer total calories and less of the high fat foods in response to the high stress anagram condition. In order to determine if higher DM is associated with decreased stress-induced eating, a 3x2 ANOVA was conducted (levels of mindfulness $\mathrm{x}$ stress condition) on the nutritional content of the foods consumed (calories and fat grams). Individuals with 
higher DM were predicted to be less reactive to the stress induction, and therefore, were expected to eat less calories and fat grams than individuals in the low mindfulness groups. In contrast, individuals in the low mindfulness groups were predicted to demonstrate greater reactivity to stress, as evidenced by consuming more calories and fat grams in response to the high stress task than those in the high mindfulness group. Those in the average mindfulness group were expected to fall in the middle of the low and high mindfulness group in terms of their food consumption.

In order to determine whether any additional variables might exert control over the relationship between DM, stress condition, and food intake, four separate $3 \times 2$ (level of mindfulness $\mathrm{x}$ stress condition) ANCOVA analyses were proposed to be conducted on total calories consumed, with the following potential covariates: 1) Restrained Eating (DEBQ subscale); 2) Emotional Eating (DEBQ subscale); and 3) Uncontrolled Eating (TFEQ subscale). The subscales were selected because they have each been identified as factors which can influence stress-induced eating in prior studies.

\subsection{5.) Hypothesis E. DM will be predictive of greater awareness of eating behaviors.}

A 3x2 ANOVA (levels of mindfulness $x$ stress condition) on accuracy scores was conducted to test this hypothesis. Accuracy scores were computed by subtracting the amount eaten from the amount participants estimated they had eaten. Participants provided estimates in numerical form (number of food items) and through using a visual model of the foods provided. It was predicted that participants with high DM would be more accurate in their estimation of the amount of food eaten during experiment, while participants in the average and low DM groups would demonstrate less accuracy. No differences between the types of estimate were theorized, based upon DM score. 


\section{RESULTS}

\section{1) Sample Characteristics}

\section{1.) Demographic Characteristics}

Study participants ranged in age from 18 to 53 years old, with an average age of 21.29 years $(\mathrm{SD}=0.29)$. Sociodemographic characteristics of the sample, including ethnicity, marital status, employment status, and living situation are presented in Table 1.

Table 1. Demographic Characteristics of the Sample

\begin{tabular}{lll}
\hline \multicolumn{1}{c}{ Variable } & Frequency & Percentage \\
\hline Ethnicity & 112 & \\
White/Caucasian & 22 & $70.9 \%$ \\
African American & 11 & $13.9 \%$ \\
Asian American & 7 & $7.0 \%$ \\
Other & 4 & $4.4 \%$ \\
Hispanic & 1 & $2.5 \%$ \\
Native American & & $0.6 \%$ \\
Marital Status & 154 & \\
Never Married & 3 & $97.5 \%$ \\
Currently Married & 1 & $1.9 \%$ \\
Divorced & & $0.6 \%$ \\
& & \\
Employment Status & 87 & $55.1 \%$ \\
Student and part-time job & 53 & $33.5 \%$ \\
Student & 14 & $8.9 \%$ \\
Student and full-time job & 4 & $2.5 \%$ \\
Other & &
\end{tabular}

\section{2.) Body Composition}

The average weight of participants in this sample was $148.41(\mathrm{SD}=38.65)$, with values ranging from 92.2-360.6 pounds (see Figure 1). The average BMI score was $24.63(\mathrm{SD}=$ 
5.90), which is classified as the upper end of the normal weight category (Overweight $=$ 25 or greater). The distribution across BMI classifications was as follows: 1)

Underweight $=10 \%(\mathrm{n}=16) ;$ Normal Weight $=55 \%(\mathrm{n}=87) ;$ Overweight $=21.5 \%(\mathrm{n}=34)$; and Obese $=13.5 \%(\mathrm{n}=21)$. The range of BMI scores extended from 12.20 to 55.20. Both weight and BMI scores were positively skewed.

The average waist-hip ratio in this sample was $0.79(\mathrm{SD}=0.06)$, ranging from 0.63-0.95. WHR values exceeding 0.85 are associated with significantly higher risk of metabolic complications (World Health Organization [WHO], 2008). Approximately $22 \%(\mathrm{n}=35)$ were found to be at elevated risk, based upon their WHR.

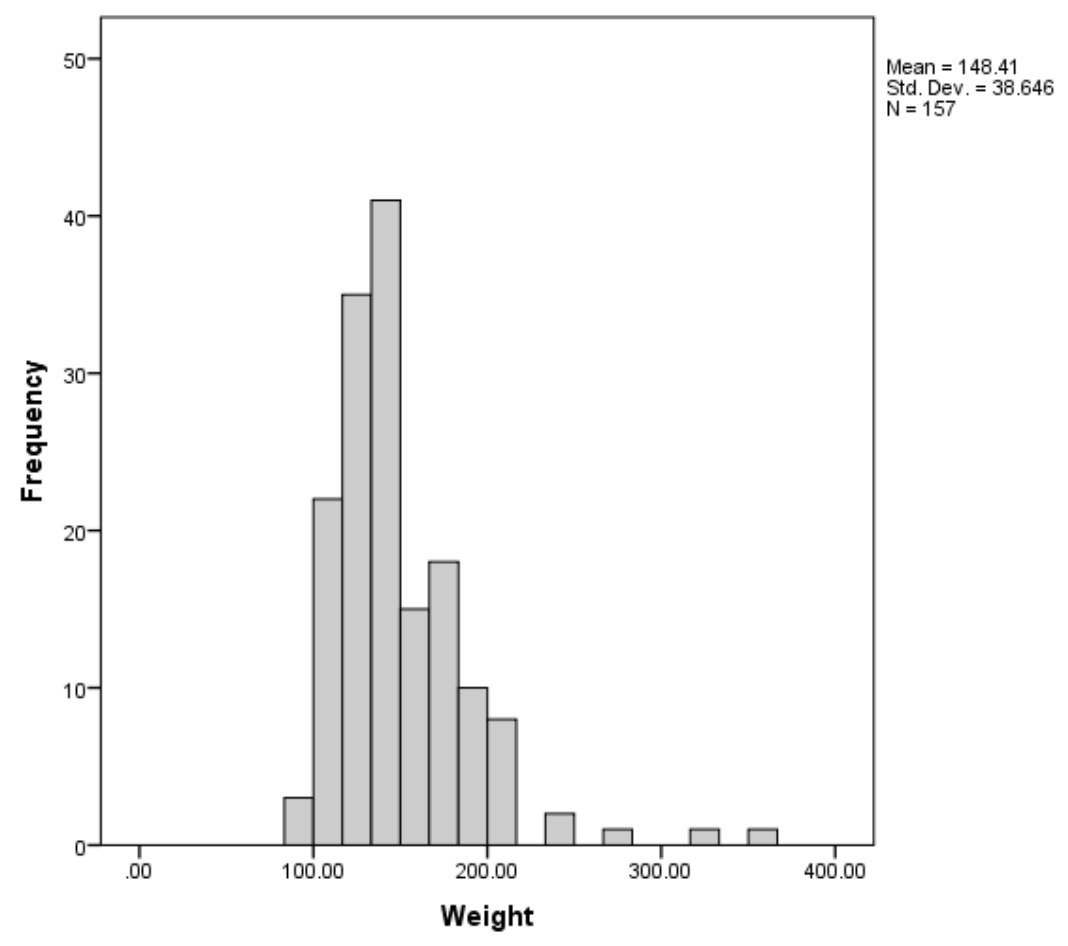

Figure 1. Weight distribution of sample 


\section{3.) Psychometric Data}

\section{Dispositional Mindfulness}

FFMQ. The average total score on the FFMQ $(M=128.59, \mathrm{SD}=13.77)$ was highly consistent with values reported in the validation study conducted by Baer and colleagues (2008), which reported an average total score of 124.34. It was also found to be similar to more recent results obtained from a large sample of university students $(M=129.55$, $\mathrm{SD}=13.94)$, reported by de Bruin, Topper, Muskens, Bogels, \& Kamphuis (2012). FFMQ total scores ranged from 80-159, out of a maximum possible range of 31-196. For comparison purposes, a sample of experienced meditators had an average score of 150.02 (Baer et al., 2008). Information regarding the mean scores and range of scores on the subscales of the FFMQ is provided in Table 2. Each FFMQ subscale scores had a maximum possible range of $8-40$, with the exception of Nonreactivity, which ranged from 7-35.

Table 2. Five Facet Mindfulness Questionnaire Subscale Scores

\begin{tabular}{llll}
\hline \multicolumn{1}{c}{ Variable } & $N$ & Mean (SD) & Range \\
& & & \\
\hline Total FFMQ Score & 158 & $128.59(13.77)$ & $80-159$ \\
Non-Reactivity & 158 & $21.56(3.88)$ & $10-33$ \\
Observing & 158 & $27.08(4.69)$ & $15-38$ \\
Acting with Awareness & 158 & $25.17(5.05)$ & $9-38$ \\
Describing & 158 & $28.27(5.66)$ & $8-40$ \\
Non-Judging & 158 & $26.51(5.92)$ & $12-39$ \\
\hline
\end{tabular}

Participants were placed into either the low, average, or high DM group based upon the percentile rank of their FFMQ total score. There were 38 participants classified in the low mindfulness group (below $25^{\text {th }}$ percentile); 79 participants classified in the average mindfulness group $\left(25^{\text {th }}-75^{\text {th }}\right.$ percentile $)$; and 41 participants classified in the high mindfulness group (above $75^{\text {th }}$ percentile). Average scores from individuals in the high 
mindfulness group were highly similar to the scores of experienced meditators, with the exception of an Observing, which was lower among this sample of high dispositionally mindful individuals as compared with experienced meditators.

\section{Perceived Stress}

PSS. Mean scores on the 14-item PSS (M=27.78, SD=7.46) were slightly higher than the average scores for two samples of female undergraduate students published in the initial validation article $(M=23.57, S D=7.55$ and $M=25.71, S D=6.20$; Cohen et al., 1983).

\section{Emotional Regulation}

DERS. Mean total scores on the DERS (M=77.94, $\mathrm{SD}=19.36)$ were highly consistent with the results of the validation study, which administered the DERS to a large sample $(n=260)$ of female undergraduate students $(M=77.99, \mathrm{SD}=20.72$; Gratz \& Roemer, 2004). Total scores from this sample ranged from 40-128, with a maximum possible range of 36-180. Higher scores indicated greater difficulty with emotional regulation. Scores on each subscale except difficulties with goal setting were positively skewed. Additional information regarding the mean, standard deviation, and range of each DERS subscale is provided in Table 3. Maximum possible ranges for subscales varied Table 3. Difficulties with Emotional Regulation Scale (DERS) Subscale Scores

$\begin{array}{llll}\text { Variable } & N & \text { Mean (SD) }\end{array}$

\begin{tabular}{llll}
\hline DERS Total Score & 157 & $77.94(19.36)$ & $40-128$ \\
Nonacceptance of emotions & 157 & $12.28(5.21)$ & $6-27$ \\
Difficulties with goal-directed behavior & 157 & $14.61(5.11)$ & $5-25$ \\
Impulse control problems & 158 & $10.95(4.40)$ & $6-27$ \\
Lack of emotional awareness & 157 & $13.51(4.37)$ & $6-26$ \\
Limited emotion regulation strategies & 158 & $15.90(6.51)$ & $8-37$ \\
Lack of emotional clarity & 157 & $10.68(3.64)$ & $5-25$ \\
\hline
\end{tabular}




\section{4) Self-Reported Eating Behaviors}

\section{Mindful Eating}

$\underline{\text { MEQ. }}$ Mean scores on the Mindful Eating Questionnaire $(\mathrm{M}=2.87, \mathrm{SD}=0.31)$ were comparable to the average scores reported in the validation study of this assessment instrument $(\mathrm{M}=2.92, \mathrm{SD}=0.37$; Framson et al., 2009$)$. Average MEQ scores ranged from 1.96-3.79, out of a maximum possible range of 1-4. Higher scores are representative of more mindful eating tendencies. For information regarding the mean, standard deviation, and range of the MEQ subscales, see Table 4.

Table 4. Mindful Eating Questionnaire (MEQ) Subscale Scores

Variable $N$ Mean (SD) Range

Disinhibition

$\begin{array}{lll}157 & 3.02(.59) & 1.38-4.00 \\ 157 & 2.48(.59) & 1.29-3.86 \\ 157 & 2.86(.58) & 1.33-4.00 \\ 157 & 3.16(.64) & 1.00-4.00 \\ 157 & 3.04(.58) & 1.00-4.00\end{array}$

Organoleptic awareness

External cues $157 \quad 3.04(.58)$

$1.00-4.00$

\section{Disordered Eating}

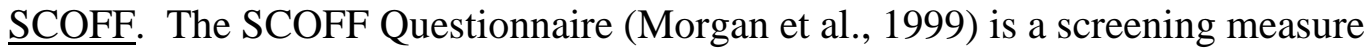
comprised of five items which are indicators of disordered eating. Six participants (3.8\%) endorsed vomiting due to fullness. Sixty-one participants $(38.6 \%)$ endorsed worry regarding losing control over eating. A total of 11 participants $(7.0 \%)$ reported weight loss of greater than 15 pounds during the past three months. Thirty participants $(19.0 \%)$ endorsed believing that they were fat when others described them as too thin. A total of 27 participants (17.1\%) endorsed feeling that food dominates their lives. Using the suggested cut-off score of two or more affirmative responses on this five-item disordered eating screening, a total of 40 participants $(25.3 \%$ of the sample) scored positively, indicating an increased risk of an eating disorder. Unfortunately, this is highly 
consistent with the elevated rate of disordered eating among female undergraduates, with $25 \%$ endorsing using bingeing/purging as a method of weight management (Renfrew Center for Eating Disorders, 2003). Participants with elevated scores were offered an informational pamphlet about eating disorders, which included contact information for local treatment options.

\section{External Eating, Restrained Eating, and Emotional Eating}

DEBQ. External Eating scores in this sample $(\mathrm{M}=3.06, \mathrm{SD}=0.63)$ were higher than reported in the validation study $(\mathrm{M}=2.68, \mathrm{SD}=0.54)$. External eating scores ranged from 1.40-4.60 out of a maximum possible range of 1-5. Restrained Eating was also higher in this sample ( $\mathrm{M}=2.69, \mathrm{SD}=0.96)$ when compared with results from the validation study $(\mathrm{M}=2.49, \mathrm{SD}=0.93)$. Restrained eating scores ranged from $0.80-4.90$, with a maximum possible range of 0.8-5. Similarly, Emotional Eating scores were found to be higher in this sample $(\mathrm{M}=2.21, \mathrm{SD}=0.93)$ as compared with the validation group $(\mathrm{M}=2.06$, $\mathrm{SD}=0.72$ ). Emotional eating scores ranged from 0.92-5.00, with a possible range of from 0.3-5. Although these results indicated greater presence of unhealthy eating patterns when compared to the original normative sample (van Strien et al., 1986), it is notable that the study was conducted over two decades ago. A more recent study of eating styles reported levels of External Eating $(M=3.07, S D=0.45)$, Restrained Eating $(M=2.70$, $\mathrm{SD}=0.76)$, and Emotional Eating $(\mathrm{M}=2.66, \mathrm{SD}=0.70)$ that are highly consistent with the results obtained from this sample (Anschutz, van Strien, van de Ven, \& Engels, 2009).

\section{Uncontrolled Eating/Disinhibition}

TFEQ. The Uncontrolled Eating subscale of the TFEQ was included in order to supplement information obtained from the DEBQ. The results from this sample 
$(\mathrm{M}=2.15, \mathrm{SD}=0.58)$ was somewhat higher than the validation sample $(\mathrm{M}=1.94, \mathrm{SD}=0.59$; Cappelleri et al., 2009). Scores ranged from 1.11-3.78, out of a maximum possible range of $1-4$.

\section{Positive and Negative Affect}

$\underline{\text { PANAS. }}$ Participants completed the PANAS before and after the stress manipulation to detect changes affective state. They were instructed to rate their current mood at that moment (momentary mood rating). Prior to the stress manipulation, participants endorsed levels of positive affect $(M=28.30 ; S D=8.13)$ and negative affect $(M=15.94$; $\mathrm{SD}=6.04$ ). The possible range for both these scores is 10-50. These results are consistent with previous studies of momentary mood ratings for both positive affect $(\mathrm{M}=$ 29.7, $\mathrm{SD}=7.9)$ and negative affect $(\mathrm{M}=14.8 ; \mathrm{SD}=5.4)$. The post-experiment PANAS scores will be discussed within the context of the stress manipulation check (see Results section 2.2).

\section{5) In Vivo Eating Behaviors}

Participants ate an average total of 25.36 grams of food $(\mathrm{SD}=22.31)$ during the experiment (see Figure 2). Due to the differences in the weight of the foods offered, information regarding nutritional content (calories and fat) was also calculated. These variables were selected given their principle importance in weight management. Based on the nutritional content of each food, an average of 117.86 calories $(\mathrm{SD}=105.27$; see Figure 3) and 4.88 grams of fat $(\mathrm{SD}=4.76)$ ingested during the experiment (see Table 5 for a breakdown of calorie and fat consumed by food type). A total of 31 participants chose not to eat any of the foods available. Consumption of high fat foods was higher in both the low stress $(t(77)=3.43, p<.01)$ and high stress groups $(t(78)=3.44, p<.01)$. 
The low stress group had a slightly higher average intake of calories $(\mathrm{M}=125.76, \mathrm{SD}=$ $11.95)$ and fat grams $(M=5.26, S D=4.82)$ than the high stress group $(M=109.97$ calories, $\mathrm{SD}=104.36 ; \mathrm{M}=4.49$ grams of fat, $\mathrm{SD}=4.70$ ). However, this difference was not statistically significant for either calories $(t(156)=0.94, p>.05)$ or fat grams $(t(156)$ $=1.03, p>.05)$.

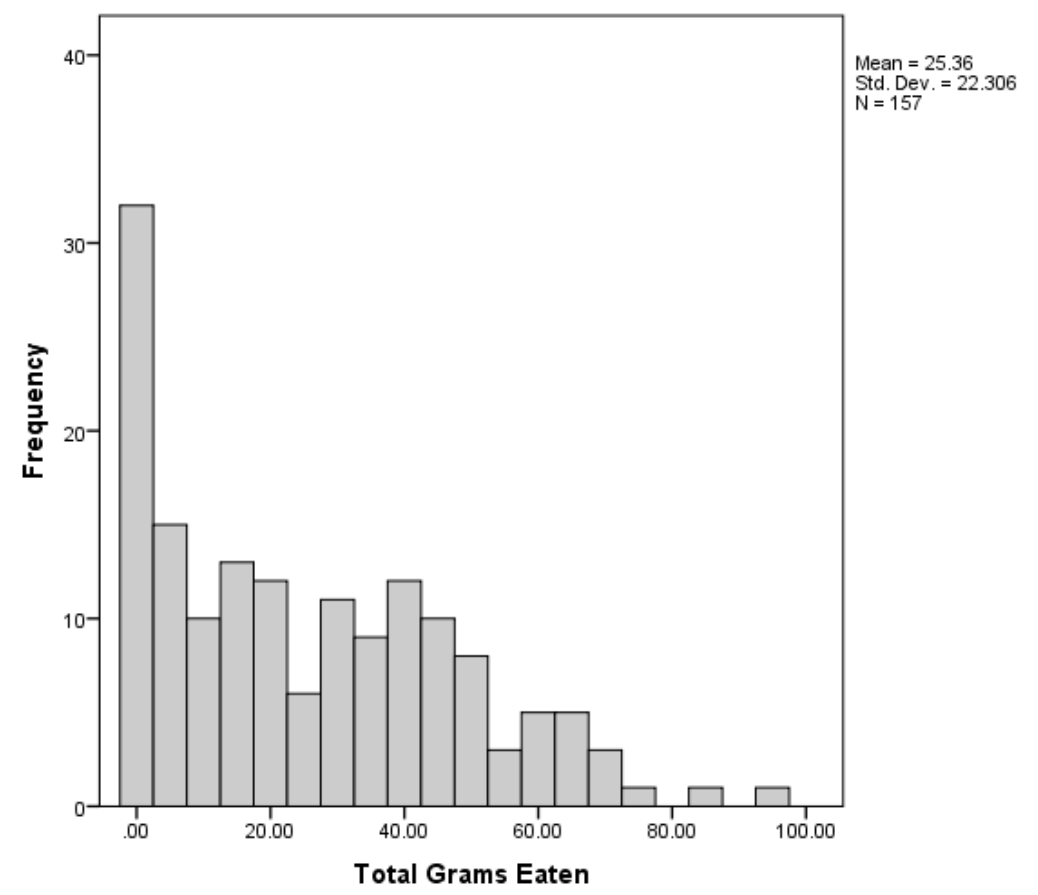

Figure 2. Distribution of total grams consumed

Table 5. Average Food Intake

\begin{tabular}{llll}
\hline \multicolumn{1}{c}{ Variable } & $N$ & Mean Calories (SD) & Mean Fat Grams (SD) \\
\hline Total Consumed & 158 & $117.86(105.27)$ & $4.88(4.76)$ \\
M\&M's & 158 & $52.88(69.84)$ & $2.28(3.02)$ \\
Graham Crackers & 158 & $16.87(34.02)$ & $0.40(0.81)$ \\
Potato Chips & 158 & $29.75(44.67)$ & $2.00(3.00)$ \\
Pretzels & 158 & $18.37(29.19)$ & $0.19(0.30)$ \\
\hline
\end{tabular}

\section{6.) Accuracy of Food Intake}

In order to determine whether greater levels of mindfulness might correlate with increased awareness of the amount of food eating, participants were asked to estimate 
their food intake at the end of the experiment. They provided two forms of estimation: numerical (e.g., number of chips) and visual, which were used to calculate the total number of grams participants estimated they had consumed. The estimated numbers of grams were compared with their actual food intake in order to create two variables:

numerical accuracy and visual accuracy. The visual estimates $(M=-2.54, S D=11.22)$ tended to be more accurate than the numerical estimates $(\mathrm{M}=-9.01, \mathrm{SD}=13.79)$, because they were closest to zero, which would represent a perfectly accurate estimate. Overall, participants tended to slightly overestimate the amount of food consumed. Pairedsamples t-test revealed that numeric estimates were significantly lower than the visual estimates $(t(156)=6.552, p<.001)$.

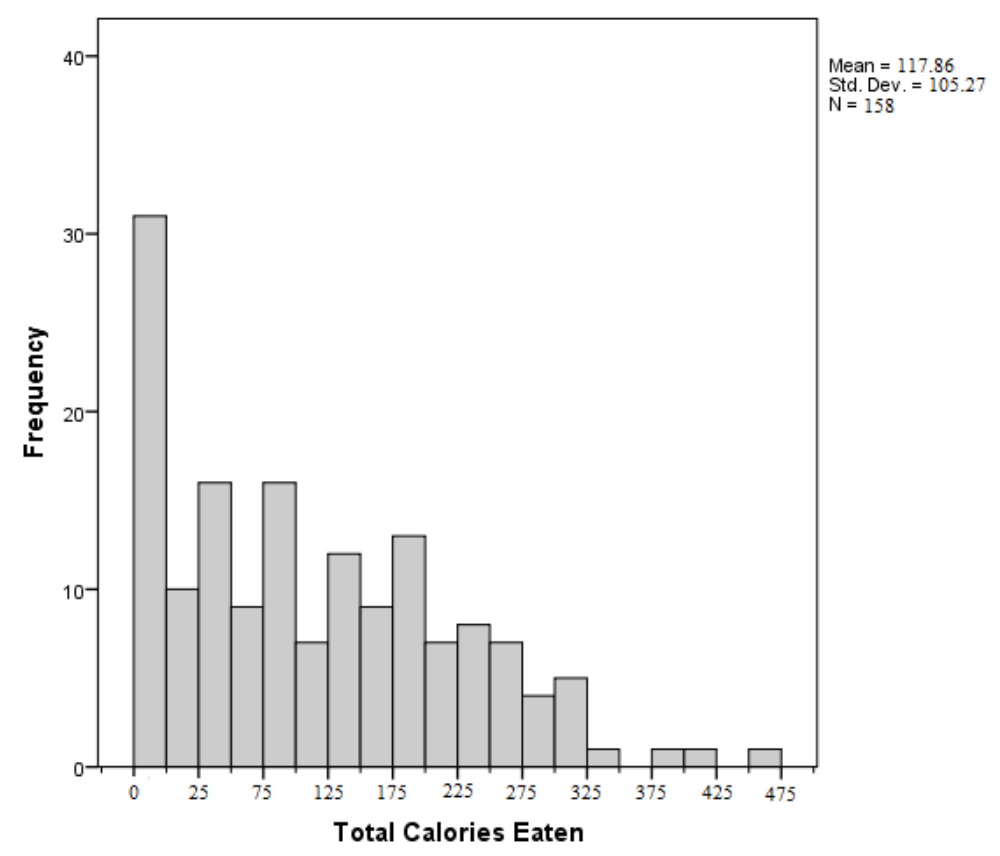

Figure 3. Distribution of total calories consumed 


\section{2.) Preliminary Analyses}

\section{1.) Randomization Check}

Randomization of participants into high stress $(n=79)$ and low stress $(n=78)$ groups was highly successful, with no statistically significant differences between groups in any demographic variables, body composition, or any outcome variables, as determined through independent samples $t$-tests and chi-square tests of independence.

\section{2) Stress Manipulation Check}

In order to assess the effectiveness of the stress manipulation, independent samples $t$-test were conducted on the descriptive ratings of the anagram task obtained directly after participants completed the anagram task. Participants were asked to rate the anagrams from $0-10$ in the following dimensions just after completing the anagram task: 1) frustrating; 2) stressful; 3) enjoyable; 4) engaging; 5) difficult; 6) challenging. The reason for having participants complete these ratings was to assess the degree to which these tasks elicited a differential response and include a subtle rating of perceived stress that was couched within a broader context of ratings.

Five out of the six ratings were significantly different between the low and high stress groups, with the unsolvable anagrams described as significantly more frustrating $(t(155)=-8.09, p<.001) ;$ stressful $(t(146)=-7.50, p<.001) ;$ engaging $(t(144)=-3.08, p$ $<.01)$; difficult $(t(130)=-13.89, p<.001)$; and challenging $(t(124)=-12.82, p<.001)$, suggesting that the participants experience of completing these tasks differed substantially. Interestingly, there was no significant different between the rating of enjoyment derived from the low versus high stress condition $(t(155)=1.338, p>.05)$. It should be noted that degrees of freedom were altered for several of these ratings, because 
Levene's test indicated unequal variances. Levene's test was significant for the following ratings: stressful $(F=5.9, p<.05)$; engaging $(F=8.96, p<.01)$; difficult $(F=$ $18.45, p<.001)$; and challenging $(F=22.679, p<.001)$.

In addition to ratings of stressfulness, independent samples $t$-tests were conducted on the positive and negative affect subscales of the PANAS. There was no significant between groups difference prior to the stress manipulation regarding positive affect $(t(154)=-1.03, p>.05)$ or negative affect $(t(155)=0.98, p>.05)$. However, the between group differences in both positive affect $(t(155=0.90, p>.05)$ and negative affect $(t(155=-0.26, p>.05)$ following the stress manipulation were also non-significant, indicating that although this manipulation was perceived as "stressful" it was not as successful in elicited negative affect.

\section{3.) Hypothesis Testing}

3.1) Hypothesis A. DM was negatively correlated with perceived stress and emotion regulation problems

Bivariate correlations revealed that participants who exhibited greater DM tended to report significantly less perceived stress $(r=-.48, p<.001)$. In addition, more mindful participants reported fewer problems with emotion regulation, with significant negative correlations (all $p<.001)$ between the DERS total score $(r=-.62)$ as well as each of its subscales: Nonacceptance of emotions $(r=-.40)$; Difficulties with Goal-Directed Behavior $(r=-.42)$; Impulse Control Problems $(r=-.41)$; Lack of Emotional Awareness $(r=-.38$; Limited Emotion Regulation Strategies $(r=-.43)$; and Lack of Emotional Clarity $(r=-.60)$. Results of exploratory analyses examining the relationships between the FFMQ subscales and each of these variables are provided in Table 6. 
Table 6. Bivariate Correlations between FFMQ Scores and Psychological Variables

\begin{tabular}{lllllll}
\hline & $\begin{array}{l}\text { FFMQ } \\
\text { Total }\end{array}$ & $\begin{array}{l}\text { Non- } \\
\text { react }\end{array}$ & Observe & $\begin{array}{l}\text { Act } \\
\text { Aware }\end{array}$ & Describe & $\begin{array}{l}\text { Non- } \\
\text { judging }\end{array}$ \\
\hline $\begin{array}{l}\text { Perceived Stress } \\
\text { (PSS) }\end{array}$ & $-.484^{* *}$ & $-.466^{* *}$ & .016 & $-.329^{* *}$ & -.102 & $-.445^{* *}$ \\
& & & & & & \\
Difficulties with & & & & & & \\
Emotion Regulation & & & & & & \\
$\quad$ Nonacceptance & $-.395^{* *}$ & $-.263^{* *}$ & $.162^{*}$ & $-.173^{*}$ & -.136 & $-.588^{* *}$ \\
Diff. with goals & $-.424^{* *}$ & $-.528^{* *}$ & -.099 & $-.392^{* *}$ & -.068 & $-.168^{*}$ \\
Impulse Control & $-.405^{* *}$ & $-.492^{* *}$ & .143 & $-.280^{* *}$ & -.073 & $-.424^{* *}$ \\
Awareness & $-.379^{* *}$ & -.097 & $-.272^{* *}$ & $-.202^{*}$ & $-.435^{* *}$ & -.015 \\
Strategies & $-.425^{* *}$ & $-.489^{* *}$ & .067 & $-.268^{* *}$ & -.137 & $-.361^{* *}$ \\
Clarity & $-.602^{* *}$ & $-.187^{*}$ & -.097 & $-.295^{* *}$ & $-.670^{* *}$ & $-.307^{* *}$ \\
\hline
\end{tabular}

Note: $p<.05^{*}, p<.01^{* * *}$

\section{2.) Hypothesis B. DM was significantly negatively correlated with emotional} eating, external eating, and uncontrolled eating.

An inverse relationship was detected between DM (FFMQ total score) and several maladaptive eating patterns. There were significant negative correlations between DM and the emotional eating (DEBQ Emotional Eating subscale; $r=-.23, p<.01$ ). DM was also negatively correlated with uncontrolled eating (TFEQ Uncontrolled Eating subscale; $r=-.26, p=.001$ ) and external eating (DEBQ External Eating subscale; $r=-.20, p<.05$ ). There were no significant correlations between DM and mindful eating $(r=-.04, p>.05)$, restrained eating (DEBQ restrained eating subscale; $r=.05, p>.05)$, or disordered eating (SCOFF total score; $r=-.12, p>.05$ ). Results of exploratory analyses examining the relationship between subscales of the FFMQ and the self-reported eating measures are provided in Table 7. 
Table 7. Bivariate Correlations between FFMQ Scores and Measures of Eating Behavior

\begin{tabular}{lllllll}
\hline & $\begin{array}{l}\text { FFMQ } \\
\text { Total }\end{array}$ & $\begin{array}{l}\text { Non- } \\
\text { react }\end{array}$ & Observe & $\begin{array}{l}\text { Act } \\
\text { Aware }\end{array}$ & Describe & $\begin{array}{l}\text { Non- } \\
\text { judging }\end{array}$ \\
\hline $\begin{array}{l}\text { Mindful Eating } \\
\text { (MEQ) }\end{array}$ & $.363^{* *}$ & $.268^{* *}$ & $.350^{* *}$ & .122 & $.168^{*}$ & .127 \\
$\begin{array}{l}\text { Disordered Eating } \\
\text { (SCOFF) }\end{array}$ & -.120 & $-.237^{* *}$ & .018 & $-.162^{*}$ & .096 & -.093 \\
$\begin{array}{l}\text { Restrained Eating } \\
\text { (DEBQ) }\end{array}$ & -.052 & $-.166^{*}$ & $.189^{*}$ & $-.211^{* *}$ & .088 & $-.166^{*}$ \\
$\begin{array}{l}\text { External Eating } \\
\text { (DEBQ) }\end{array}$ & $-.202^{*}$ & $-.177^{*}$ & .011 & $-.192^{*}$ & -.035 & $-.162^{*}$ \\
$\begin{array}{l}\text { Emotional Eating } \\
\text { (DEBQ) }\end{array}$ & $-.227^{* *}$ & $-.305^{* *}$ & -.049 & -.060 & -.090 & -.156 \\
$\begin{array}{l}\text { Uncontrolled Eating } \\
\text { (TFEQ) }\end{array}$ & $-.262^{* *}$ & $-.247^{* *}$ & -.010 & -.157 & -.133 & $-.178^{*}$ \\
\hline Note: $p<.05^{*}, p<.01^{* *}$ & & & & & &
\end{tabular}

3.3.) Hypothesis C. Individuals with higher mindfulness scores will report less negative affect and stress, due to the high stress anagram condition.

The 3x2 ANOVA (level of mindfulness $\mathrm{x}$ stress condition) conducted on perceived stressfulness of the anagram task demonstrated significant main effects of both $\operatorname{DM}(F(2,151)=7.77, p<.001)$ and stress condition $(F(1,151)=52.95, p<.001)$ as illustrated in Figure 4. However, the ANOVA analysis did not reveal any significant interaction effects between mindfulness level and stress condition $(F(2,151)=0.76, p>$ $.05)$.

The $3 \times 2$ ANOVA (level of mindfulness $x$ stress condition) conducted on negative affect (PANAS) demonstrated a main effect of $\operatorname{DM}(F(2,149)=8.13, p<.001)$, as shown in Figure 5. There was no main effect for stress condition $(F(1,149)=1.99, p>$ $.05)$, nor was there an interaction between these variables $(F(2,149)=0.26, p>.05)$. 


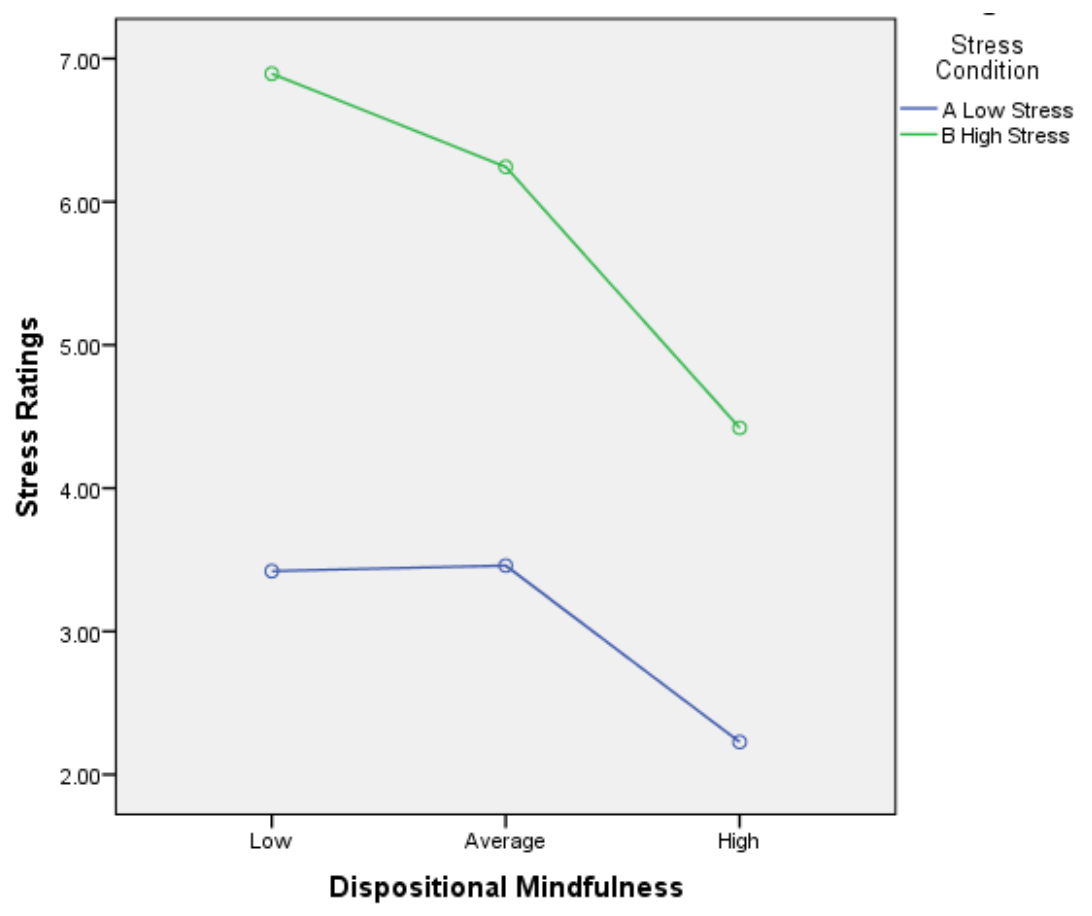

Figure 4. Main effects of DM and stress condition on stress rating

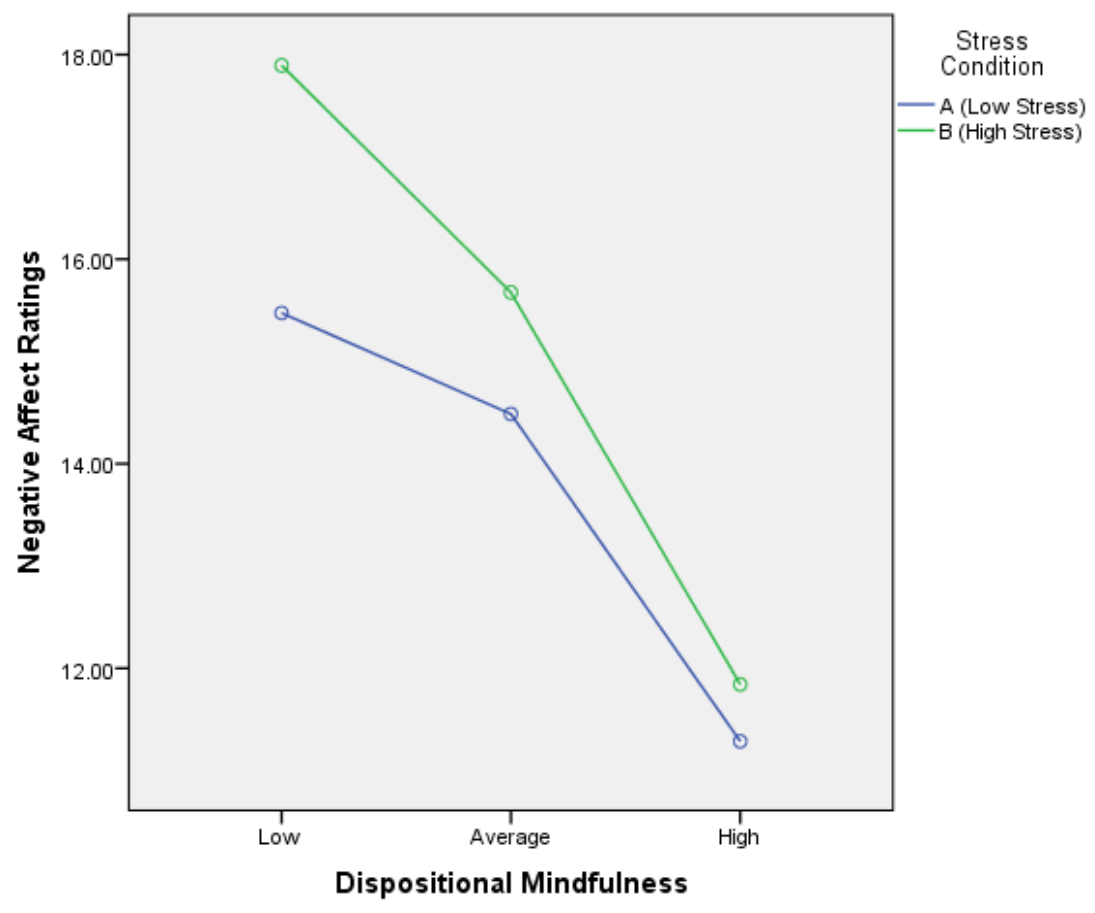

Figure 5. Main effect of DM on negative affect 
3.4.) Hypothesis D. No relationship between mindfulness and food intake in response to the stress manipulation was observed.

In order to determine if higher DM is associated with decreased stress-induced eating, a 3x2 ANOVA was conducted (levels of mindfulness $x$ stress condition) on the nutritional content of the foods consumed (total calories and total fat). Although results were in the predicted direction, the ANOVA conducted on total calories consumed did not reveal significant main effects of $\operatorname{DM}(F(2,151)=1.82, p>.05)$ or stress condition $(F(1,151)=1.75, p>.05)$, nor was there a significant interaction between these variables $(F(2,151)=0.53, p>.05)$. Similarly, the ANOVA based on total fat grams consumed did not yield significant results regarding the main effects of $\operatorname{DM}(F(2,151)=1.92, p>$ $.05)$ or stress condition $(F(2,151)=1.92, p>.05)$. Again, there was not a significant interaction between these variables $(F(2,151)=0.92, p>.05)$.

To determine if other variables might influence these analyses, four $3 \times 2$ ANCOVA analyses (level of mindfulness x stress condition) on the total number of calories eaten during the stress induction were proposed to be conducted with the following possible covariates: Restrained Eating (DEBQ); Emotional Eating (DEBQ); Disinhibited Eating (DEBQ); and SCOFF total score. However, none of these variables were significantly correlated with the dependent variable (total calories eaten), and were therefore omitted.

3.5.) Hypothesis E. The relationship between mindfulness scores and accuracy of food intake estimates was non-significant.

A 3x2 ANOVA (levels of mindfulness x stress condition) on visual accuracy scores did not reveal significant main effects of $\operatorname{DM}(F(2,151)=0.384, p>.05)$ or stress 
condition $(F(1,151)=0.3, p>.05)$, nor was there a significant interaction $(F(2,151)=$ $0.79, p>.05)$. Similarly, a 3x2 ANOVA (levels of mindfulness $\mathrm{x}$ stress condition) on numerical accuracy scores did not reveal a significant main effect of $\operatorname{DM}(F(2,151)=$ $0.83, p>.05)$; main effect of stress condition $(F(1,151)=1.23, p>.05)$; or interaction between mindfulness and stress condition $(F(2,151)=0.12, p>.05)$.

\section{4.) Additional Analyses}

Several additional series of analyses were conducted in order to explore potential issues which might influence, or help explain, the results of the primary hypotheses. These analyses included: 1) an examination of possible experimenter effects; 2) comparison of potential systematic differences based upon the endorsement of high levels of suspicion; and 3) comparison of potential differences based upon the presence or absence of elevated disordered eating tendencies on the SCOFF screening measure. Although the risk of Type I error was increased by conducting these exploratory analyses, it was important to explore the presence of possible confounding factors.

\section{1.) Experimenter Effects}

In order to explore for possible differences between the three experimenters who were involved in data collection, a chi-square test of independence were performed to test whether any of the experimenters were more or less likely to arouse suspicion as to the

nature of the experiment. The result of this analysis yielded a non-significant value $\left(X^{2}\right.$ $(4,158)=5.64, p>.05)$, indicating that the experimenters did not vary significantly in terms of the level of suspicion they evoked.

To assess for possible experimenter effects in ratings of stress or negative affect following the anagram task, one-way ANOVAs were run on these variables for both the 
high and low stress groups. There was no indication of a significant different between experimenter in perceived stressfulness of the task $(F(2,76)=0.10, p>.05)$ or negative affect $(F(2,75)=36.86, p>.05)$ in the high stress group. Similarly, there was no significant difference between experimenter in perceived stressfulness of the anagrams $(F(2,75)=0.45, p>.05)$ or negative affect $(F(2,74)=94.35, p>.05)$ in the low stress group.

Finally, there were no significant differences between experimenters in the total number of calories consumed by participants in either the high stress $(F(2,76)=0.31, p>$ $.05)$ or low stress group $(F(2,76)=0.61, p>.05)$. In summary, the use of multiple (3) experimenters did not appear to impact the results of key analyses. The fact that all three were female gender and carefully trained to administer the protocol likely contributed to this uniformity.

\section{2.) Suspicion Level}

During the debriefing process, participants were asked whether or not they were suspicious about being invited to eat the foods offered during the anagram task. Whereas the majority $(n=106)$ denied being curious about this, nearly one-third $(n=51)$ reported some degree of suspicion, and a small minority $(n=10)$ stating they believed their suspicion consciously influenced their eating behaviors during the experiment. A series of independent samples $t$-tests was conducted to examine how participants who endorsed suspicion differed from participants who did not. Participants who endorsed having suspicion tended to rate the anagram task as more challenging $(t(155=-2.38, p<.05)$ and stressful $(t(155=-2.33, p<.05)$. Although these ratings were higher among participants assigned to the high stress condition, a chi square test of independence comparing 
reported suspicion in the high versus low stress groups was not significant $\left(X^{2}(2,158)=\right.$ $4.32, p>.05)$. Participants endorsing suspicion were exhibited significantly higher restrained eating (DEBQ; $t(152)=-3.03, p<.01)$. Similarly, a chi square test of independence revealed a significant relationship between current dieting and endorsement of suspicion $\left(X^{2}(1,156)=4.02, p<.05\right)$. There was also a significant difference in the amount of calories eaten, with more suspicious participants tending to eat an average of 36.44 more calories than participants who did not report suspicion $(t(75)=-2.34, p<.05)$. The degrees of freedom in the previous analysis was adjusted due to Levene's test indicating unequal variances $(F=10.37, p<.01)$.

Qualitative feedback from participants indicated that many individuals randomized to complete the unsolvable anagrams were suspicious that these anagrams were impossible to solve, likely leading to greater overall suspicion regarding both the anagrams and the presence of the snack foods. It is interesting that more suspicious participants tended to eat significantly more during the stress manipulation, which is counter to the evidence suggesting that the perception of social observation would inhibit eating.

\section{3.) Disordered Eating}

Forty participants (25.6\%) were found to have possible signs of an eating disorder, as determined by responding affirmatively to two or more questions on the SCOFF screening instrument. Independent $t$-tests are conducted to examine potential preexisting differences between participants who endorsed high levels of disordered eating and those who did not. 
The results of the independent samples t-tests revealed several significant differences. Participants who endorsed more disordered eating tended to report: higher perceived stress (PSS; $t(150)=-2.42, p<.05)$; fewer strategies available for dealing with negative affect (DERS strategies subscale; $t(154)=-2.20, p<.05)$; and lower nonreactivity (FFMQ non-reactivity subscale; $t(154)=2.82, p<.01)$. Regarding selfreported eating behaviors, participants who endorsed greater disordered eating also report significantly greater restrained eating (DEBQ Restrained Eating subscale; $t(151)=-4.02$, $p<.001$ ); greater emotional eating (MEQ Emotional Eating subscale; $t(154)=2.72, p<$ .01 ); and greater uncontrolled eating (TFEQ Uncontrolled Eating subscale; $t(56)=-4.30$, $p<.001)$. The degrees of freedom was adjusted in the TFEQ uncontrolled eating $t$-test, due to a positive Levene's test indicating unequal variances $(F=6.41, p<.05)$. A chi square test of independence indicated that participants who endorsed higher levels of disordered eating were significantly more likely to report that they were currently dieting $\left(X^{2}(1,156)=14.89, p<.001\right)$ 


\section{DISCUSSION}

\section{1.) Main Findings}

1.1.) Relationships between DM and self-reported psychological variables (perceived $\underline{\text { stress and emotional regulation) }}$

Results of the bivariate correlations between the Five-Facet Mindfulness Questionnaire (FFMQ) and both the Perceived Stress Scale (PSS) and the Difficulties in Emotional Regulation Scale (DERS) support the presence of a significant negative relationship between DM and these self-reported indicators of psychological stress and poor emotional regulation skills. In addition, secondary analyses revealed that there were several significant negative correlations between individual subscales of the FFMQ and both of these psychological variables. These findings, including their potential implications for the topic of stress-induced eating, will be discussed in detail below.

\section{Perceived Stress Scale}

DM and psychological variables indicative of better mental health have shown consistent positive relationships in a plethora of prior cross-sectional studies (Brown \& Ryan, 2003; Keng, Smoski, \& Robins, 2011). Thus, the significant negative association found between DM and perceived stress is highly consistent with previous research (Weinstein et al., 2009).

Results of the secondary analyses, which examined the relationship between perceived stress and the individual facets that comprise the FFMQ also yielded 
significant findings. Specifically, perceived stress was negatively correlated with three facets of the FFMQ: Non-judging, Non-reactivity, and Acting with Awareness. These results are supportive of prior research indicating that the Non-judging and Acting with Awareness subscales demonstrate the strongest relationship with measures of positive psychological adaptation (Baer et al., 2006; Cash \& Whittingham, 2010) Conversely, the relationships between perceived stress and the Describing and Observing subscales of the FFMQ were non-significant. A similar finding was reported by Fisak \& von Lehe (2012), who report that three of the five FFMQ subscales were significantly and uniquely predictive of worry symptoms. Consistent with the results obtained in the current study, Describing and Observing were the two subscales that were not predictive of worry (Fisak \& von Lehe, 2012).

It is possible that the absence of a significant relationship between perceived stress and either the Describing and Observing subscales might be due to measurement issues inherent to the FFMQ. The Describe subscale has received harsh criticism from some mindfulness researchers, described by Grossman and Van Dam as a "verbal expressiveness subscale that appears to have little to do with a traditional understanding of mindfulness" (2011, p. 232). Furthermore, these authors note that although the Observing subscale appears to be theoretically related to the construct of mindfulness some of its items appear to operate differently in meditators versus non-meditators (Van Dam, Earleywine, \& Danoff-Burg, 2009), potentially explaining why this subscale does not consistently load upon the same hierarchical factor as the four other subscales (Van Dam, Hobkirk, Danoff-Burg, \& Earleywine, 2012). In addition, the Observe subscale has sometimes yielded unexpected findings in previous research, including significant 
positive correlations with psychological symptoms (Baer et al., 2006); thought suppression (de Bruin et al., 2012; Baer et al., 2006); and dissociation (Baer, et al., 2006).

The authors of the FFMQ recently conducted a study exploring the relationships between the FFMQ subscales and substance use. Interestingly, they found evidence of an interaction between the Observing and Non-reactivity subscales (Eisenlohr-Moul, Walsh, Charnigo, Baer, \& Lynam, 2012). When Non-reactivity is high, the Observing subscale was associated with less substance use. However, when Non-reactivity is low, the opposite trend occurs. This type of interaction might help better understand the seemingly anomalous findings which have been reported in regards to the Observing subscale.

In summary, the FFMQ and three of its subscales (Non-reactivity, Non-judging, and Acting with Awareness) were significantly negative correlated with perceived stress. The ability to manage stress effectively is a skill with relevance to both physical and emotional health, with obvious potential implications for eating behaviors.

\section{Difficulties with Emotional Regulation Scale}

There was a significant negative relationship between DM (FFMQ total score) and difficulties with emotional regulation (DERS total score and subscale scores), which is consistent with previous research (Chambers, Gullone, \& Allen, 2009). In fact, Chambers et al. (2009) propose an integrative model of mindful emotion regulation. They hypothesize that mindful emotion regulation is characterized by greater awareness of affect, regardless of the valence or intensity; similarly, they propose that mindful emotion regulation is predictive of less efforts at avoiding painful feelings. 
The secondary analyses examining the relationships between the facets of the FFMQ and DERS also resulted in several significant findings. Most notably, the Acting with Awareness subscale was significantly negatively correlated with each of the six DERS subscales, indicating that the ability to be aware of one's actions in the moment is a key variable in emotion regulation. Secondly, both the Non-judging and Nonreactivity subscales of the FFMQ were significantly negatively correlated with five of the six DERS subscale, with the exception of the Lack of Emotional Awareness (DERS) subscale. Again, the Describing and Observing subscales demonstrated the weakest relationships with this measure, correlating significantly with only two out of six DERS subscales.

Overall, these results suggest that the FFMQ total score, as well as three of its subscales (Non-judging, Nonreactivity, and Acting with Awareness) exhibit consistent associations with measures of adaptive stress management and emotion regulation. These results have potential implications regarding stress-induced eating, given that reductions in stress and difficulty managing emotion might be helpful in averting habitual maladaptive eating responses. The following section will discuss the cross-sectional relationships that exist between DM and several self-report measures of eating behaviors.

\subsection{Relationships between DM and self-reported eating patterns.}

Bivariate correlations were conducted between the FFMQ and a variety of selfreport eating measures, including: Emotional Eating (DEBQ); External Eating (DEBQ); Restrained Eating (DEBQ); Uncontrolled Eating (TFEQ); Eating disorder symptomatology (SCOFF Screener); and Mindful Eating (MEQ). As predicted, a significant positive correlation was found between DM and the Mindful Eating 
Questionnaire (MEQ). In addition, significant negative correlations were found between DM and emotional eating, external eating, and uncontrolled eating. Relationships between DM and other self-reported eating patterns were non-significant. These findings are discussed in greater detail below.

\section{MEQ (Mindful Eating Questionnaire Total Score)}

Bivariate correlations revealed a significant positive relationship between the FFMQ total score and the MEQ average score $(r=.51, p<.001)$. Currently, there are very few measures that examine mindful awareness of specific activities, so it is notable that this measure was significantly correlated with the FFMQ, a more general measure of mindfulness. In addition, the MEQ average score correlated positively with the following FFMQ subscales: Observing $(r=.35, p<.001)$; Describing $(r=.17, p<.05)$; and Nonreactivity $(r=27, p<.01)$.

\section{DEBQ (Emotional Eating Subscale)}

DM was negative correlated with the Emotional Eating subscale of the DEBQ. Regarding the secondary analyses examining the relationships between Emotional Eating and the facets of the FFMQ, it is notable that although Emotional Eating showed a negative correlational trend with each FFMQ subscale. However, the only statistically significant negative correlation was with the Nonreactivity subscale. This subscale is reflective of the ability to avoid reacting impulsively; rather, it is characterized by more conscious and deliberate responses to stressors. This finding is particularly relevant to the problem of emotional eating, which tends to occur impulsively and is often followed by feelings of guilt and shame (Dube et al., 2005). Developing better coping strategies might enable individuals who tend to eat in order to avoid negative feelings to reduce the 
frequency and intensity of negative affect. However, developing the ability to tolerate distress until it subsides - rather than react - would likely be even more helpful for individuals who habitually use utilize overeating or the consumption of comfort foods as a coping strategy.

\section{DEBQ (External Eating Subscale)}

Significant negative correlations were found between DM and the External Eating subscale of the DEBQ. Regarding the secondary analyses exploring the relationships between External Eating and the FFMQ subscales, significant relationships were found between External Eating and two facets of mindfulness: Acting with Awareness and Nonreactivity. It is likely that individuals with greater awareness of internal and external present moment experience would be less reliant on, and affected by, external cues. This finding supports the possible utility of including mindful eating practices, such as those utilized in MB-EAT, within standard weight management interventions. Cultivating greater awareness of physical hunger cues, combined with didactic instruction regarding the influence of external factors, may elicit greater insight in habitual eating patterns. Similarly, greater non-reactivity might buffer against cravings or overeating that can be elicited by external factors such as smell or food presentation (Wansink, 2006).

\section{DEBQ (Restrained Eating Subscale)}

Contrary to predictions, the relationship between DM and Restrained Eating (DEBQ subscale) was non-significant. However, secondary analyses examining associations between FFMQ subscales and dietary restraint yielded an interesting correlational pattern. Restrained Eating was significantly negatively correlated with the Acting with Awareness and Non-judging subscales of the FFMQ. Conversely, there was 
a significant positive correlation between the Observe subscale and dietary restraint. There are a variety of potential explanations for this unexpected finding. It is possible that individuals who are more attentive to their internal and external experiences might naturally be more aware of the foods they take in, thereby resulting in greater tendencies toward dietary restraint. Alternately, there could be interaction effects with other facets of mindfulness, similar to the findings reporting regarding the relationship between Observing and substance use, in the absence of high non-reactivity. Third, this finding might represent another example of the problematic pattern of relationships that have been noted with this particular subscale (Baer et al., 2006; de Bruin et al., 2012), casting further doubt upon its validity.

\section{TFEQ (Uncontrolled Eating Subscale)}

Significant negative correlations were found between DM (FFMQ Total Score) and the Uncontrolled Eating subscale of the TFEQ. Regarding secondary analyses examining the relationships between Uncontrolled Eating and FFMQ subscales, there were significant negative correlations between Uncontrolled Eating and both the Nonreactivity and Non-judging subscales of the FFMQ. In addition, the relationship between Uncontrolled Eating and the Acting with Awareness subscale of the FFMQ also approached significance.

In considering the known triggers of overeating, which include: negative affect (Macht, 2008); stress (O’Connor \& Conner, 2011); external cues (Wansink, 2006); and high levels of dietary restraint (Greeno \& Wing, 1994), there are several ways Nonreactivity and Non-judging might buffer against overeating. As might be expected, there was a strong relationship between Emotional Eating (DEBQ subscale) and 
Uncontrolled Eating $(r=.49, p<.001)$. As discussed above, Nonreactivity in might protect against engaging in habitual patterns of overeating in response to emotioninduced eating. Secondly, Nonjudgment might be useful in averting disinhibited eating. For example, individuals who tend to exert rigid restraint over their food intake might be more likely to 'relapse' on their diet, due to high levels of negative self-judgmental cognitions following a dietary violation. Cultivation of greater non-judgment might help develop more healthy levels of flexible restraint that are conducive to health eating patterns and weight (Westenhoefer et al., 1999). Similarly, greater nonjudgment regarding body image might reduce feelings of negative affect that are sometimes responsible for triggering periods of uncontrolled eating (Macht, 2008).

SCOFF Screener (Total Score)

The relationship between DM (FFMQ total score) and the SCOFF disordered eating screener was non-significant. However, the secondary analyses exploring the relationships between the SCOFF and specific facets of DM (FFMQ subscales) revealed significant negative correlations between the SCOFF and two subscales of the FFMQ: Acting with Awareness and Nonreactivity. Given that some of the SCOFF items involve behaviors characterized by an element of impulsivity (e.g., vomiting when feeling full and worrying that one has "lost control" over eating), the relationship with the Nonreactivity subscale is highly intuitive. Similarly, greater levels of awareness might also be associated with fewer disordered eating symptoms through greater distress tolerance. Finally, it is interesting that the relationship between the SCOFF screener and the Non-judging subscale was non-significant, because it has been hypothesized that greater self-acceptance cultivated by mindfulness interventions may protect against 
negative body image and associated disordered eating patterns (Mitchell, Mazzeo, Raush, \& Cooke, 2007).

\section{3.) DM buffered against perceived stress and negative affect in response to the stress} induction

As hypothesized, there was a significant main effect of DM on both ratings of stress and self-reported negative affect scores obtained following the stress induction. This finding is strongly consistent with a large body of literature demonstrating the powerful effects of mindfulness in reducing stress perceptions (Kabat-Zinn, 2003). This finding appears to indicate that DM serves as a buffer against stress, with individuals perceiving the same task as significantly less stressful, based upon self-reported mindfulness scores.

Interestingly, among individuals with the highest mindfulness scores, selfreported negative affect following the stress manipulation revealed almost identically low negative affect scores, regardless of being in the low or high stress group. These results strongly support the effectiveness of mindfulness-based interventions for stress and other psychological symptoms. Regarding eating behavior, this finding indicates that mindfulness may be particularly useful for those who eat in response to negative affect.

\section{4) No observed relationship between DM and in vivo eating behaviors}

Contrary to expectations, the relationship between DM score and both the total amount eaten (both calories and fat) and type of food (high-fat versus low-fat) were nonsignificant. It is interesting that the in vivo hypotheses were not supported, in light of the significant results regarding the buffering effects of DM against stress and negative affect

detected in this sample. Although there were significant differences in stress perception 
between the low, average, and high mindfulness groups, this did not correspond to observable differences in eating behaviors, even when controlling for the effects of known moderators of the stress/eating relationship (Emotional Eating (DEBQ); Restrained Eating (DEBQ); Uncontrolled Eating (TFEQ); and SCOFF Screening Measure).

It is possible that there was not sufficient variability in terms of the amount eaten to reveal a pattern of significant results. A sizable number of participants ate nothing ( $n$ $=31)$ and the maximum number of calories consumed was less than 500. It is also possible that this stressor was not sufficient to alter the eating behaviors of those in the high stress group. This explanation is supported by the lack of a significant difference in negative affect between groups. However, laboratory stressors involving cognitive strain have been shown to elicit disinhibition among restrained eaters, even in the absence of negative affect (Lattimore \& Maxwell, 2004). Potential reasons why the predicted effects on eating behavior were not observed will be discussed further in the limitations section.

\section{5.) No observed relationship between DM and accuracy of estimated food intake}

Contrary to predictions, the relationship between DM (FFMQ Total Score) and accuracy of estimated food intake (both Numeric and Visual) was non-significant. It is possible that this lack of significant results may be due to utilizing the total mindfulness score, rather than one or more of the subscale scores that might be more closely related to this ability. A correlational analysis indicated that accuracy (based on visual cues) was significantly associated with the Acting with Awareness subscale of the FFMQ $(r=-.17$, $p<.05)$. Given the direct connection between the construct measured by this subscale 
and the behaviors that would engender more accurate awareness of eating, variation in this specific facet of mindfulness might better predict accuracy.

\section{Limitations}

There are several limitations which are important to acknowledge regarding this research study. Like many studies of its kind, this study sought to examine mindfulness, stress, and eating in women only, due to the established gender differences that exist with respect to male and female stress-related eating patterns (Greeno \& Wing, 1994). Therefore, it is not possible to generalize these results to eating behavior in males. In addition, all participants were undergraduate students who were recruited primarily through an introductory psychology course. This resulted in a sample that is younger in age and more highly educated than the general population. Due to this sampling technique, the results of this study may not be generalizable to the general population. Further, offering course credit $(n=145)$ or $\$ 10$ of financial compensation $(n=13)$ may have caused some individuals who were not motivated to respond accurately to participate in exchange for these incentives.

Another limitation of this study involves the high proportion of individuals who reported suspicion. This might represent another issue inherent to recruiting primarily psychology undergraduates, given the likelihood that they might have learned about the use of laboratory stressors, such as impossible anagrams, thus eliciting higher than expected rates of suspicion regarding the study. Indeed, based on qualitative feedback, a several participants noted that they had heard of similar study designs. Due to the importance of obtaining an accurate depiction of participants' natural eating behaviors, it was necessary to use some deception regarding the true nature of the study. However, 
despite attempting to provide a plausible rationale for the presence of the foods offered, many participants noted that they were somewhat suspicious about this element of the study. Although most denied believing that their suspicion consciously influenced their eating behaviors, there is a large body of research indicating that individuals are often unaware of the factors that affect their food intake (Wansink, 2006). It is possible that participants' suspicion did exert some influence over their eating behaviors, and may have resulted in the somewhat high proportion of individuals who chose not to eat any of the foods offered. Other reasons why participants stated that they did not eat included: not being hungry, dislike of foods offered, and current attempts to lose weight. The limited range of variability of the amount of foods eaten may also have made it more difficult to identify a significant relationship between DM and in vivo eating behaviors, despite the correlational findings indicating that this relationship is likely to exist.

Contrary to expectations, the low stress group, on average, consumed more than the high stress group. It is important to consider potential reasons for this unexpected finding. Based on feedback from participants, the low stress anagrams were potentially too easy to solve. Several participants noted that they had been finished with the low stress anagrams well before the time limit (ten minutes) had elapsed. It is possible that that the amount of food consumed by the low stress group may therefore have been related to feelings of boredom. In contrast, nearly all participants randomized to complete the unsolvable anagrams were still working when the experimenter returned, potentially affording them less opportunity to eat.

Another potential reason for the lack of increased food intake among the high stress group might pertain to the limitations inherent to artificial, laboratory-based 
stressors. The effects of a laboratory stressor are highly distinct from the chronic stressors that individuals are likely to experience in life. Although the high stress anagrams were rated significantly more stressful, they did not elicit strong feelings of negative affect among those in the high stress group. Indeed, these anagrams represented a time-limited task with virtually no consequences for poor performance, which may help to explain its lack of effect on mood. Therefore, it is possible that this stress manipulation was not sufficient in severity to alter food intake.

The timing of this stress task may also have interfered with the ability to detect differences in in vivo eating behaviors. Participants were only offered the snack foods during the ten minute stress-induction portion of the experiment. This was done in order to avoid unintentionally measuring the effects of distracted/mindless eating that would have likely occurred as the participants completed the second set of questionnaires. In addition, it was important that participants complete the eating portion of the experiment prior to completing questionnaires pertaining to eating behavior, due to potential changes in behavior that might have occurred in response to these items. In retrospect, allowing participants to continue to eat the foods available may have provided a more valid assessment of naturally occurring stress-induced eating. Also, given that the physiological stress response does not begin instantaneously, it is possible that this measurement window was too short to capture physiologically-based tendencies to select foods with higher fat and sugar content.

One notable oversight in the development of this study was the lack of any assessment of prior mindfulness training or practice. Although it is unlikely that a large number of the students in this sample are likely to engage in meditation regularly, the 
prevalence of meditation (as well as other forms of complementary and alternative medicine) is growing, with $9.4 \%$ of adults in the United States endorsing use of meditation within the past year (National Center for Complementary and Alternative Medicine [NCCAM], 2007). Therefore, it is important to assess mindfulness meditation experience in any study of DM, as it may represent a serious potential confounding factor that will need to be controlled for in statistical analyses.

It is also important to consider the limitations related to attempting to accurately quantify DM. The conceptualization and measurement of mindfulness continues to be a highly controversial issue among researchers. As noted previously, some mindfulness theorists have strongly questioned whether any existing mindfulness inventories can adequately measure this construct (Grossman \& Van Dam, 2011). Grossman and Van Dam (2011) argue that the concept of self-report measures of mindfulness is fundamentally flawed for a number of reasons, in part due to their basis on the individual's perception of these qualities within themselves. They also highlight the problematic nature of measuring self-reported lapses in attention (i.e., the Acting with Awareness subscale of the FFMQ), because doing so successfully inherently requires some degree of meta-cognitive ability. In addition, Grossman and Van Dam (2011) assert that the lack of a "gold standard" of reference to evaluate these measures limits their validity and may result in oversimplified mindfulness measures that are unrelated to its Buddhist origins, and argue for limiting these measures to those who engage in mindfulness practice.

In response, others have acknowledged the limitations of existing measures, but note that mindfulness is one of many psychological variables lacking an external referent 
for comparison (Brown, Ryan, Loverich, Biegel, \& West, 2011). Brown and colleagues (2011) argue that mindfulness is an "inherent human capacity...in which there are meaningful individual differences" (p. 1042) and advocate for continuing to refine measurement in order to better understand the mechanisms of mindfulness interventions and relationships of mindfulness with other variables of interest. Overall, scholars on both side of this debate propose valid arguments. However, considering the benefits that many people have derived from mindfulness-based interventions and the potential usefulness of these assessment instruments in better understanding and further refining these interventions, it is hopeful that the unique challenges of measuring this construct will continue to be embraced.

\section{3.) Future Directions}

In order to expand upon the findings of this study, it would be helpful to utilize a research design that results in lower levels of suspicion. A more naturalistic study conducted within the context of a restaurant or meal setting would likely reduce the chance that suspiciousness or social desirability might negatively influence results of the study. In regards to the anagram task, it may be helpful to use solvable anagrams that are slightly more challenging, in order to ensure that the participants are engaged in the task for the same length of time as those in the high stress group. Similarly, a more threatening stressor (e.g., Trier Stress Test) would likely elicit a stronger response that would be more successful in changing food intake patterns. In addition, given the documented impact of stress-related hormones (e.g., cortisol) on eating behaviors, future studies would benefit from the measurement of these variables and determining how they 
might relate with DM. Future studies should also assess these relationships within males.

Overall, these patterns of cross-sectional findings indicate that that several facets of mindfulness are consistently related to self-reported eating behaviors. Therefore, this study supports the potential utility of mindfulness-based treatments for individuals struggling with problematic eating behaviors, particularly emotional eating, overeating, and eating due to external factors. In particular, it appears that greater nonreactivity, nonjudgment, and awareness are the facets most strongly related with eating behaviors. Given these relationships, mindfulness-based eating interventions might seek to provide a particular emphasis on these skills.

\section{4.) Summary and Conclusions}

This study evaluated the relationships between DM, self-reported eating tendencies, and in-vivo eating behaviors in the context of a randomized stress-induction experiment utilizing a non-clinical sample of female undergraduate students. Analyses

revealed that the stress induction was successful, with participants randomized to the high stress group reporting that the unsolvable anagrams were significantly more frustrating, stressful, engaging, difficult, and challenging than the anagrams in the low stress condition, that were capable of being solved. In addition, there was a main effect of stress condition (high versus low) on the perceived stressfulness of the anagram task. It is notable that there was no significant difference in either positive or negative affect between the high and low stress groups, following the stress manipulation.

As predicted, correlational analyses found significant inverse relationships between DM and both perceived stress and problems with emotion regulation. The 
hypothesis that DM would protect against stress and negative affect was supported. ANOVA analyses revealed that there was a significant main effect of DM on the rating of stress following the anagram task, with participants in the high mindfulness group demonstrating more benign appraisals of stress than those in the average and low mindfulness groups. Similarly, there was a main effect of DM on negative affect following the anagram task. Despite this evidence of decreased reactivity to stress, the relationship between levels of mindfulness and in vivo eating behaviors was nonsignificant. In addition, there was no significant relationship between DM and the accuracy of estimated food intake. However, DM was also inversely correlated with several problematic self-reported eating behaviors, including: emotional eating, uncontrolled eating, and external eating.

This study strengthens the body of literature which has documented the relationship between DM and reduced stress perception. Although the hypotheses regarding in vivo eating behaviors were not supported, these findings confirm a relationship between DM and several self-reported eating tendencies among a nonclinical population, which are believed to be important in maintaining healthy eating patterns and weight. These results offer support for the utilization of mindfulness skills in weight management intervention, suggesting that a particular focusing on the cultivation of greater non-reactivity, non-judgment, and awareness is most likely to influence problematic eating patterns. 


\section{REFERENCES}

Adam, T.C., \& Epel, E.S. (2007). Stress, eating, and the reward system. Physiology \& Behavior, 91(4), 449-58.

Adams, C.E., Apperson McVay, M., Kinsaul, J., Benitez, L, Vinci, C., Stewart, D.W., \& Copeland, A.L. (2012). Unique relationships between facets of mindfulness and eating pathology among female smokers. Eating Behaviors, 13(4), 390-3.

Alberts, H.J., Thewissen, R., \& Raes, L. (2012). Dealing with problematic eating behavior. The effects of a mindfulness-based intervention on eating behavior, food cravings, dichotomous thinking and body image concern. Appetite, 58(3), $847-51$.

American Psychiatric Association. (2013). Diagnostic and statistical manual of mental disorders (5th ed.). Washington, DC: Author

Anderson, J.W., Konz, E.C., Frederich, R.C., \& Wood, C.L. (2001). Long-term weight loss maintenance: A meta-analysis of US studies. American Journal of Clinical Nutrition, 74, 579-584.

Anschutz, D.J., van Strien, T., van de Ven, M.O., \& Engels, R.C. (2009). Eating styles and energy intake in young women. Appetite, 53(1), 119-22.

Baer, R. (2003). Mindfulness training as a clinical intervention: A conceptual and empirical review. Clin Psychol Sci Prac, 10(2), 125-143. 
Baer, R. (2007). Mindfulness, assessment, and transdiagnostic processes. Psychological Inquiry, 18(4), 238-271.

Baer, R.A., Fischer, S., \& Huss, D.B. (2005a). Mindfulness-based cognitive therapy applied to binge eating: A case study. Cognitive and Behavioral Practice, 12, 351-358.

Baer, R.A., Fischer, S., Huss, D.B. (2005b). Mindfulness and acceptance in the treatment of disordered eating. Journal of Rational-Emotive and Cognitive-Behavior Therapy, 23(4), 2005.

Baer, R.A., Hopkins, J., Krietemeyer, J., Smith, G.T., \& Toney, L. (2006). Using selfreport assessment methods to explore facets of mindfulness. Assessment, 13(1), 27-45.

Baer, R.A., Smith, G.T., \& Allen, K.B. (2004). Assessment of mindfulness by report. The Kentucky Inventory of Mindfulness Skills. Assessment, 11, 191-206.

Baer, R. A., Smith, G. T., Hopkins, J., Krietemeyer, J., \& Toney, L. (2006). Using selfreport assessment methods to explore facets of mindfulness. Assessment, 13, 2745.

Baer, R. A., Smith, G. T., Lykins, E., Button, D., Krietemeyer, J., Sauer, S., ... \& Williams, J.M.G. (2008). Construct validity of the five facet mindfulness questionnaire in meditating and nonmeditating samples. Assessment, 15, 329-342.

Baer, R.A., Walsh, E., \& Lykins E.L.B (2009). Assessment of mindfulness. In F. Didonna, (Ed.), Clinical Handbook of Mindfulness (17-35). New York, NY: Springer. 
Berteus Forslund, H., Torgerson, J.S., Sjostrom, L., \& Lindroos, A.K. (2005). Snacking frequency in relation to energy intake and food choices in obese men and women compared to a reference population. International Journal of Obesity 29(6):711719.

Bishop, S.R., Lau, M, Shapiro, S., Carlson, L, Anderson, N.D., Carmody, J., \& Segal, Z.V. (2004). Mindfulness: A proposed operational definition. Clinical Psychology: Science and Practice, 11(3), 230-241.

Blair, E.H., Wing, R.R., \& Wald, A. (1991). The effects of laboratory stressors on glycemic control and gastrointestinal transit time. Psychosomatic Medicine, 53, 133-143.

Blass, E.M. (2008). Obesity: Causes, Mechanisms, Prevention, and Treatment. Sunderland, MA: Sinaeuer Associates, Inc.

Blevins, N.C. (2008). Mindfulness meditation as an intervention for body image and weight management in college women: A pilot study. Dissertation, The Graduate School, University of Florida, Gainsville, FL.

Block, J.P., He, Y., Zaslavsky, A.M., Ding, L., \& Ayanian, J.Z. (2009). Psychosocial stress and change in weight among US adults. American Journal of Epidemiology, 170(2), 181-192.

Bond, D.S., Phelan, S., Leahey, T.M., Hill, J.O., \& Wing, R.R. (2009). Weight-loss maintenance in successful weight losers: Surgical vs. non-surgical methods. International Journal of Obesity, 33(1), 173-80. 
Brown, K.W., \& Ryan, R.M. (2003). The benefits of being present: Mindfulness and its role in psychological well-being. Journal of Personality and Social Psychology, 84(4), 822-848.

Brown, K.W., Ryan, R.M., \& Creswell, J.D. (2007). Addressing fundamental questions about mindfulness. Psychological Inquiry, 18(4), 272-281.

Brown, K.W., Ryan, R.M., Loverich, T.M., Biegel, G.M., \& West, A.M. (2011). Out of the armchair and into the streets: Measuring mindfulness advances knowledge an improves interventions: Reply to Grossman (2011). Psychological Assessment, $23,1041-1046$.

Brown, K.W., West, A.M., Loverich, T.M., \& Biegel, G.M. (2011). Assessing adolescent mindfulness: Validation of an adapted Mindful Attention Awareness Scale in adolescent normative and psychiatric population. Psychological Assessment, 23(4), 1023-33.

Brownell, K., \& Horgen, K.B. (2004) Food fight: the inside story of the food industry, America's obesity crisis, and what we can do about it. New York, NY: McGrawHill.

de Bruin, E., Topper, M., Muskens, J.G., Bogels, S.M., \& Kamphuis, J.H. (2012). Psychometric properties of the Five Facet Mindfulness Questionnaire (FFMQ) in a meditating and a non-meditating sample. Assessment, 19(2), 187-97.

Buchheld, N., Grossman, P., \& Walach, H. (2001). Measuring mindfulness in insight meditation (Vipassana) and meditation-based psychotherapy: the development of the Freiburg Mindfulness Inventory (FMI). Journal for Meditation and Meditation Research, 1, 11-34. 
Caballero, B. (2007) The global epidemic of obesity: an overview. Epidemiologic Reviews, 29(1), 1-5.

Cappelleri, J.C., Bushmakin, A.G., Gerber, R.A., Leidy, N.K., Sexton, C.C., Lowe, M.R., Karlsson, J. (2009). Psychometric analysis of the Three-Factor Eating Questionaire-R21: Results from a large diverse sample of obese and non-obese participants. International Journal of Obesity, 33(6), 611-20.

Cardaciotto, L., Herbert, J. D., Forman, E. M., Moitra, E., \& Farrow, V. (2008). The assessment of present-moment awareness and acceptance: The Philadelphia mindfulness scale. Assessment, 15, 204-223.

Carmody, J. (2009). Evolving conceptions of mindfulness in clinical settings. Journal of Cognitive Psychotherapy: An International Quarterly, 23(3), 270-280.

Carmody, J., Baer, R.A., Lykins, L.B., \& Olendzki, N. (2009). An empirical study of the mechanisms of mindfulness in a mindfulness-based stress reduction program. Journal of Clinical Psychology, 65(6), 613-626.

Cash, M. \& Whittingham, K. (2010). What facets of mindfulness contribute to psychological well-being and depressive, anxious, and stress-related symptomatology? Mindfulness, 1(3), 177-182.

Centers for Disease Control and Prevention (2011). Behavioral Risk Factor Surveillance System Survey Data. Atlanta, Georgia: U.S. Department of Health and Human Services, Centers for Disease Control and Prevention.

Center for Mindfulness in Medicine, Health Care, and Society at UMass Medical School. (2011). 30 Years of International Distinction. Retrieved June 28, 2011, from http://www.umassmed.edu/content.aspx?id=41252 
Chadwick, P., Hember, M., Symes, J., Peters, E., Kuipers, E., \& Dagnan, D. (2008). Responding mindfully to unpleasant thoughts and images: Reliability and validity of the Southampton mindfulness questionnaire (SMQ). British Journal of Clinical Psychology, 47(4), 451-455.

Chambers, R., Gullone, E., \& Allen, N.B. (2009). Mindful emotion regulation: An integrative review. Clinical Psychology Review, 29, 560-572.

Chaput, J.P., Doucet, E., \& Tremblay, A. (2012). Obesity: a disease or a biological adaptation? An update. Obesity Reviews, 13(8), 181-91.

Chiesa, A., \& Serretti, A. (2009). Mindfulness-based stress reduction for stress management in healthy people: A review and meta-analysis. The Journal of Alternative and Complementary Medicine, 15(5), 593- 600.

Coelho, H.F., Canter, P.H., \& Ernst, E. (2007). Mindfulness-based cognitive therapy: Evaluating current evidence and informing future research. Journal of Consulting and Clinical Psychology, 75(6), 1000-1005.

Cohen, S., \& Janicki-Deverts, D. (2012). Who's stressed? Distributions of psychological stress in the United States in probability samples from 1983, 2006, and 2009. Journal of Applied Social Psychology, 42, 1320-1334.

Cohen, S., Kamarck, T., \& Mermelstein, R. (1983). A global measure of perceived stress, Journal of Health and Social Behavior, 24, 385-396.

Cohen, S., \& Williamson, G. (1988). Perceived stress in a probability sample of the United States. In S. Spacapan, \& S. Oskamp (Eds.), The social psychology of health: Claremont Symposium on applied social psychology. Newbury Park, CA: Sage. 
Conner, M., Fitter, M., \& Fletcher, W. (1999). Stress and snacking: A diary study of daily hassles and between-meal snacking. Psychology and Health, 14, 51-63.

Cordon, S.L., \& Finney, S.J. (2008). Measurement invariance of the mindful attention awareness scale across adult attachment style. Measurement and Evaluation in Counseling and Development , 40(4), 18, 228-245.

Courbasson, C.M., Nishikawa, Y., \& Shapira, L.B. (2011). Mindfulness-action based cognitive behavioral therapy for concurrent binge eating disorder and substance use disorders. Eating Disorders: The Journal of Treatment \& Prevention, 19(1), 17-33.

Crawford, J.R., \& Henry, J.D. (2004) The positive and negative affect schedule (PANAS): Construct validity, measurement properties and normative data in a large non-clinical sample. British Journal of Clinical Psychology, 43, 245-265.

Dallman, M.F., Pecoraro, N., Akana, S.F., la Fleur, S.E., Gomez, F., Houshyar, H, ... \& Manalo, S. (2003). Chronic stress and obesity: A new view of "comfort food." Proceedings of the National Academy of Sciences in the United States of America, 100(20), 11696-11701.

Daubenmier, J., Kristeller, J., Hecht, F.M., Maninger, N., Kuwata, M., Jhaveri, K., .. \& \& Epel, E. (2011) Mindfulness intervention for stress eating to reduce cortisol and abdominal fat among overweight and obese women: An exploratory randomized controlled study. Journal of Obesity, (2011), doi: 10.1155/2011/651936.

Davis, K.K. (2008). Effect of mindfulness meditation and home-based resistance exercise on weight loss, weight behaviors, and psychosocial correlates in overweight 
adults. Dissertation, Department of Health and Physical Activity, University of Pittsburgh, Pittsburgh, PA.

Didonna, F. (Ed.). (2009). Clinical handbook of mindfulness. New York, NY: Springer.

Dikeos, D.G., \& Soldatos, C.R. (2005). The condition of insomnia: Etiopathogenetic considerations and their impact on treatment practices. International Review of Psychiatry, 17(4), 255-262.

Dimidjian, S., \& Linehan, M.M. (2003). Defining an agenda for future research on the clinical application of mindfulness practice. Clin Psychol Sci Prac, 10, 166-171.

Douketis, J.D., Macie, C., Thabane, L. \& Williamson, D.F. (2005) Systematic review of long-term eight loss studies in obese adults: Clinical significant and applicability to clinical practice. International Journal of Obesity, 29, 1153-1167.

Dube, L., LeBel, J., \& Lu, J. (2005). Affect asymmetry and comfort food consumption. Physiology \& Behavior, 94, 384-392.

Eisenlohr-Moul, T., Walsh, E., Charnigo, R., Baer, R., \& Lynam, D. (2012). The "what" and the "how" of mindfulness: Using interactions among the subscales of the Five-Facet Mindfulness Questionnaire to understand its relation to substance use. Assessment, 19(3), 276-286.

Engstrom, D. (2007). Eating mindfully and cultivating satisfaction: Modifying eating patterns in a bariatric surgery patient. Bariatric Nursing and Surgical Patient Care, 2(4), 245-250.

Epel, E., Lapidus, R., McEwen, B., Brownell, K. (2001). Stress may add bite to appetite in women: a laboratory study of stress-induced cortisol and eating behavior. Psychoneuroendocrinology, 26, 37-49. 
Esler, M., Schwarz, R., Alvarenga, M. (2008). Mental stress in a cause of cardiovascular diseases: From skepticism to certainty. Stress \& Health: Journal of the International Society for the Investigation of Stress, 24(3), 175- 180.

Faul, F., Erdfelder, E., Buchner, A., \& Lang, A.-G. (2009). Statistical power analyses using $\mathrm{G}^{*}$ Power 3.1: Tests for correlation and regression analyses. Behavior Research Methods, 41, 1149-1160.

Feigenbaum, J. (2007). Dialectical behaviour therapy: An increasing evidence base. Journal of Mental Health, 16(1), 51-68.

Feldman, G.C., Hayes, A.M. , Kumar, S., Greeson, J., \& Laurenceau, J-P (2007). Development, factor structure, and initial validation of the Cognitive and Affective Mindfulness Scale. Journal of Psychopathology and Behavioral Assessment, 29, 177-190.

Finkelstein, E.A., Ruhm, C.J., \& Kosa, K.M. (2005). Economic causes and consequences of obesity. Annual Review of Public Health, 26, 239-257.

Fisak, B. \& von Lehe, A.C. (2012). The relation between the five facets of mindfulness and worry in a non-clinical sample. Mindfulness, 3, 15-21.

Forman, E.M., Butryn, M.L., Hoffmann, K.L., \& Herbert, J.D. (2009). An open trial of an acceptance-based behavioral intervention for weight loss. Cognitive and Behavioral Practice, 16, 223-235.

Foster, G.D., \& Kendall, P.C. (1994). The realistic treatment of obesity: Changing the scales of success. Clinical Psychology Review, 14, 701-736. 
Framson, C., Kristal, A., Schenk, J, Littman, A., Zeliadt, S., \& Benitez, D. (2009). Development and validation of the mindful eating questionnaire. Journal of the American Dietetic Association, 109(8), 1439-1444.

Federici, A. (2008) Effectiveness of a dialectical behaviour therapy skills group for the treatment of suicidal/self-injurious behaviour and eating disorder symptoms in patients with borderline personality disorder. $\mathrm{PhD}$ dissertation, Faculty of Graduate Studies, York University, Toronto, ON, Canada.

Fronsdale, G. (Ed.). (2006). The Dhammapada: A new translation of the Buddhist classic with annotations. Boston, MA: Shambhala Publications, Inc.

Glandt, M., \& Raz, I. (2011). Present and future: Pharmacologic treatment of obesity. Journal of Obesity, 2011, 1-13.

Gokee-LaRose, J., Gorin, A.A., Raynor, H.A., Laska, M.N., Jeffery, R.W., Levy, R.L., \& Wing, R.R. (2009) Are standard behavioral weight loss programs effective for young adults? International Journal of Obesity, 33, 1374-1380.

Goldman, R., Jaffa, M., \& Schachter, S. (1968). Yom Kippur, Air France, dormitory food, and the eating behavior of obese and normal persons. Journal of Personality and Social Psychology, 10(2), 117-123.

Gratz, K., \& Roemer, L. (2004). Multidimensional assessment of emotion regulation and dysregulation: Development, factor structure, and initial validation of the difficulties in emotion regulation scale. Journal of Psychopathology and Behavioral Assessment, 26(1), pp. 41-54

Greco, L.A., Baer, R.A., \& Smith, G.T. (2011). Assessing mindfulness in children and adolescents: Development and validation of the child and adolescent mindfulness 
measure (CAMM). Psychological Assessment, Advance online publication. Doi: $10.1037 / \mathrm{a} 0022819$

Greeno, C.G. \& Wing, R.R. (1994). Stress-induced eating. Psychological Bulletin, 115(3) 444-464.

Greeson, J.M. (2009). Mindfulness research update: 2008. Complementary health practice review, 14(1), 10-18.

Grossman, P., Niemann, L, Schmidt, S., \& Walach, H. (2004). Mindfulness-based stress reduction and health benefits: A meta-analysis. Journal of Psychosomatic Research, 57(1), 35-43.

Grossman, P., \& Van Dam, N.T. (2011). Mindfulness, by any other name...:Trials and tribulations of sati in western psychology and science. Contemporary Buddhism, 12(1), 219-39.

Habhab, S., Sheldon, J.P., \& Loeb, R.C. (2009) The relationship between stress, dietary restraint, and food preferences in women. Appetite, 52(2) 437-44.

Hagan, M.M., Chandler, P.C., Wauford, P.K., Rybak, R.J., \& Oswald, K.D. (2003). The role of a palatable food and hunger as trigger factors in an animal model of stress induced binge eating. International Journal of Eating Disorders, 34(2), 183-97.

Hammen, C. (2005). Stress and depression. Annual Review of Clinical Psychology, 1, 293-319.

Heatherton, T.F., \& Baumeister, R.F. (1991). Binge eating as an escape from selfawareness. Psychological Bulletin, 110, 86-108. 
Heffner, M., Sperry, J., Eifert, G., \& Detweiler, M. (2002) Acceptance and commitment therapy in the treatment of an adolescent female with anorexia nervosa: A case example. Cognitive and Behavioral Practice, 9(3), 232-236.

Hepworth, N.S. (2011). A mindful eating group as an adjunct to individual treatment for eating disorders: A pilot study. Eating Disorders: The Journal of Treatment \& Prevention, 19(1), 6-16.

Herman, C.P., \& Mack, D. (1975). Restrained and unrestrained eating. Journal of Personality, 43, 647-660.

Herman, C.P., \& Polivy, J. (1980). Restrained eating. In A.J. Stunkard (Ed.), Obesity (pp. 208-225). Philadelphia, PA: Saunders.

Herman, C.P., \& Polivy, J. (2005). Normative influences on food intake. Physiology \& Behavior, 86, 762-72.

Hewitt, P.L., Flett, G.L., \& Mosher, S.W. (1992). The Perceived Stress Scale: Factor structure and relation to depression symptoms in a psychiatric sample. Journal of Psychopathology and Behavioral Assessment, 14(3), 247-257.

Hobfoll, S.E. (2004). Stress, culture, and community: The psychology and philosophy of stress. New York, NY: Springer.

Hollis-Walker, L., \& Colosimo, K. (2011). Mindfulness, self-compassion, and happiness in non-meditators: A theoretical and empirical examination. Personality and Individual Differences, 50, 222-227.

Howarth, N.H., Huang, T.T.K., Roberts S.B., Lin B.H., McCrory, M.A. (2007). Eating patterns, dietary composition, and energy regulation in younger and older participants in the CSFII 1994-96. International Journal of Obesity, 31, 675-84. 
Howell, A. J., Digdon, N. L. \& Buro, K. (2010). Mindfulness predicts sleep-related selfregulation and well-being. Personality and Individual Differences, 48, 419-424.

Hughes, S., \& Dennison, C.R. (2009). Economic downturn = cardiovascular disease risk uptick? Cardiovascular Nursing, 24(4), 287-289.

Hulbert-Williams, L., Nichols, W., Joy, J., \& Hulbert-Williams, N. (2013). Initial validation of the Mindful Eating Scale. Mindfulness, doi: 10.1007/s12671-0130227-5.

Hwang, G., Kim, S.K., Kim, J.H., Kim, H.R., Park, S.H., \& Kim, S.H. (2008). Influence of psychological stress on physical pain. Stress and Health, 24, 159-164

Jeffery, R.W., Epstein, L.H., Wilson, G.T., Drewnowski, A., Stunkard, A.J., \& Wing, R. (2000). Long-term maintenance of weight loss. Health Psychology, 19(1, Suppl), $5-16$.

Jones, A., McMillan, M.R., Jones, R.W., Kowalik, G.T., Steeden, J.A., Deanfield, J.E. ... Muthurangu, V. (2012). Adiposity is associated with blunted cardiovascular, neuroendocrine, and cognitive responses to acute mental stress. PLoS ONE, 7(6), doi: 10.1371/journal.pone.0039143.

Kabat-Zinn, J. (1982). An outpatient program in behavioral medicine for chronic pain based on the practice of mindfulness meditation. General Hospital Psychiatry, 4, $33-47$.

Kabat-Zinn, J. (1990). Full catastrophe living: Using the wisdom of your body and mind to face stress, pain, and illness. New York: Delacorte.

Kabat-Zinn, J. (2003). Mindfulness-based interventions in context: Past, present, and future clinical. Clinical Psychology: Science and Practice, 10, 144-56. 
Kaplan, H.I., \& Kaplan, H.S. (1957). The psychosomatic concept of obesity. Journal of Nervous and Mental Disease, 125, 181-201.

Kenardy, J., Butler, A., Carter, C., \& Moor, S. (2003) Eating, mood, and gender in a noneating disorder population. Eating Behaviors, 4(2), 149-58.

Keng, S.L., Smoski, M.J., \& Robins, C.J. (2011). Effects of mindfulness on psychological health: A review of empirical studies. Clinical Psychology Review, 31(6), 1041-56.

Kern, L.S., Friedman, K.E., Reichmann, S.K., Costanzo, P.R., \& Musante, G.J. (2002). Changing eating behavior: A preliminary study to consider broader measures of weight control treatment success. Eating Behaviors, 3, 113-121.

Kiefer, I., Rathmanner, T., \& Kunze, M. (2005). Eating and dieting differences in men and women. The Journal of Men's Health and Gender, 2, 194-201.

Koenders, P., \& van Strien, T. (2011). Emotional eating, rather than lifestyle behavior, drives weight gain in a prospective study in 1562 employees. Journal of Occupational and Environmental Medicine, 53(11), 1287-1293.

Kristeller, J.L., Baer, R.A., \& Quillian-Wolever, R. (2006). Mindfulness-based approaches to eating disorders. In Baer, R.A. (Ed.) Mindfulness-based treatment approaches: Clinician's guide to evidence base and applications (75-91). New York, NY: Elsevier Academic Press.

Kristeller, J.L., \& Hallett, C.B. (1999). An exploratory study of a meditation-based intervention for binge eating disorder. Journal of Health Psychology, 4(3), 357363. 
Kristeller, J.L., Wolever, R.Q., Sheets, V. (2013). Mindfulness-based eating awareness training (MB-EAT) for binge eating: A randomized clinical trial. Mindfulness, 2013, doi: 10.1007/s12671-012-0179-1.

Langer, E.J. (1989). Mindfulness. United States of America: Perseus Books.

Larsen, J.K., van Strien, T., Eisinga, E., \& Engels, R.C.M.E. (2006) Gender differences in the association between alexithymia and emotional eating in obese individuals. Journal of Psychosomatic Research, 60, 237-243.

Lattimore, P., Fisher, N., \& Malinowski, P. (2011). A cross-sectional investigation of trait disinhibition and its association with mindfulness and impulsivity. Appetite, $56,241-48$.

Lattimore, P., \& Maxwell, L. (2004) Cognitive load, stress, and dininhibited eating. Eating Behaviors, 5(4), 315-324.

Lavender, J.M., Gratz, K.L, \& Tull, M.T. (2011). Exploring the relationship between facets of mindfulness and eating pathology in women. Cognitive Behavior Therapy, 40(3), 174-82.

Lavender, J.M., Jardin, B.F., \& Anderson, D.A. (2009). Bulimic symptoms in undergraduate men and women: Contributions of mindfulness and thought suppression. Eating Behaviors, 10, 228-31.

Lazarus, R. S., \& Folkman, S. (1984). Stress, Appraisal, and Coping. New Yorkn NY: Springer.

Leahey, T.M., Crowther, J.H., \& Irwin, S.R. (2008). A cognitive-behavioral mindfulness group therapy intervention for the treatment of binge eating in bariatric surgery patients. Cognitive and Behavioral Practice, 15(4), 364-375. 
Lee, R.E., Greiner, K.A., Hall, S., Born, W., Kimminau, K.S., Allison, A., \& Ahluwalia, J.S. (2007). Ecologic correlates of obesity in rural obese adults. J Am Coll Nutr, 26(5), 424-433.

Lemmons, S.G., Rutters, F., Born, J.M., \& Westerterp-Plantenga, M.S. (2011). Stress augments food 'wanting' and energy intake in visceral overweight subjects in the absence of hunger. Physiology \& Behavior, 103, 157-163.

Lillis, J., Hayes, S.C., Bunting, K., Masuda, A. (2009). Teaching acceptance and mindfulness to improve lives of the obese: A preliminary test of a theoretical model. Annals of Behavioral Medicine, 37, 58-69.

Luck, A.J., Morgan, J.F., Reid, F., O’Brien, A., Brunton, J., Price, C., Perry, L., \& Lacey, J.H. (2002). The SCOFF questionnaire and clinical interview for eating disorders in general practice: comparative study. BMJ, 325, 755-756.

Lundgren, J. (2005). A mindfulness-based behavioral treatment for weight loss.

Dissertation, Department of Psychology, State University of New York at Albany, Albany, NY.

Lynch, T.R., Trost, W.T., Salsman, N., \& Linehan, M.M. (2007). Dialectical behavior therapy for borderline personality disorder. Annual Review of Clinical Psychology, 3, 181-205.

Macht, M. (2008). How emotions affect eating: A five-way model. Appetite, 50, 1-11.

Macht, M., Haupt, C., \& Salewsky, A. (2004). Emotions and eating in everyday life: Application of the experience-sampling method. Ecology of Food and Nutrition, 43, 327-337. 
Macht, M., \& Simons, G. (2000). Emotions and eating in everyday life. Appetite, 35, 6571.

Mann, T., Tomiyama, A.J., Westling, E., Lew, A.M., Samuels, B., \& Chatman, J. (2007). Medicare's search for effective obesity treatments: Diets are not the answer. American Psychologist, 62(3), 220-33.

Manson, J.E., Skerrett, P.L., \& Willett, W.C. (2001). Epidemiology of health risks associated with obesity. In C.G. Fairburn, \& K.D. Brownell (Eds.), Eating disorders and obesity. NewYork, NY: Guilford Publications.

Marks, A.D., Sobanski, D.J., \& Hine, D.W. (2010). Do dispositional rumination and/or mindfulness moderate the relationship between life hassles and psychological dysfunction in adolescents? Aust N Z J Psychiatry, 44(9), 831-838.

Masuda, A., Price, M., \& Latzman, R.D. (2012). Mindfulness moderates the relationship between disordered eating cognitions an disordered eating behaviors in a nonclinical college sample. Journal of Psychopathology and Behavioral Assessment, $34,107-115$.

Masuda, A., \& Wendelll, J.W. (2010). Mindfulness mediates the relation between disordered eating-related cognitions and psychological distress. Eating Behaviors, $11,293-296$.

McEwen, B.S. (2000). Allostasis and allostatic load: Implications for neuropsychopharmacology. Neuroendocrinology, 22(2), 108-124.

McIver, S., O’Halloren, P., McGartland, M. (2009). Yoga as a treatment for binge eating disorder: A preliminary study. Complementary Therapies in Medicine, 17, 196202. 
Mental Health America (2006). Mental Health American attitudinal survey: Part I:

Findings on stress in America. Alexandria, VA: Mental Health America.

Retrieved March 4, 2010, from

http://www.nmha.org/files/Mental_Health_America_Attitudinal_Survey_-

_Executive_Summary.pdf

Mills, J.S., \& Palandra, A. (2008). Perceived caloric content of a preload and disinhibition among restrained eaters. Appetite, 50, 240-245.

Mitchell, K.S., Mazzeo, S.E., Rausch, S.M., Cooke, K.L. (2007). Innovative interventions for disordered eating: Evaluating dissonance-based and yoga interventions. International Journal of Eating Disorders, 40(2) 120-128.

Mittal, S. (2010). The effects of mindfulness-based cognitive therapy on disordered eating. Dissertation, Department of Psychology, Hofstra University, Hempstead, NY.

Moldovan, A.R., \& David, D. (2011). Effect of obesity treatments on eating behavior: Psychosocial interventions versus surgical interventions: A systematic review. Eating Behaviors. 12, 161-167.

Morgan, J.F., Reid, F., \& Lacey, J.H. (1999). The SCOFF questionnaire: assessment tool for eating disorders. BMJ, 319, 1467-8.

Must, A., Spadano, J., Coakley, E., Field, A., Colditz, G., \& Dietz, W.H. (1999). The disease burden associated with overweight and obesity. The Journal of the American Medical Association, 282, 16, 1523-1529. 
National Institutes of Health (NIH), \& National Heart, Lung, and Blood Institute (NHLBI). Clinical guidelines on the identification, evaluation, and treatment of overweight and obesity in adults. HHS, Public Health Service (PHS); 1998.

Nguyen-Rodriguez, S.T., Unger, J.B., \& Spruijt-Metz, D. (2009). Psychological Determinants of Emotional Eating In Adolescence. Eating Disorders, 17, 211224.

Noma, S., Nakai, Y., Hamagaki, S., Uehara, M. Hayashi, A., \& Hayashi, T. (2006) Comparison between the SCOFF Questionnaire and the Eating Attitudes Test in patients with eating disorders. International Journal of Psychiatry in Clinical Practice, 10(1), 27-32.

O’Connor, D.B., \& Conner, M. (2011). Effects of stress on eating behavior. In R. Contrada \& A. Baum (Eds.) The handbook of stress science: biology, psychology, and health (275-286). New York, NY: Springer Publishing Company, LLC.

O’Connor, D.B., Jones, F., Conner, M., McMillan, B., \& Ferguson, E. (2008) Effects of daily hassles and eating style on eating behavior. Health Psychology, 27(1), S20S31.

Oliver, G., \& Wardle, J. (1999) Perceived effects of stress on food choice. Physiology \& Behavior, 66(3), 511-515

Oliver, G., Wardle, J., \& Gibson, E.L. (2000). Stress and food choice: A laboratory study. Psychosomatic Medicine, 62, 853-865.

Pan, H.J., Cole, B.M., \& Geliebter, A. (2011). The benefits of body weight loss on health-related quality of life. Journal of the Chinese Medical Association, 74, 169-175. 
Pedersen, A.F., Zachariae, R., \& Bovbjerg, D.H. (2009). Psychological stress and antibody response to influenza vaccination: A meta-analysis. Brain, Behavior, and Immunity, 23, 427-433.

Perry, L., Morgan, J., Reid, F., Brunton, J., O’Brien, A., Luck, A., \& Lacey, H. (2002). Screening for symptoms of eating disorders: Reliability of the SCOFF screening tool with written compared to oral delivery. International Journal of Eating Disorders, 32, 466-472.

Pinto, A.M, LaRose, J., \& Wing, R.R. (2007) Behavioral approaches to weight control: A review of current research, Women's Health, 3(3), 341-354.

Polivy, J., \& Herman, C.P. (1999). Distress and eating: Why do dieters overeat? International Journal of Eating Disorders, 26(2), 153-164.

Powers, M.B., Vording, M., \& Emmelkamp, P.M.G. (2009) Acceptance and commitment therapy: A meta-analytic review. Psychotherapy and Psychosomatics, 78(2), 7380.

Proulx, K. (2008). Experiences of women with bulimia nervosa in a mindfulness-based eating disorder treatment group. Eating Disorders, 16, 52-72.

Pull, C.B. (2009). Current empirical status of acceptance and commitment therapy. Current Opinion in Psychiatry, 22(1), 55-60.

Rasmussen, M., \& Pidgeon, A. (2011). The direct and indirect benefits of DM on selfesteem and social anxiety. Anxiety, Stress, and Coping, 24(2), 227-233.

Renfrew Center Foundation for Eating Disorders (2003). Eating disorders 101 guide: A summary of issues, statistics, and resources. Retrieved from: http://www.renfrew.org. 
Roberti, J., Harrington, L., Storch, E. (2006). Further psychometric support for the 10item version of the perceived stress scale. Journal of College Counseling, 9(2), pp. $135-147$.

Roberts, K.C., \& Danoff-Burg, S. (2010) Mindfulness and health behaviors: Is paying attention good for you? Journal of American College Health, 59 (3), 165-173.

Roemer, L, \& Orsillo, S.M. (2009). Mindfulness and acceptance based behavioral therapies in practice. New York, NY: The Guilford Press.

Rodin, J. (1981). Current status of the internal-external hypothesis for obesity: What went wrong? American Psychologist, 36(4), 361-372.

Rosch, E. (2011). More than mindfulness: When you have a tiger by the tail, let it eat you. Psychological Inquiry, 18(4), 258-264.

Royal, J.D., \& Kurtz, J.L. (2010). I ate what?! The effect of stress and dispositional eating style on food intake and behavioral awareness. Personality and Individual Differences, 49, 565-9.

Rutters, F., Nieuwenhuizen, A.G., Lemmens, S.G., Born, J.M., Westerterp-Plantenga, M.S. (2009) Acute stress-related changes in eating in the absence of hunger. Obesity, 17(1), 72-77.

Salmon, P., Santorelli, S.F., Sephton, S.E., \& Kabat-Zinn, J. (2009) Intervention elements promoting adherence to mindfulness-based stress reduction (MBSR) programs in a clinical behavioral medicine setting. In S.A. Shumaker, J.K. Ockene, \& K.A. Reikert (Eds.) The handbook of health behavior change, Third Edition, (pp. 271285). New York: Springer. 
Salmon, P.G., Sephton, S.E., \& Dreeben, S.J. (2010). Mindfulness-based stress reduction. In J.D. Herbert \& E.M. Forman (Eds.) Acceptance and mindfulness in cognitive behavior therapy: Understanding and applying the new therapies. Hoboken, New Jersey: John Wiley \& Sons, Inc.

Santorelli, S.F., \& Kabat-Zinn, J. (Eds.). (2004). MBSR professional training manual.

Worcester, MA.: Center for Mindfulness in Medicine, Health Care, and Society.

Sapolsky, R.M. (2004). Why zebras don't get ulcers. ( $3^{\text {rd }}$ ed.). New York, NY: Holt Paperbacks.

Schachter, S. , Goldman, R., \& Gordon, A. (1968). Effects of fear, food deprivation, and obesity on eating. Journal of Personality and Social Psychology, 10(2), 91-97.

Schellekens, H., Finger, B.C., Dinan, T.G., \& Cryan, J.F. (2012). Ghrelin signaling and obesity: At the interfact of stress, mood, and food reward. Pharmacology \& Therapeutics, 135(3), 316-26.

Shapiro, S.L., Carlson, L.E., Astin, J.A., \& Freedman, B. (2006). Mechanisms of mindfulness. Journal of Clinical Psychology, 62, 373-386.

Siegel, R.D., Germer, C.K., \& Olendzki, A. (2009). Mindfulness: What is it? Where did it come from? In Didonna, F. (Ed.), Clinical Handbook of Mindfulness, (17-35). New York, NY: Springer.

Singh, N.N., Lancioni, G.E., Singh, A.N., Winton, A.S., Singh, J., McAleavey, K.M., \& Adkins, A.D. (2008a). A mindfulness-based health wellness program for an adolescent with Prader-Willi syndrome. Behavioral Modification, 32, 167-181. 
Singh, N.N., Lancioni, G.E., Singh, A.N., Winton, A.S., Singh, J., McAleavey, K.M., ... \& Joy, S.D.S. (2008b). A mindfulness-based health wellness program for managing morbid obesity. Clinical Case Studies, 7(4), 327-339.

Singh, N.N., Lancioni, G.E., Singh, A.N., Winton, A. S., Singh, A.D., \& Singh, J. (2011). A mindfulness-based health wellness program for individuals with Prader-Willi syndrome. Journal of Mental Health Research in Intellectual Disabilities. 4, 90106.

Smith, B.W., Shelley, B.M., Dalen, J., Wiggins, K., Tooley, E., \& Bernard, J. (2008). A pilot study comparing the effects of mindfulness-based and cognitive-behavioral stress reduction, The Journal of Alternative and Complementary Medicine, 14(3), 251-258.

Smith, B.W., Shelley, B.M., Leahigh, L., \& Vanleit, B. (2006). A preliminary study of the effects of a modified mindfulness intervention on binge eating. Complementary Health Practice Review, 11(3), 133-143.

Stice, E., Fisher, M., \& Lowe, M.R. (2004). Are dietary restraint scales valid measures of acute dietary restriction? Unobtrusive observational data suggest not. Psychological Assessment. 16(10), 51-59.

Striegel-Moore, R.H., Rosselli, Fl, Perrin, N., DeBar, L., Wilson, G.T., May, A., \& Kraemer, H. (2009). Gender difference in the prevalence of eating disorder symptoms. International Journal of Eating Disorders, 42(5), 471-474.

Stroebe, W., Papies, E.K., \& Aarts, H. (2008). From homeostatic to hedonic theories of eating: Self-regulatory failure in food-rich environments. Applied Psychology: An International Review, 57, 172-193. 
Stunkard, A.J., \& Messick, S. (1985). The three-factor eating questionnaire to measure dietary restraint, disinhibition, and hunger. J Psychosom Res, 29(1), 71-83.

Sun, J., Buys, N., Stewart, D., \& Shum, D. (2011). Mediating effects of coping, personal belief, and social support on the relationships among stress, depression, and smoking behavior in university students. Health Education, 111(2), 133-46.

Tapper, K., Shaw, C., Ilsley, J., Hill, A.J., Bond, F.W., \& Moore, L. (2009). Exploratory randomized controlled trial of a mindfulness-based weight loss intervention for women. Appetite, 52, 396-404.

Telch, C.F., Agras, W.S., \& Linehan, M.M. (2000). Group dialectical behavioral therapy for binge-eating disorder: A preliminary, uncontrolled trial. Behavior Therapy, $31,569-582$.

Thorpe, K.E. (2009). The future costs of obesity: National and state estimates of the impact of obesity on direct health care expenses. A collaborative report from the United Health Foundation, the American Public Health Association, and Partners for Prevention.

Tomiyama, A.J., Mann, T., Vinas, D., Hunger, J.M., Dejager, J., \& Taylor, S.E. (2010). Low calorie dieting increases cortisol. Psychosomatic Medicine, 72(4), 357-64.

Torres, S.J., \& Nowson, C.A. (2007). Relationship between stress, eating behavior, and obesity. Nutrition, 23, 887-894.

Tremblay, A., \& Chaput, J.P. (2012). Obesity: The allostatic load of weight loss dieting. Physiology \& Behavior, 106(1), 16-21. 
Tryon, M.S., DeCant, R., \& Laugero, K.D. (2013). Having your cake and eating it too: A habit of comfort food may link chronic social stress exposure and acute stressinduced cortisol hyporesponsiveness.

Tuccitto, D.E., Giacobbi, P.R., Leite, W.L. (2010) The internal structure of positive and negative affect: A confirmatory factor analysis of the PANAS. Educational and Psychological Measurement, 70(1), 125-141.

Ulmer, C.S., Stetson, B.A., \& Salmon, P.G. (2010). Mindfulness and acceptance are associated with exercise maintenance in YMCA exercisers. Behaviour Research and Therapy, 48(8), pp. 805-809.

Van Dam, N.T., Earleywine, M., \& Borders, A. (2010). Measuring mindfulness? An item response theory analysis of the Mindful Attention Awareness Scale. Personality and Individual Differences, 49, 805-810.

Van Dam, N.T., Earleywine, M., \& Danoff-Burg, S. (2009). Differential item function across meditators and non-meditators on the five facet mindfulness questionnaire. Personality and Individual Differences, 47(5), 516-521.

Van Dam, N.T., Hobkirk, A.L., Danoff-Burg, S., \& Earleywine, M. (2012). Mind your words: Positive and negative items create methods effects on the Five Facet Mindfulness Questionnaire. Assessment, 19, 196-202.

Van Strien, T., Frijters, J., Bergers, G., Defares, P. (1986). The Dutch Eating Behavior Questionnaire (DEBQ) for assessment of restrained, emotional, and external eating behavior. International Journal of Eating Disorders, 5(2), pp. 295-315. 
Volkow, N.D., Wang, G.J., Maynard, L., Jayne, M., Fowler, J.S., Zhu, W. ... \& Pappas, N. (2003). Brain dopamine is associated with eating behavior in humans. International Journal of Eating Disorders, 33(2), 136-142.

Wadden, T.A., \& Butryn, M.L. (2003). Behavioral treatment of obesity. Endocrinol Metab Clin North Am, 32(4), 981-1003.

Walburn, J., Vedhara, K., Hankins, M., Rixon, L., \& Weinman, J. (2009). Psychological stress and wound healing in humans: A systematic review and meta-analysis. Journal of Psychosomatic Research, 67, 253-271.

Wallis, C., Thompson, D., \& Galvin, R.M. (1983, June 6) Stress: Can we cope? Time 121(23), 48-54.

Wallis, D.J., \& Hetherington, M.M. (2009) Emotions and eating: Self-reported and experimentally induced changes in food intake under stress. Appetite, 52(2), 355362.

Wansink, B. (2006). Mindless eating: Why we eat more than we think. New York, NY: Random House Publishing, Inc.

Wardle, J. (1987). Eating style: A validation study of the Dutch Eating Behavior Questionnaire in normal subjects and women with eating disorders. Journal of Psychosomatic Research, 31(2), 161-169.

Watson, D., Clark, L.A., \& Tellegen, A. (1988). Development and validation of brief measures of positive and negative affect: The PANAS Scales. Journal of Personality and Social Psychology, 47, 1063-1070 
Way, B.M., Creswell, J.D., Eisenberger, N.I., \& Lieberman, M.D. (2010). DM and depressive symptomatology: Correlations with limbic and self-referential neural activity during rest. Emotion, 10(1), 12-24.

Weinstein, N., Brown, K.W., \& Ryan, R.M. (2009). A multi-method examination of the effects of mindfulness on stress attribution, coping, and emotional well-being. Journal of Research in Personality, 43, 374-385.

Weinstein, S.E., Shidle, D.J., \& Rolls, B.J. (1997). Changes in food intake in response to stress in men and women: Psychological factors. Appetite, 28, 7-18.

Westenhoefer, J., Broeckmann, P., Munch, A.K., \& Pudel, V. (1994). Cognitive control of eating behavior and the disinhibiting effect. Appetite, 23(1), 27-41.

Westenhoefer, J., Engel, D., Holst, C., Lorenz, J., Peacock, M., Stubbs, J., ... \& Raats, M. (2013). Cognitive and weight-related correlates of flexible and rigid restrained eating behavior. Eating Behaviors, 14(1), 69-72.

Westenhoefer, J., Stunkard, A.J., \& Pudel, V. (1999). Validation of the flexible and rigid control dimensions of dietary restraint. International Journal of Eating Disorders, 26(1), 53-64.

Wiser, S., \& Telch, C.F. (1999). Dialectical behavior therapy for binge eating disorder. Journal of Clinical Psychology, 55, 755-768.

Wisniewski, L, \& Kelly, E. (2003). Can DBT be used to effectively treat eating disorders? Cognitive and Behavioral Practice, 10, 131-138.

Wolever, R.Q. \& Best, J.L. (2009) Mindfulness-based approaches to eating disorders. In Didonna, F. (Ed.), Clinical Handbook of Mindfulness, (17-35). New York, NY: Springer. 
World Health Organization (2008). Waist circumference and waist-hip ratio: Report of a WHO expert consultation, 8-11. Retrieved July 2, 2013.

Zellner, D.A., Loaiza, S., Gonzalez, Z, Pita, J., Morales, J., Pecora, D., \& Wolf, A. (2006) Food selection changes under stress. Physiol Behav, 87(4), 789-93.

Zellner, D.A., Saito, S., Gonzalez, J. (2007) The effect of stress on men's food selection. Appetite, 49(3), 696-9.

Zhang, Q., \& Wang, Y. (2004). Trends in the association between obesity and socioeconomic status in US adults: 1971 to 2000. Obesity Research, 12(10), 1622-1632.

Zvolensky, M.J., Solomon, S., \& McLeish, A. (2006). Incremental validity of mindfulness-based attention in relation to the concurrent prediction of anxiety and depressive symptomology and perceptions of health. Cognitive Behavioral Therapy, 35, 148. 
Appendix A

\begin{tabular}{|c|c|c|c|c|c|c|c|c|}
\hline Study & Intervention & $N$ & Population & $\begin{array}{l}\text { Study } \\
\text { Design }\end{array}$ & $\begin{array}{l}\text { Mindfulness } \\
\text { Measure }\end{array}$ & $\begin{array}{c}\text { Stress } \\
\text { Measure }\end{array}$ & $\begin{array}{c}\text { Eating } \\
\text { Measure }\end{array}$ & Results \\
\hline $\begin{array}{l}\text { Kristeller \& } \\
\text { Hallett, } 1999\end{array}$ & $\begin{array}{l}\text { 7-session } \\
\text { MB-EAT }\end{array}$ & 18 & $\begin{array}{c}\text { Obese } \\
\text { females } \\
\text { with BED }\end{array}$ & UCT & --- & --- & $\begin{array}{l}\text { BES, number } \\
\text { of binges }\end{array}$ & $\begin{array}{l}\text { Sig. improvement in binges, } \\
\text { BES, sense of mfn. while } \\
\text { eating, awareness of hunger } \\
\text { and satiety }\end{array}$ \\
\hline $\begin{array}{l}\text { Telch, } \\
\text { Agras, \& } \\
\text { Linehan, } \\
2000\end{array}$ & $\begin{array}{l}\text { 20-session } \\
\text { Modified } \\
\text { DBT }\end{array}$ & 11 & $\begin{array}{l}\text { Females } \\
\text { with BED }\end{array}$ & UCT & --- & --- & $\begin{array}{l}\text { EDE, weight, } \\
\text { BES, EES }\end{array}$ & $\begin{array}{c}\text { 95\% reduction in binge } \\
\text { eating; weight loss of } 6.9 \\
\text { pounds; reductions in all } \\
\text { EDE scales except restraint }\end{array}$ \\
\hline $\begin{array}{l}\text { Baer, } \\
\text { Fischer, \& } \\
\text { Huss, } \\
\text { 2005(a) }\end{array}$ & $\begin{array}{l}\text { 10-session } \\
\text { modified } \\
\text { MBCT }\end{array}$ & 1 & $\begin{array}{l}\text { Females } \\
\text { with BED }\end{array}$ & $\mathrm{CS}$ & KIMS & --- & $\begin{array}{l}\text { EDE; BES; } \\
\text { EEI }\end{array}$ & $\begin{array}{l}\text { Increased in mfn; decreased } \\
\text { weight; decreased binges }\end{array}$ \\
\hline $\begin{array}{l}\text { Baer, } \\
\text { Fischer, \& } \\
\text { Huss, } \\
\text { 2005(b) }\end{array}$ & $\begin{array}{l}\text { 10-session } \\
\text { modified } \\
\text { MBCT }\end{array}$ & 10 & $\begin{array}{l}\text { Females } \\
\text { with } \\
\text { history of } \\
\text { binge } \\
\text { episodes }\end{array}$ & UCT & KIMS & --- & $\begin{array}{l}\text { EDE; BES; } \\
\text { EEI; } \\
\text { objective } \\
\text { subjective } \\
\text { binges } \\
\end{array}$ & $\begin{array}{c}\text { Decrease in objective binges } \\
\text { but increase in subjective } \\
\text { binges; increased mfn.; } \\
\text { mixed results on eating } \\
\text { measures }\end{array}$ \\
\hline $\begin{array}{l}\text { Lundgren, } \\
2005 \\
\text { (Disser- } \\
\text { tation) }\end{array}$ & $\begin{array}{c}\text { 6-session } \\
\text { mfn training } \\
+14 \text { sessions } \\
\text { of standard } \\
\text { weight loss } \\
\text { treatment }\end{array}$ & 33 & $\begin{array}{l}\mathrm{OW} / \mathrm{OB} \\
\text { adults }\end{array}$ & UCT & --- & $\begin{array}{l}\text { PSS, } \\
\text { Weekly } \\
\text { Stress } \\
\text { Inventory } \\
\text { (WSI) }\end{array}$ & BES; TFEQ & $\begin{array}{l}\text { Reduction in restraint and } \\
\text { disinhibition; reduction in } \\
\text { binge eating; reduced impact } \\
\text { of weekly stressors (WSI); } \\
\text { No sig. weight loss }\end{array}$ \\
\hline
\end{tabular}




\begin{tabular}{|c|c|c|c|c|c|c|c|c|}
\hline Study & Intervention & $N$ & Population & $\begin{array}{c}\text { Study } \\
\text { Design }\end{array}$ & $\begin{array}{c}\text { Mindfulness } \\
\text { Measure }\end{array}$ & $\begin{array}{c}\text { Stress } \\
\text { Measure }\end{array}$ & $\begin{array}{c}\text { Eating } \\
\text { Measure }\end{array}$ & Results \\
\hline $\begin{array}{l}\text { Smith, } \\
\text { Shelley, } \\
\text { Leahigh, \& } \\
\text { Vanleit, } \\
2006\end{array}$ & $\begin{array}{l}\text { 8-session } \\
\text { MBSR plus } \\
\text { eating } \\
\text { meditation }\end{array}$ & 27 & $\begin{array}{l}\text { Adults } \\
\text { seeking } \\
\text { "stress } \\
\text { reduction" }\end{array}$ & UCT & MAAS & --- & BES & $\begin{array}{l}\text { Sig. improvements in binge } \\
\text { eating. Sig. increases in } \\
\text { mfn. }\end{array}$ \\
\hline $\begin{array}{c}\text { Engstrom, } \\
2007\end{array}$ & $\begin{array}{c}\text { 8-session } \\
\text { mfn and } \\
\text { behavioral } \\
\text { intervention } \\
\end{array}$ & 1 & $\begin{array}{l}\text { Female } \\
\text { bariatric } \\
\text { surgery } \\
\text { patient } \\
\end{array}$ & CS & MAAS & --- & EBI & $\begin{array}{l}\text { Sig. decreased grazing and } \\
\text { emotional eating; sig. } \\
\text { increased mfnl; } 48 \mathrm{lb} \text { weight } \\
\text { loss during treatment }\end{array}$ \\
\hline $\begin{array}{l}\text { Mitchell, } \\
\text { Mazzeo, } \\
\text { Rausch, \& } \\
\text { Cook, 2007 }\end{array}$ & $\begin{array}{l}\text { 6-session } \\
\text { yoga \& } \\
\text { meditation } \\
\text { group/6- } \\
\text { session } \\
\text { dissonance } \\
\text { group/control }\end{array}$ & 113 & $\begin{array}{l}\text { Female } \\
\text { students } \\
\text { dissatis- } \\
\text { fied with } \\
\text { body }\end{array}$ & RCT & -- & --- & $\begin{array}{c}\text { EDDS; BES; } \\
\text { EDI; TFEQ }\end{array}$ & $\begin{array}{l}\text { No improvements in control } \\
\text { or yoga \& meditation group. } \\
\text { Sig. improvement in } \\
\text { dissonance group }\end{array}$ \\
\hline $\begin{array}{l}\text { Davis, } 2008 \\
\text { (Disser- } \\
\text { tation) }\end{array}$ & $\begin{array}{c}\text { Standard } \\
\text { behavioral } \\
\text { weight loss } \\
\text { (SBWL)/ } \\
\text { SBWL plus } \\
\text { resistance } \\
\text { training/ } \\
\text { SBWL plus } \\
\text { mfn training }\end{array}$ & 71 & $\begin{array}{l}\text { Over- } \\
\text { weight } \\
\text { adults }\end{array}$ & $\mathrm{RCT}$ & -- & -- & Weight & $\begin{array}{l}\text { Each group achieved sig. } \\
\text { weight loss and increased } \\
\text { physical activity. No } \\
\text { evidence of additional } \\
\text { improvements in resistance } \\
\text { or mfn training groups }\end{array}$ \\
\hline
\end{tabular}




\begin{tabular}{|c|c|c|c|c|c|c|c|c|}
\hline Study & Intervention & $N$ & Population & $\begin{array}{c}\text { Study } \\
\text { Design }\end{array}$ & $\begin{array}{l}\text { Mindfulness } \\
\text { Measure }\end{array}$ & $\begin{array}{c}\text { Stress } \\
\text { Measure }\end{array}$ & $\begin{array}{l}\text { Eating } \\
\text { Measure }\end{array}$ & Results \\
\hline $\begin{array}{l}\text { Leahey, } \\
\text { Crowther, \& } \\
\text { Irwin, } 2008\end{array}$ & $\begin{array}{c}\text { 10-session } \\
\text { CBT mfn- } \\
\text { based group }\end{array}$ & 7 & $\begin{array}{l}\text { Gastric } \\
\text { bypass } \\
\text { patients }\end{array}$ & UCT & --- & --- & $\begin{array}{c}\text { EDE-Q; } \\
\text { EES; ESES }\end{array}$ & $\begin{array}{l}\text { Qualitative analysis shows } \\
\text { improvements in binge } \\
\text { eating, guilt, and emotional } \\
\text { eating in most participants }\end{array}$ \\
\hline Proulx, 2008 & $\begin{array}{l}\text { 8-session } \\
\text { mfn-based } \\
\text { ED group }\end{array}$ & 6 & $\begin{array}{l}6 \text { college } \\
\text { age } \\
\text { women } \\
\text { with BN }\end{array}$ & UCT & -- & --- & -- & $\begin{array}{l}\text { Used hermeneutic approach; } \\
\text { improved self-awareness, } \\
\text { coping; judgmental thoughts } \\
\text { and emotional reactivity }\end{array}$ \\
\hline $\begin{array}{l}\text { Singh, et al., } \\
2008 \text { (a) }\end{array}$ & $\begin{array}{l}\text { "Mindfulness } \\
\text { training" }\end{array}$ & 1 & $\begin{array}{c}\text { Morbidly } \\
\text { obese } \\
\text { male }\end{array}$ & CS & --- & --- & Weight & $\begin{array}{c}\text { Weight decreased from } 315 \\
\text { to } 171 \text { pounds; developed } \\
\text { healthier diet; ate more } \\
\text { slowly }\end{array}$ \\
\hline $\begin{array}{l}\text { Singh, et al., } \\
2008 \text { (b) }\end{array}$ & $\begin{array}{l}\text { "Food } \\
\text { awareness" } \\
\text { and } \\
\text { "Mindfulness } \\
\text { training" }\end{array}$ & 1 & $\begin{array}{l}\text { Morbidly } \\
\text { obese } \\
\text { adolescent } \\
\text { male with } \\
\text { Prader- } \\
\text { Willi } \\
\text { Syndrome }\end{array}$ & $\begin{array}{c}\text { CS } \\
\text { with } \\
\text { ABCD } \\
\text { design }\end{array}$ & -- & --- & Weight & $\begin{array}{l}\text { Introduction of mindfulness } \\
\text { preceded a decreased pace of } \\
\text { eating and increased rate of } \\
\text { weight loss. }\end{array}$ \\
\hline $\begin{array}{l}\text { Smith et al., } \\
2008\end{array}$ & $\begin{array}{c}\text { 8-session } \\
\text { MBSR + } \\
\text { eating } \\
\text { meditation/ } \\
\text { CBT-based } \\
\text { Stress } \\
\text { Reduction }\end{array}$ & 64 & $\begin{array}{l}\text { Adults } \\
\text { seeking } \\
\text { "stress } \\
\text { reduction" } \\
\text { program }\end{array}$ & $\begin{array}{l}\text { SS- } \\
\text { CT }\end{array}$ & MAAS & $\begin{array}{c}\text { PSS } \\
\text { (10 item) }\end{array}$ & BES & $\begin{array}{l}\text { Sig. improvements on all } \\
\text { measures in MBSR group } \\
\text { (effect size twice that of } \\
\text { CBSR); sig. increase in mfn } \\
\text { in MBSR only. }\end{array}$ \\
\hline
\end{tabular}




\begin{tabular}{|c|c|c|c|c|c|c|c|c|}
\hline Study & Intervention & $N$ & Population & \begin{tabular}{|l} 
Study \\
Design
\end{tabular} & $\begin{array}{l}\text { Mindfulness } \\
\text { Measure }\end{array}$ & $\begin{array}{c}\text { Stress } \\
\text { Measure }\end{array}$ & $\begin{array}{l}\text { Eating } \\
\text { Measure }\end{array}$ & Results \\
\hline $\begin{array}{l}\text { Blevins } \\
(2009) \\
\text { (Disser- } \\
\text { tation) }\end{array}$ & $\begin{array}{l}\text { 8-session } \\
\text { Standard wt } \\
\text { loss/ } \\
\text { Standard wt } \\
\text { loss }+\mathrm{mfn}\end{array}$ & 41 & $\begin{array}{l}\text { Females } \\
\text { with BMI } \\
\text { of } 25-35\end{array}$ & RCT & MAAS & -- & $\begin{array}{l}\text { Quest. of } \\
\text { Eating and } \\
\text { Weight } \\
\text { Patterns } \\
\text { (QEWP-R) }\end{array}$ & $\begin{array}{l}\text { No significant differences } \\
\text { between standard treatment } \\
\text { and mindfulness groups. }\end{array}$ \\
\hline $\begin{array}{l}\text { Forman, } \\
\text { Butryn, } \\
\text { Hoffman, \& } \\
\text { Herbert, } \\
2009\end{array}$ & $\begin{array}{l}\text { 12-session } \\
\text { Acceptance- } \\
\text { based } \\
\text { behavioral } \\
\text { group } \\
\text { therapy for } \\
\text { weight loss }\end{array}$ & 29 & $\begin{array}{c}\text { OW/OB } \\
(\mathrm{BMI}> \\
25) \text { female } \\
\text { employees } \\
\text { at urban } \\
\text { university }\end{array}$ & UCT & PHLMS & --- & $\begin{array}{l}\% \text { Weight } \\
\text { loss; FAAQ; } \\
\text { subscales of } \\
\text { EI; DEBQ }\end{array}$ & $\begin{array}{l}\text { 6.6\% body weight; } 9.6 \% \text { at } \\
\text { 6-month follow-up. } \\
\text { Eating measures and } \\
\text { PHLMS changed } \\
\text { significantly }\end{array}$ \\
\hline $\begin{array}{c}\text { Lillis, } \\
\text { Hayes, } \\
\text { Bunting, \& } \\
\text { Masuda, } \\
2009\end{array}$ & $\begin{array}{l}1 \text { day (6 } \\
\text { hour) mfn } \\
\text { and } \\
\text { acceptance } \\
\text { workshop/ } \\
\text { control }\end{array}$ & 84 & $\begin{array}{l}\text { Patients in } \\
\text { weight } \\
\text { loss } \\
\text { program. }\end{array}$ & RCT & --- & --- & Weight & $\begin{array}{l}\text { Sig. difference in acceptance } \\
\text { and weight loss between } \\
\text { ACT and control groups }\end{array}$ \\
\hline $\begin{array}{l}\text { McIver, } \\
\text { O'Halloran, } \\
\text { \& McGart- } \\
\text { land, } 2009\end{array}$ & $\begin{array}{l}\text { 12-session } \\
\text { yoga/medi- } \\
\text { tation/wait- } \\
\text { list control } \\
\text { grp } \\
\end{array}$ & 90 & $\begin{array}{c}\text { Female } \\
\text { binge } \\
\text { eaters } \\
(\mathrm{BMI}> \\
25) \\
\end{array}$ & RCT & --- & -- & $\begin{array}{l}\text { BES, BMI, } \\
\text { Waist and } \\
\text { hip circum- } \\
\text { ference }\end{array}$ & $\begin{array}{l}\text { Decreased binge eating; } \\
\text { increased physical activity. } \\
\text { No change in controls. }\end{array}$ \\
\hline
\end{tabular}




\begin{tabular}{|c|c|c|c|c|c|c|c|c|}
\hline Study & Intervention & $N$ & Population & \begin{tabular}{|c|} 
Study \\
Design \\
\end{tabular} & $\begin{array}{l}\text { Mindfulness } \\
\text { Measure }\end{array}$ & $\begin{array}{c}\text { Stress } \\
\text { Measure }\end{array}$ & $\begin{array}{l}\text { Eating } \\
\text { Measure }\end{array}$ & Results \\
\hline $\begin{array}{l}\text { Tapper et } \\
\text { al., } 2009\end{array}$ & $\begin{array}{l}\text { 4-session } \\
\text { mfn-based } \\
\text { weight loss } \\
\text { treatment } \\
\text { /control } \\
\text { group }\end{array}$ & 62 & $\begin{array}{l}\text { Females } \\
\text { (BMI > } \\
20) \text { who } \\
\text { are } \\
\text { currently } \\
\text { dieting }\end{array}$ & RCT & --- & -- & $\begin{array}{l}\text { BMI; DEBQ; } \\
\text { EEQ; BES; } \\
1 \text {-item } \\
\text { dietary } \\
\text { adherence } \\
\text { measure } \\
\end{array}$ & $\begin{array}{c}\text { Intervention group lost } \\
1.35 \mathrm{~kg} \text { more than controls at } \\
6 \text { month f/u. BMI reduction } \\
\text { mediated by less binge } \\
\text { eating }\end{array}$ \\
\hline $\begin{array}{l}\text { Federici, } \\
2010 \\
\text { (Disser- } \\
\text { tation) } \\
\end{array}$ & $\begin{array}{l}\text { 20-session } \\
\text { modified } \\
\text { DBT } \\
\text { program }\end{array}$ & 33 & $\begin{array}{l}\text { Female } \\
\text { Borderline } \\
\text { PD } \\
\text { patients } \\
\end{array}$ & UCT & KIMS & -- & EDI; EDE & $\begin{array}{l}\text { Increase in mindfulness; No } \\
\text { sig. change in binge-eating } \\
\text { or purging; }\end{array}$ \\
\hline $\begin{array}{l}\text { Courbasson, } \\
\text { Nishikawa, } \\
\text { \& Shapira, } \\
2011 \\
\end{array}$ & $\begin{array}{l}\text { 16-session } \\
\text { "Mindfulness } \\
\text {-Action } \\
\text { Based CBT" } \\
\end{array}$ & 38 & $\begin{array}{c}\text { Patients } \\
\text { with BED } \\
\text { and SUD }\end{array}$ & UCT & --- & -- & EDE-Q & $\begin{array}{l}\text { Reduced binge eating; } \\
\text { reduced subscale abuse; }\end{array}$ \\
\hline $\begin{array}{l}\text { Hepworth, } \\
2011\end{array}$ & $\begin{array}{l}\text { 10-session } \\
\text { mindful } \\
\text { eating group }\end{array}$ & 33 & $\begin{array}{l}\text { Patients in } \\
\text { long-term } \\
\text { ED } \\
\text { treatment }\end{array}$ & UCT & -- & -- & EAT-26 & Reduced disordered eating; \\
\hline $\begin{array}{l}\text { Mittal, } 2011 \\
\text { (Disser- } \\
\text { tation) }\end{array}$ & $\begin{array}{l}\text { 8-session } \\
\text { MBCT }\end{array}$ & 10 & $\begin{array}{l}\text { Students } \\
\text { w/ high } \\
\text { disordered } \\
\text { eating } \\
\end{array}$ & UCT & KIMS & --- & TFEQ-R18 & $\begin{array}{c}\text { Increased mindfulness; } \\
\text { decreased experiential } \\
\text { avoidance; No change in } \\
\text { disorder eating } \\
\end{array}$ \\
\hline $\begin{array}{l}\text { Singh et al., } \\
\quad 2011\end{array}$ & $\begin{array}{l}\text { Mindfulness- } \\
\text { based well- } \\
\text { ness program }\end{array}$ & 3 & $\begin{array}{l}\text { Prader- } \\
\text { Willi } \\
\text { patients }\end{array}$ & UCT & -- & --- & Weight & $\begin{array}{l}\text { Significant weight loss and } \\
\text { successful maintenance over } \\
\text { three year follow-up period }\end{array}$ \\
\hline
\end{tabular}




\begin{tabular}{|c|c|c|c|c|c|c|c|c|}
\hline Study & Intervention & $N$ & Population & $\begin{array}{c}\text { Study } \\
\text { Design }\end{array}$ & $\begin{array}{c}\text { Mindfulness } \\
\text { Measure }\end{array}$ & $\begin{array}{c}\text { Stress } \\
\text { Measure } \\
\end{array}$ & $\begin{array}{c}\text { Eating } \\
\text { Measure }\end{array}$ & Results \\
\hline $\begin{array}{l}\text { Alberts, } \\
\text { Thewissen, } \\
\text { \& Raes, } \\
2012\end{array}$ & $\begin{array}{c}\text { 8-session } \\
\text { MBCT-based } \\
\text { intervention/ } \\
\text { wait-list } \\
\text { control group }\end{array}$ & 26 & $\begin{array}{l}\text { Non- } \\
\text { clinical } \\
\text { females } \\
\text { w/ dis. } \\
\text { eating }\end{array}$ & RCT & KIMS & --- & $\begin{array}{l}\text { DEBQ; } \\
\text { weight }\end{array}$ & $\begin{array}{c}\text { Increased mindfulness; } \\
\text { Decreased food cravings; } \\
\text { dichotomous thinking; } \\
\text { emotional eating, external } \\
\text { eating; body image concerns }\end{array}$ \\
\hline $\begin{array}{c}\text { Daubenmier } \\
\text { et al., } 2012\end{array}$ & $\begin{array}{l}\text { Combination } \\
\text { of MBSR } \\
\text { and MB- } \\
\text { EAT/wait- } \\
\text { list control } \\
\text { group }\end{array}$ & 47 & $\begin{array}{l}\text { OW/OB } \\
\text { women }\end{array}$ & RCT & KIMS & $\begin{array}{l}\text { Wheaton } \\
\text { Chronic } \\
\text { Stress } \\
\text { Inventory } \\
\text {;Salivary } \\
\text { Cortisol }\end{array}$ & DEBQ & $\begin{array}{l}\text { No sig. difference between } \\
\text { groups in telomere length; } \\
\text { changes in restraint, cortisol, } \\
\text { perceived stress, anxiety } \\
\text { associated with telomere } \\
\text { activity }\end{array}$ \\
\hline $\begin{array}{c}\text { Kristeller, } \\
\text { Wolever, \& } \\
\text { Sheets, } 2013\end{array}$ & $\begin{array}{l}\text { 12- session } \\
\text { MB-EAT/ } \\
\text { CBT/wait- } \\
\text { list control } \\
\text { group }\end{array}$ & 150 & $\begin{array}{l}\text { OW/OB } \\
\text { people } \\
(66 \% \text { met } \\
\text { criteria for } \\
\text { BED) }\end{array}$ & RCT & --- & --- & BES & $\begin{array}{c}\text { Decreased binge eating; } 95 \% \\
\text { of participants in MB-EAT } \\
\text { no longer met criteria for } \\
\text { BED at follow-up }\end{array}$ \\
\hline
\end{tabular}

Note: Mfn = mindfulness; $\mathbf{R C T}=$ Randomized-Controlled Trial; $\mathbf{S S}-\mathbf{C T}=$ Self-Selected Controlled Trial; $\mathbf{C S}=$ Case Study; $\mathbf{U C T}=$ Uncontrolled Trial; $\mathbf{B E S}=$ Binge Eating Scale; EDE = Eating Disorder Examination $(\mathbf{E D E}-\mathbf{Q}=$ questionnaire version $)$; EES = Emotional Eating Questionnaire; EEI = Eating Expectancy Inventory; EDDS = Eating Disorder Diagnostic Scale; EDI = Eating Disorder Inventory; TFEQ = Three Factor Eating Questionnaire; EBI = Eating Behavior Inventory; ESES = Eating Self-Efficacy Scale; DEBQ = Dutch Eating Behavior Questionnaire; EEQ = Emotional Eating Questionnaire; EI = Eating Inventory 


\section{APPENDIX B: Description of data collection procedures/standard script}

1) Arrival. Participant will arrive (individually) at the Biobehavioral Research Laboratory. We will request in prior email that she not eat or drink for 3 hours prior to appointment, as a condition of eligibility.

a. If participant is more than $\mathbf{1 5}$ minutes late, contact her by email. Reschedule if needed. b. When participant arrives, thank them for coming and provide overview of experiment: "Hi, my name is [FIRST NAME]. Thank you for coming in today. This experiment will involve providing a saliva sample, filling out several written questionnaires, working on word puzzles, and obtaining some physical measurements. In return for your participation, you will receive one hour of course credit or extra credit. Before we can get started, we need to go over some information."

Informational Document. Participants will be given an opportunity to read over the informational document upon arrival. Afterward, each section will be reviewed and participants will be given the opportunity to ask questions about the experiment.

"This document contains information about the study. This study is focused on the relationships between stress, personality variables, and performance on an anagram task. It is being conducted by Dr. Paul Salmon in the Psychology Department and Megan Jablonski, a graduate student in Clinical Psychology. You will be doing several things during this experiment, if you choose to participate:

1) You will provide a saliva sample using a cotton swab, in order to measure your levels of salivary cortisol. Cortisol is a stress hormone found in the body that indicates how much stress you've been feeling lately.

2) You will fill out several self-report questionnaires about a variety of topics

3) You will work on an anagram test

4) You will provide several physical measurements (ie, height, weight, waist circumference, hip circumference)

Overall, about 150 participants will be invited to take part in this study. As a research participant, it is important that you understand your rights. You have the right to stop your participation at any point during this experiment, if you choose. Also, when you are filling out the questionnaires, you may skip any questions you are not comfortable answering. Although we will make all efforts to keep your data confidential, complete privacy cannot be assured. There are several agencies responsible for overseeing research activities that might access your information. However, please note that a code number will be used to replace your name, so that you are not directly connected to any information you disclose. All information is kept in a secure location. If you have any questions or complaints about this study, there is information regarding whom to contact. What questions or concerns do you have about participating in this study?

Please print and sign your name if you agree to participate. Also, please write today's date in the blank beside your name. 
2) Saliva Sample. In order to standardize level of hunger, participants have been asked to refrain from eating for 3 hours prior to their scheduled experiment. As a compliance check, participants will be asked to give a saliva sample and asked if they have eaten during the past three hours and at what time they last ate/drank. This information should be recorded at the bottom of the post-experiment questionnaire.

As we mentioned in the description of this study and the email you received, you will be providing a saliva sample today. By giving this sample, we can assess your stress level by measuring a hormone known as "salivary cortisol," that increases during times of stress. Because foods and beverages can alter cortisol levels, we asked you not to eat for three hours prior to this appointment. Have you eaten anything within this time period? [If yes, record food type, amount, and time on post-experiment questionnaire]. Also, at what time did you eat most recently? [Record time on post-experiment questionnaire].

"Please remove the cap from this tube \{demonstrate with model\} and place the piece of cotton in your mouth. When the cotton is saturated completely, put it back inside the tube. This should only take about a minute."

3) Questionnaire Packet A. Participant should be given first questionnaire packet, clipboard, and a pen.

"Please complete the following questionnaires. Take your time and try not to accidentally skip any questions. However, if there are questions you do not wish to answer, remember that you are free to leave them blank."

5) Anagram Task. Participant will next be randomly given one of two envelopes, containing either:

1) Form A. Solvable anagrams (low stress control condition)

2) Form B. Unsolvable anagrams (high stress condition)

"You will now be given an anagram completion test, which has been shown to correlate highly with IQ scores. Please read the instructions and complete these anagrams as quickly as you can. You will have ten minutes.

6) Food items provided. Immediately after the experimenter provides an anagram envelop and explains the task, participant will be offered set of pre-weighed refreshments on table at which they will work.

"Also, since you weren't able to eat for several hours before this experiment, we've provided some snacks for you to have while you work. We have plenty, so feel free to eat as much as you'd like."

7) Experimenter leaves participant to complete anagrams. In order to avoid having participants feel as though they are being observed or self-conscious about what she is eating, experimenter will leave the room, stating that she has to begin processing saliva sample and will return when time has elapsed.

"I need to begin processing your saliva sample. I will be back when your time is up."

8) Complete Post-Experiment Questionnaire. Read all questions to participants and record responses. This questionnaire is to be completed orally in order to conduct a suspicion probe. This will also include a verbal estimate of how much food was eaten during the anagram task as well as a physical estimate. 
9) Questionnaire Packet B. Upon completion of the anagrams/expiration of time, anagrams will be collected and participant will complete a second questionnaire packet. "You will now complete the second set of questionnaires. These contain a number of questions related to eating and health, due to the relationship between salivary cortisol and these factors. Please take your time and try not to accidentally skip any questions. Again, if there are questions you do not wish to answer, remember that you are free to leave them blank."

10) Obtain anthropomorphic information. Measure height, weight, waist circumference, and hip circumference.

"I now need to collect some physical measurements."

11) Debrief participant. After second questionnaire packet is complete, experimenter will thank participant for their time and provide an explanation of the true nature of the study. They will be asked not to disclose this information to classmates and friends, in the event that they may participate.

"Thank you for your participation in this study. In order to obtain valid results, a small degree of deception was necessary regarding the true nature of the nature of this research. The goal of this study was to examine how a personality quality known as "mindfulness" might affect eating due to stress. Stress has been shown to cause overeating in some people. Mindfulness is a personality quality which involves non-judgmental awareness of the present moment, and has been shown to help people cope with stress. Therefore, we predict that people who are more mindful will be less likely to overeat or choose unhealthy foods when they are in a stressful situation.

In order to test this hypothesis, it was very important to for us to study your eating behaviors without you knowing that your eating was being measured. It was also important that all participants had approximately the same hunger level at the beginning of the experiment. Therefore, we asked you to avoid food and drink for three hours before your appointment, stating that you would be giving a saliva sample. In fact, we will not actually be analyzing the saliva sample you provided. This sample will not be used in any way and has already been disposed of while you were working on the anagrams.

Further, the anagrams that some participants completed actually included many which were not solvable, in order to bring about a feeling of stress. Other participants were given very easy solvable anagrams. Your performance on these word puzzles is NOT actually related to IQ. Snacks were provided in order to study your eating behaviors when exposed to stress or a control condition. The amount of food you ate will be measured. Also, these amounts will be compared to your estimates of how much you ate, in order to determine if mindfulness predicts greater awareness of food consumption.

We appreciate your participation in this study. It is extremely important that all participants of this study are unaware that their food intake is being measured in order to obtain valid results. Please do not share any information about this study with other students in psychology courses, who may also participate."

12) Weigh remaining foods. All remaining foods will be weighed and information will be recorded on the post-experiment questionnaire prior to disposing of leftover snacks. 


\section{APPENDIX C: Copy of the solvable anagram set (low-stress condition).}

Anagram Test

The following anagram test is designed to measure verbal ability. Please try to solve the following anagrams to the best of your ability. You must use ALL 5 letters in the original word to create a new word. For example, unscrambling the letters crave creates the word carve but NOT ear or race. Each of the anagrams may have one answer or multiple answers. Your responses to the anagrams will be kept confidential.

1. SHAR P

2. T A S T E

3. S MA S H

4. S P R A Y

5. L I C K S

6. S H O K

7. H A L L S

8. S W A P S

9. E A R L Y

10. W E A R S

11. MEAT S

12. S C A R E 


\section{APPENDIX D: Copy of the unsolvable anagram set (high stress condition)}

\section{Anagram Test}

The following anagram test is designed to measure verbal ability. Please try to solve the following anagrams to the best of your ability. You must use ALL 5 letters in the original word to create a new word. For example, unscrambling the letters crave creates the word carve but NOT ear or race. Each of the anagrams may have one answer or multiple answers. Your responses to the anagrams will be kept confidential.

1. C R E A M

2. T A S T E

3. J U I C E

4. R A D I O

5. FE N C E

6. EXI T S

7. P A I N T

8. $\mathrm{CHECK}$

9. C R A F T

10. W E A R S

11. P H O N E

12. F O O S 


\section{CURRICULUM VITAE}

Megan Elizabeth Jablonski

317 Life Sciences Building, University of Louisville

Department of Psychological and Brain Sciences

Louisville, KY 40292

\section{EDUCATION AND TRAINING:}

2007- 2013 Doctoral Candidate

Clinical Psychology (APA-Accredited)

Department of Psychological and Brain Sciences

University of Louisville

Louisville, Kentucky

2012-2013 Pre-doctoral Clinical Psychology Intern

(APA-Accredited Program)

James H. Quillen Veteran's Affairs Medical Center

Mountain Home, Tennessee

2007-2010

Master of Arts, Clinical Psychology (APA-Accredited)

Department of Psychological and Brain Sciences

University of Louisville

Louisville, KY

2003-2007

Bachelor of Arts, Psychology, With Highest Distinction Minor: Social and Economic Justice University of North Carolina at Chapel Hill

Chapel Hill, North Carolina

HONORS, AWARDS, AND GRANTS:

University of Louisville Research on Women Grant (2012)

University of Louisville Graduate Student Union Research Grant (2011)

University Fellowship, University of Louisville (2007 - 2009)

Phi Beta Kappa, National Academic Honor Society (inducted 2007)

Psi Chi, National Honor Society in Psychology (inducted 2005)

Dean's List, University of North Carolina at Chapel Hill (seven semesters)

William R. Davie Scholarship, University of North Carolina at Chapel Hill (2003-2007) 


\section{PROFESSIONAL AFFILIATIONS}

Kentucky Psychological Association

\section{PUBLICATIONS}

Salmon, P., \& Jablonski, M. E. (2012). Assessment of Psychosocial Status. In J. Ehrman (Ed.), ACSM's Resource Manual for Guidelines for Exercise Testing and Prescription (7th ed.). Baltimore, MA: Lippincott Williams \& Wilkins. (Invited resubmission for new edition)

Salmon, P., \& Jablonski, M. E. (2010). Assessment of Psychosocial Status. In J. Ehrman (Ed.), ACSM's Resource Manual for Guidelines for Exercise Testing and Prescription (6th ed.). Baltimore, MA: Lippincott Williams \&Wilkins.

Salmon, P., Lush, E., Jablonski, M. E., \& Sephton, S. E. (2009). Yoga and mindfulness: Clinical aspects of an ancient mind/body practice. Cognitive and Behavioral Practice, 16, 59-72.

\section{$\underline{\text { PRESENTATIONS }}$}

Salmon, P., Dreeben, S. J., Jablonski, M. E., Litvan, I., Houghton,D., Constantino, A., Giese-Davis, J., Sokhadze, T., Fernandez-Botran, R., Eismann, E. A., Hanneman,S., \& Sephton, S. E. (2011, April). A Randomized-Controlled Pilot Study of Mindfulness-Based Stress Reduction for Parkinson's Disease Patient and Caregiver Dyads. Oral presentation at the Annual International Mindfulness Conference for Clinicians, Researchers and Educators, Norwood, MA.

Sephton, S. E., Dreeben, S. J., Jablonski, M. E., Litvan, I., Houghton, D., Constantino, A., Giese-Davis, J., Sokhadze, T., Fernandez-Bortran, R., Eismann, E. A., Hanneman, S., \& Salmon, P. (2011, March). A Randomized-Controlled Pilot Trial of Mindfulness-Based Stress Reduction for Parkinson's Disease Patients and their Partners. Oral presentation at the American Psychosomatic Society Annual Scientific Meeting, San Antonio, TX.

Dreeben, S. J.,Sephton, S. E., Jablonski, M. E., Litvan, I., Houghton, D., Giese-Davis,J, Sokhadze, T., Fernandez-Bortran, R.,Eismann, E. A., Hanneman, S., \& Salmon, P. (2011, March). Mindfulness and Psychological Adjustment among Parkinson's Disease Patients and their Partners. Poster presentation at the American Psychosomatic Society Annual Scientific Meeting, San Antonio, TX.

Patel, H. R., Truttman, A. M., Jablonski, M. E., Rhodes, P. A., Martin, M. B., Salmon, P. G., \& Sephton, S. E. (2008, April). The Role of Mindfulness in Predicting Perceived Stress and General Health in College Undergraduates. Poster presentation at the University of Louisville Annual Undergraduate Research Day, Louisville, KY. 
Jablonski, M. E., Patel, H. R., Truttman, A. M., Martin, M. B., Rhodes, P. A., Sephton, S. E. \& Salmon, P. G. (2008, March). The Relationship between Mindfulness and Examination Stress in Undergraduates. Poster presentation at Society of Behavioral Medicine (SBM) Annual Meeting and Scientific Sessions, San Diego, CA.

Gabriele, J. M., Tate, D. F., Carpenter, B. C., Jablonski, M. E. \& Fisher, E. B. (2007, November). Effects of Three Support Interventions on Perceptions of Support and Weight Loss in a 12-Week Weight Loss E-Coaching Program. Poster presentation at Association for Behavioral and Cognitive Therapies (ABCT) Annual Meeting and Scientific Sessions, Philadelphia, PA.

Jablonski, M. E., Gabriele, J. M., Carpenter, B. C.,Tate, D. F., Adefolalu, M., \& Fisher, E. B. (2007, April). Specific Contribution of Nondirective Support to Program Satisfaction in a 12 Week Weight Loss E-Coaching Intervention. Poster presentation at the University of North Carolina at Chapel Hill Annual Undergraduate Research Symposium, Chapel Hill, NC.

Gabriele, J. M., Tate, D. F., Carpenter, B. C., Jablonski, M. E. \& Fisher, E. B. (2007, March). Fear of Negative Evaluation Moderates the Relationship between ECoach Support and Weight Loss. Poster presentation at Society of Behavioral Medicine (SBM) Annual Meeting and Scientific Sessions, Washington, DC.

Gabriele, J. M., Carpenter, B. C., Tate, D. F., Adefolalu, M., Jablonski, M. E., \& Fisher, E. B. (2007, March). Specific Contribution of Nondirective Support to Program Satisfaction in a 12 Week Weight Loss E-Coaching Intervention. Poster presentation at Society of Behavioral Medicine (SBM) Annual Meeting and Scientific Sessions, Washington, DC. 